Chemical Technology Division

\title{
THE DEVELOPMENT OF A ZEOLITE SYSTEM FOR UPGRADE OF THE PROCESS WASTE TREATMENT PLANT
}

S. M. Robinson, T. E. Kent, W. D. Arnold, and J. R. Parrott, Jr.

Date of Issue: October 1993

Prepared by the

OAK RIDGE NATIONAL LABORATORY

Oak Ridge, Tennessee 37831 managed by MARTIN MARIETTA ENERGY SYSTEMS, INC. for the

U.S. DEPARTMENT OF ENERGY under contract No. DE-AC05-84OR21400 


\section{CONTENTS}

LIST OF FIGURES $\ldots \ldots \ldots \ldots \ldots \ldots \ldots \ldots \ldots \ldots \ldots \ldots \ldots$

LIST OF TABLES $\ldots \ldots \ldots \ldots \ldots \ldots \ldots \ldots \ldots \ldots \ldots \ldots \ldots \ldots \ldots$

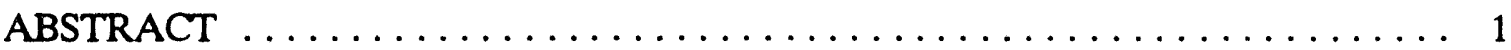

1. INTRODUCTION $\ldots \ldots \ldots \ldots \ldots \ldots \ldots \ldots \ldots \ldots \ldots \ldots \ldots \ldots$

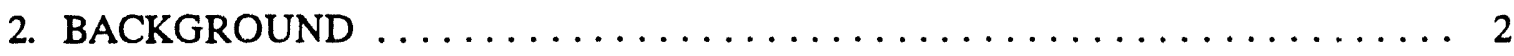

3. EQUIPMENT DESIGN STUDIES $\ldots \ldots \ldots \ldots \ldots \ldots \ldots \ldots \ldots \ldots \ldots \ldots$

3.1 LITERATURE REVIEW $\ldots \ldots \ldots \ldots \ldots \ldots \ldots \ldots \ldots \ldots \ldots \ldots$

3.2 COLUMN PLUGGING STUDIES $\ldots \ldots \ldots \ldots \ldots \ldots \ldots \ldots \ldots \ldots \ldots$

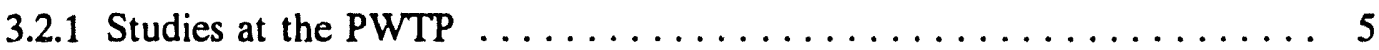

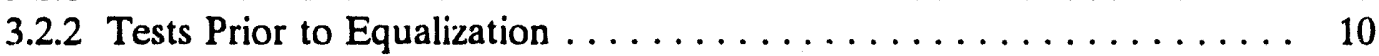

3.3 COLUMN HARDWARE DESIGN $\ldots \ldots \ldots \ldots \ldots \ldots \ldots \ldots \ldots \ldots \ldots$

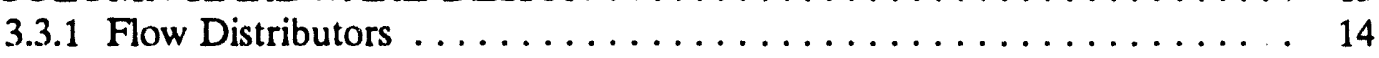

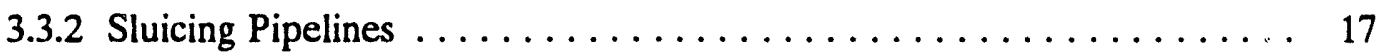

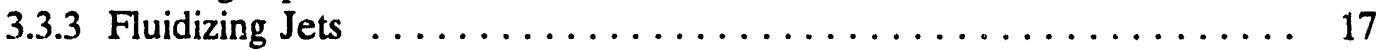

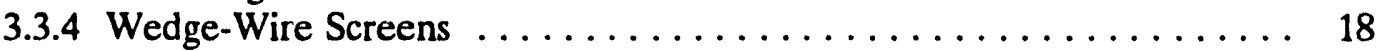

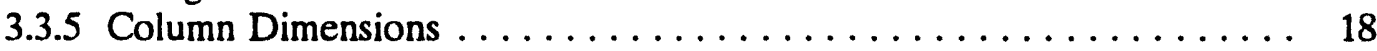

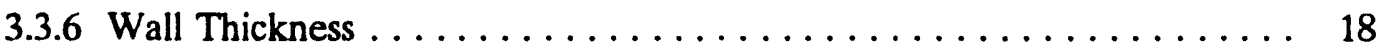

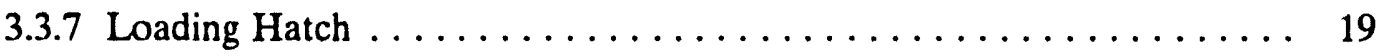

4. MODEL DEVELOPMENT FOR ION-EXCHANGE COLUMN DESIGN . . . 20

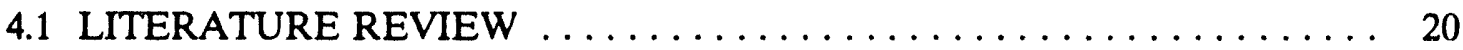

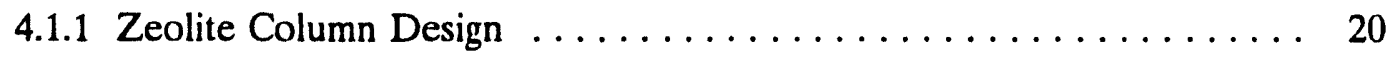

4.1.2 Model Development ...................... 22

5. EXPERIMENTAL TESTS FOR MODEL DEVELOPMENT $\ldots \ldots \ldots \ldots \ldots \ldots$

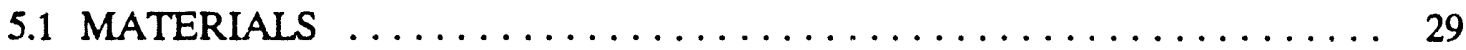

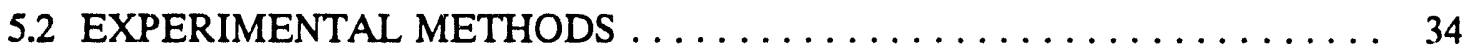

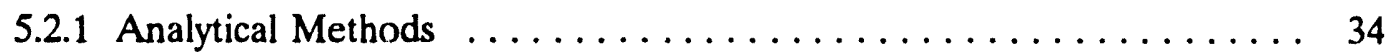

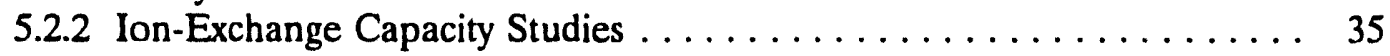

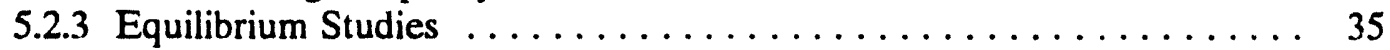

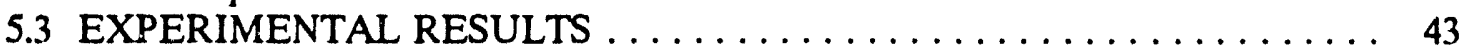

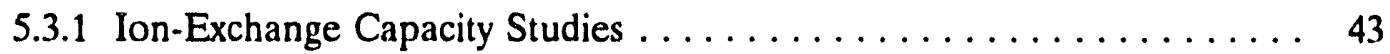

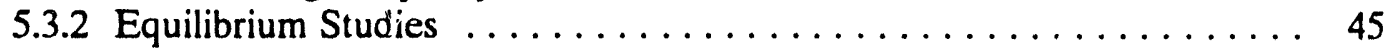

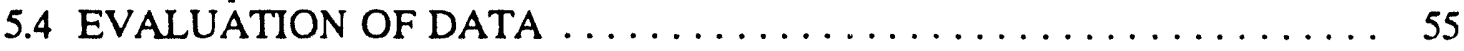

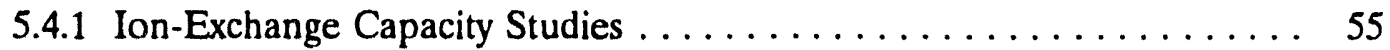

5.4 .2 Equilibrium Studies $\ldots \ldots \ldots \ldots \ldots \ldots \ldots \ldots \ldots \ldots \ldots \ldots$ 


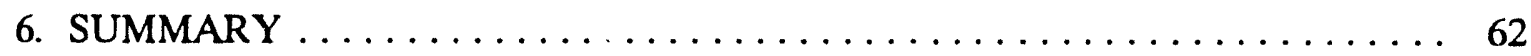

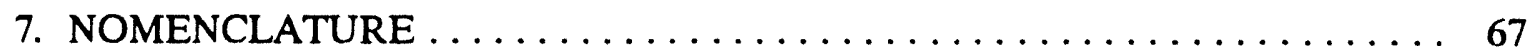

8. REFERENCES $\ldots \ldots \ldots \ldots \ldots \ldots \ldots \ldots \ldots \ldots \ldots \ldots \ldots \ldots \ldots$ 


\section{FIGURES}

1. Experimental-scale zeolite column $\ldots \ldots \ldots \ldots \ldots \ldots \ldots \ldots \ldots \ldots \ldots \ldots$

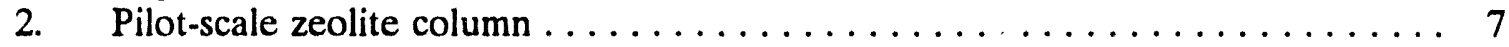

3. Near-full-scale zeolite columı $\ldots \ldots \ldots \ldots \ldots \ldots \ldots \ldots \ldots \ldots \ldots \ldots$

4. Engineering-scale sand/zeolite filter and zeolite columın $\ldots \ldots \ldots \ldots \ldots \ldots \ldots 12$

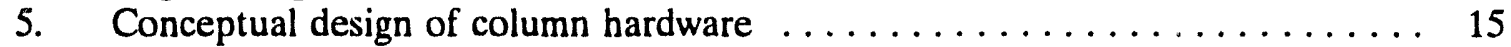

6. Schematic representation of chabazite zeolite $\ldots \ldots \ldots \ldots \ldots \ldots \ldots \ldots \ldots$

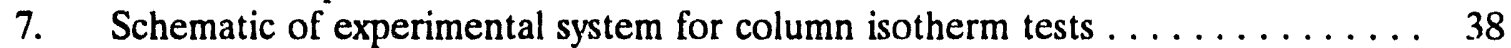

8. Experimental data from column isotherm test: (a) Sr-Na, (b) $\mathrm{Cs}-\mathrm{Na} \ldots . . . . .39$

9. The effect of experimental method on binary exchange: (a) $\mathrm{Sr}-\mathrm{Na}$ isotherm, (b)

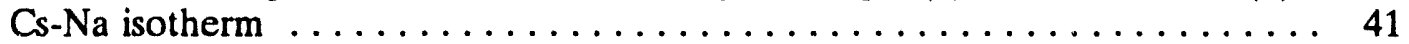

10. The effect of experimental method on ternary $\mathrm{Sr}-\mathrm{Cs}-\mathrm{Na}$ ion exchange: (a) $\mathrm{Sr}$ isotherm, (b) $\mathrm{Cs}$ isotherm . . . . . . . . . . . . . . . . . 42

11. Isotherms for binary exchange: (a) $\mathrm{Sr}-\mathrm{Na}$, (b) $\mathrm{Cs}-\mathrm{Na}$, (c) $\mathrm{Ca}-\mathrm{Na}$; (d) $\mathrm{Mg}-\mathrm{Na}$. . 49

12. Isotherms for three component ion exchange: (a) $\mathrm{Sr}-\mathrm{Cs}-\mathrm{Na}$, (b) $\mathrm{Ca}-\mathrm{Mg}-\mathrm{Na} \ldots \quad . .50$

13. Isotherms for four component ion exchange: (a) Sr-Ca-Mg-Na, (b) $\mathrm{Cs}-\mathrm{Ca}-\mathrm{Mg}$ -

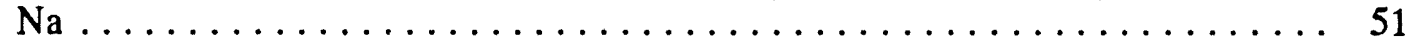

14. Isotherm for $\mathrm{Sr}-\mathrm{Cs}-\mathrm{Ca}-\mathrm{Mg}-\mathrm{Na}$ ion exchange $\ldots \ldots \ldots \ldots \ldots \ldots \ldots \ldots 2$

15. Effect of total solution concentration $\mathrm{Sr}-\mathrm{Cs}-\mathrm{Ca}-\mathrm{Mg}-\mathrm{Na}$ ion exchange: (a) $\mathrm{Sr}$ isotherm, (b) $\mathrm{Cs}$ isotherm, (c) $\mathrm{Ca}$ isotherm, (d) $\mathrm{Mg}$ isotherm ......... 53

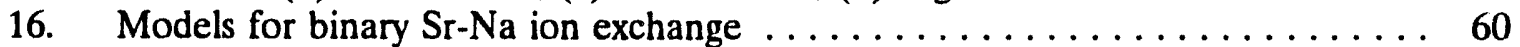

17. Models for $\mathrm{Sr}$ isotherm for $\mathrm{Sr}-\mathrm{Cs}-\mathrm{Ca}-\mathrm{Mg}-\mathrm{Na}$ ion exchange $\ldots \ldots \ldots \ldots \ldots \ldots 6$

18. Models for lumped multicomponent data: (a) Sr isotherm, (b) Cs isotherm,

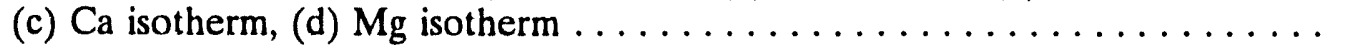




\section{TABLES}

1. Radiochemical composition of ORNL process wastewater $\ldots \ldots \ldots \ldots \ldots \ldots$

2. Chemical mnposition of ORNL process wastewater $\ldots \ldots \ldots \ldots \ldots \ldots \ldots$

3. Average composition of Ionsiv IE-96 zeolite $\ldots \ldots \ldots \ldots \ldots \ldots \ldots \ldots \ldots \ldots$

4. Physical properties of Ionsiv IE-96 zeolite $\ldots \ldots \ldots \ldots \ldots \ldots \ldots \ldots \ldots \ldots$

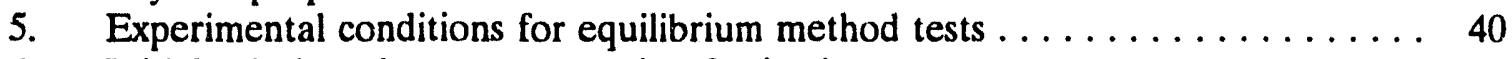

6. Initial solution-phase concentration for isotherm tests $\ldots \ldots \ldots \ldots \ldots \ldots \ldots 44$

7. Cation-exchange capacity of Ionsiv IE-96 zeolite $\ldots \ldots \ldots \ldots \ldots \ldots \ldots \ldots 44$

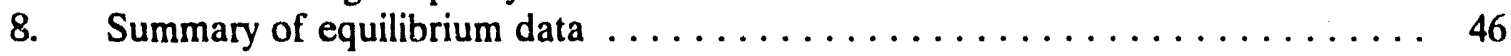

9. Model parameters for binary isotherms $\ldots \ldots \ldots \ldots \ldots \ldots \ldots \ldots \ldots$

10. Modified Dubinin-Polyani parameters for individual multicomponent isotherms $\ldots \ldots \ldots \ldots \ldots \ldots \ldots \ldots \ldots$

11. Modified Dubinin-Polyani parameters for lumped multicomponent isotherms . . 64 


\title{
THE DEVELOPMENT OF A ZEOLITE SYSTEM FOR UPGRADE OF THE ORNL PROCESS WASTE TREATMENT PLANT
}

\author{
S. M. Robinson, T. E. Kent, W. D. Arnold, and J. R. Parrott, Jr.
}

\begin{abstract}
Studies have been undertaken to design an efficient zeolite ion exchange system for use at the ORNL Process Waste Treatment Plant to remove cesium and strontium to meet discharge limits. This report focuses on two areas: (1) design of column hardware and pretreatment steps needed to eliminate column plugging and channeling and (2) development of equilibrium models for the wastewater system. Results indicate that zeolite columns do not plug as quickly when the wastewater equalization is performed in the new Bethel Valley Storage Tanks instead of the former equalization basin where suspended solids concentration is high. A down-flow column with spent zeolite was used successfully as a prefilter to prevent plugging of the zeolite columns being used to remove strontium and cesitum. Equilibrium studies indicate that a Langmuir isotherm models binary zeolite equilibrium data while the modified Dubinin-Polyani model predicts multicomponent data.
\end{abstract}

\section{INTRODUCTION}

From 1986 through 1988, treatability studies were performed to determine the most feasible methods for upgrading the Process Waste Treatment Plant (PWTP) to meet more stringent discharge limits and reduce secondary waste generation. The results from scoping tests $^{1}$ indicated that chabazite zeolite, an inorganic aluminosilicate molecular sieve, has an extremely high capacity for removal of ${ }^{137} \mathrm{Cs}$ and is the best material tested for removing ${ }^{90} \mathrm{Sr}$ in the presence of calcium and magnesium. Flo'v sheet analyses ${ }^{2}$ indicated that a series of zeolite ion-exchange columns to remove both ${ }^{90} \mathrm{Sr}$ and ${ }^{137} \mathrm{Cs}$ would be the most economical and efficient method for long-term upgrade of the PWTP. Pilot-scale demonstrations at the PWTP $^{3}$ have confirmed these results. This report summarizes studies done in support of implementing a zeolite system to replace the existing PWTP. The studies are grouped into two areas: (1) design of column hardware and pretreatment steps needed to eliminate column plugging and channeling and (2) development of an ion-exchange model to optimize column design and operating parameters. The details for this work are covered in ORNL log books A-103156-G, A-103506-G, and A-103936-G. 


\section{BACKGROUND}

Pilot-scale and near-full-scale zeolite ion-exchange columns were tested at the PWTP in 1987 to demonstrate the feasibility of the process, to verify modeling results obtained from laboratory-scale tests, and to determine factors that would be important in the full-scale design of a permanent system. These tests were performed using one-tenth-plant-scale and near-full-scale vendor supplied demineralizer pressure vessels (which were not designed specifically for this application) over 8- and 10-month periods, respectively. The studies successfully demonstrated the feasibility of zeolite systems to treat ORNL process wastewater. However, several areas were identified for additional study before permanent installation of a zeolite system at the PWTP. The details of these studies were documented by Robinson and Parrott ${ }^{3}$ and are summarized below.

The design of the columns will be a major factor in determining the efficiency of a zeolite system. Reusable columns must be designed for complete removal of loaded zeolites in order to minimize the radionuclide concentrations in the effluent streams. The demineralizer pressure vessels were becoming plugged before the chabazites had reached their sorption capacity. Additional studies are needed to determine the factors that are causing the column plugging. Columns should also be designed with adequate air sparging and backwashing capabilities to ensure maximum column life.

The data from the pilot-scale tests were modeled using industrially accepted methods. The results showed that these elementary models cannot be used to scale experimental data and design equipment for the chabazite systems. The present models do not adequately address nonidealities associated with multicomponent liquid systems. Additional studies are needed to develop models that can be used to design columns for maximum efficiency and eliminate extensive pilot-scale testing of such systems in the future. 


\section{EQUIPMENT DESIGN STUDIES}

\subsection{LTTERATURE REVIEW}

Decontamination of radioactive waste solutions using zeolites have been studied since the 1950 s. $^{4}$ Three sites are presently using zeolites to decontaminate general process wastewater containing cesium and/or strontium: (1) West Valley Nuclear Services Company, ${ }^{5.7}$ (2) the British Nuclear Fuels, ${ }^{8}$ and (2) Savannah River Plant. ${ }^{5}$ Each of these plants has experienced design and operational problems similar to those experienced in the ORNL pilot plant tests. Column plugging and channeling have been successfully dealt with by different methods at each plant.

It has been necessary to pretreat the feed at the Savannah River and British plants in order to minimize column plugging problems. Studies at the Savannah River plant showed ihat pluggage occurred in the top $15 \mathrm{~cm}$ of the zeolite columns. ${ }^{9}$ Sand filters failed to provide adequate filtration to eliminate the problem, and high performance filters (such as cartridge and Millipore disk filters) plugged rapidly. Installation of a backwashable prefilter containing zeolite upstream of the zeolite-exchange columns adequately reduced the plugging problems. The British clarify their feed with a low molecular weight polyelectrolyte, such as Nalfloc N7607 or Magnifloc 1597 , at temperatures above $20^{\circ} \mathrm{C}$ and polish with a sand pressure filter. ${ }^{8}$

The design of the flow distributors has a significant impact on column channeling. The West Valley columns contain specially designed "hanging basket" Johnson" screen distributors to evenly distribute flow through the column. ${ }^{6}$ Similar distributors are used to remove solution from the bed. The British use an inlet diffuser plate and a stainless-steel wedge wire strainer collection system to prevent channeling in their vessels. ${ }^{8}$

Zeolites are more friable material than organic resins and require specially designed columns to properly handle them. Zeolite columns require extra bed preparation and more frequent backwashing and/or air sparging than organic resin beds. Fines and air bubbles, if not removed during bed preparation, can block portions of the bed and result in the bed being underutilized.

\footnotetext{
"Johnson Division, P.O. Box 64118, St. Paul, MN 55164.
} 
Zeolites also have a higher tendency to pack over an extended period of time under enhanced fluid pressure. ${ }^{6}$ Therefore, the design of the column discharge is very important. At West Valley, the columns are designed with a bottom discharge nozzle that is placed directly at the dead center of the bottom dish and fitted with a specially designed flush bottom tank valve to facilitate complete removal of spent zeolite slurries. ${ }^{6}$ The British hydraulically transfer spent zeolite out of their vessels through top-mounted discharge lines. ${ }^{8}$ Three fluidizing rings are installed at various heights in the columns to enhance backwashing and zeolite removal. The upper rings are fitted with radial spray nozzles. The lower one is fitted with tangential spray nozzles which produce a vortex action in the vessel to assist emptying the vessel. This process allows $99.9 \%$ removal of the zeolite.

The above information indicates that the operational problems noted in the ORNL zeolite studies can be handled by proper pretreatment, column design, and operating conditions. The studies summarized in the remainder of this report address these problem areas for the ORNL application.

\subsection{COLUMN PLUGGING STUDIES}

Tests are being conducted to determine methods for eliminating plugging in the ORNL columns. The effects of superficial velocity, feed pretreatment, column configuration, and ion-exchange material are being examined. The plugging characteristics were examined in engineering-, pilot-, and near-full-scale columns containing TSM-300, a natural chabazite, with the same operating conditions. The feed conditions and ion-exchange materials are also being varied in similar experimental-scale columns. The results obtained to date are summarized below.

Three sizes of columns containing TSM-300 were operated at the same time to determine the effects of column configuration on operation and plugging. The superficial velocity was held constant since it is known to affect zeolite degradation, etc. Schematics of the columns are given in Figs. 1-3. The near-full-scale and pilot-scale columns (carbon steel demineralizer pressure vessels) were used in the previous demonstration tests. The experimental-scale glass column was designed for these tests. All three columns were operated in the down-flow mode. The pilot- and experimental-scale columns used fine-mesh Johnson screen distributors to distribute the feed solution over the radius of the bed. The near-full-scale column used 
5

lateral pipes wrapped with course screens for distributors. The column parameters used in these tests were as listed below:

\begin{tabular}{|c|c|c|c|c|}
\hline $\begin{array}{l}\text { Column } \\
\text { scale } \\
\end{array}$ & $\begin{array}{c}\begin{array}{c}\text { Resin } \\
\text { volume (L) }\end{array} \\
\end{array}$ & $\begin{array}{l}\mathrm{L} / \mathrm{D} \\
\underline{\text { ratio }}\end{array}$ & $\begin{array}{c}\begin{array}{c}\text { Actual } \\
\text { residence }\end{array} \\
\text { time (min) }\end{array}$ & $\begin{array}{c}\text { Superficial } \\
\text { velocity }(\mathrm{m} / \mathrm{min})\end{array}$ \\
\hline Experimental & 2.6 & 7.8 & 4.5 & 0.13 \\
\hline Pilot & 566 & 1.6 & 10 & 0.12 \\
\hline Near-full & 3760 & 0.63 & 13 & $0.10 \cdot 0.13$ \\
\hline
\end{tabular}

Length-to-diameter ratio.

\subsubsection{Studies at the PWTP}

Tests using the three columns shown in Figs. 1-3 were performed using PWTP feed water. This wastewater is collected from process drains throughout ORNL and transferred to the PWTP by a series of underground pipes. The pipes converge at the PWTP diversion box (DB), which feeds into an earthen equalization basin (EB). The process waste system usually collects wastewaters containing only trace quantities of radionuclides. However, generators occasionally discharge small quantities of organics, detergents, and hazardous liquids into the process system. Algae tends to grow in the open equalization pond. Silt has also accumulated in the bottom of the basin from collection of construction runoff and chemical precipitation from mixing of certain wastewaters. EB wastewater was used in all PWTP studies. It was prefiltered through a sand filter containing $0.30-$ to $0.84-\mathrm{mm}$ sand to remove debris prior to entering the ion-exchange columns.

\section{$\underline{\text { Near-full-scale column tests }}$}

The experimental conditions for near-full-scale tests were identical to those in the 1987 tests (Robinson and Parrott, 1989) ${ }^{3}$ except for the ion-exchange material used in the near-fullscale units. Ionsiv IE-95, a synthetic chabazite, was used in the previous near-full-scale test, while TSM-300, a natural chabazite, was used in this test. The natural material had a higher capacity for ${ }^{90} \mathrm{Sr}$, but the two materials had similar capacities for ${ }^{137} \mathrm{Cs}$ (based on the results from the 8,000 bed volumes that have been processed during this test). These results are consistent with previous laboratory-scale findings. 
ORNL DWG 91A-319

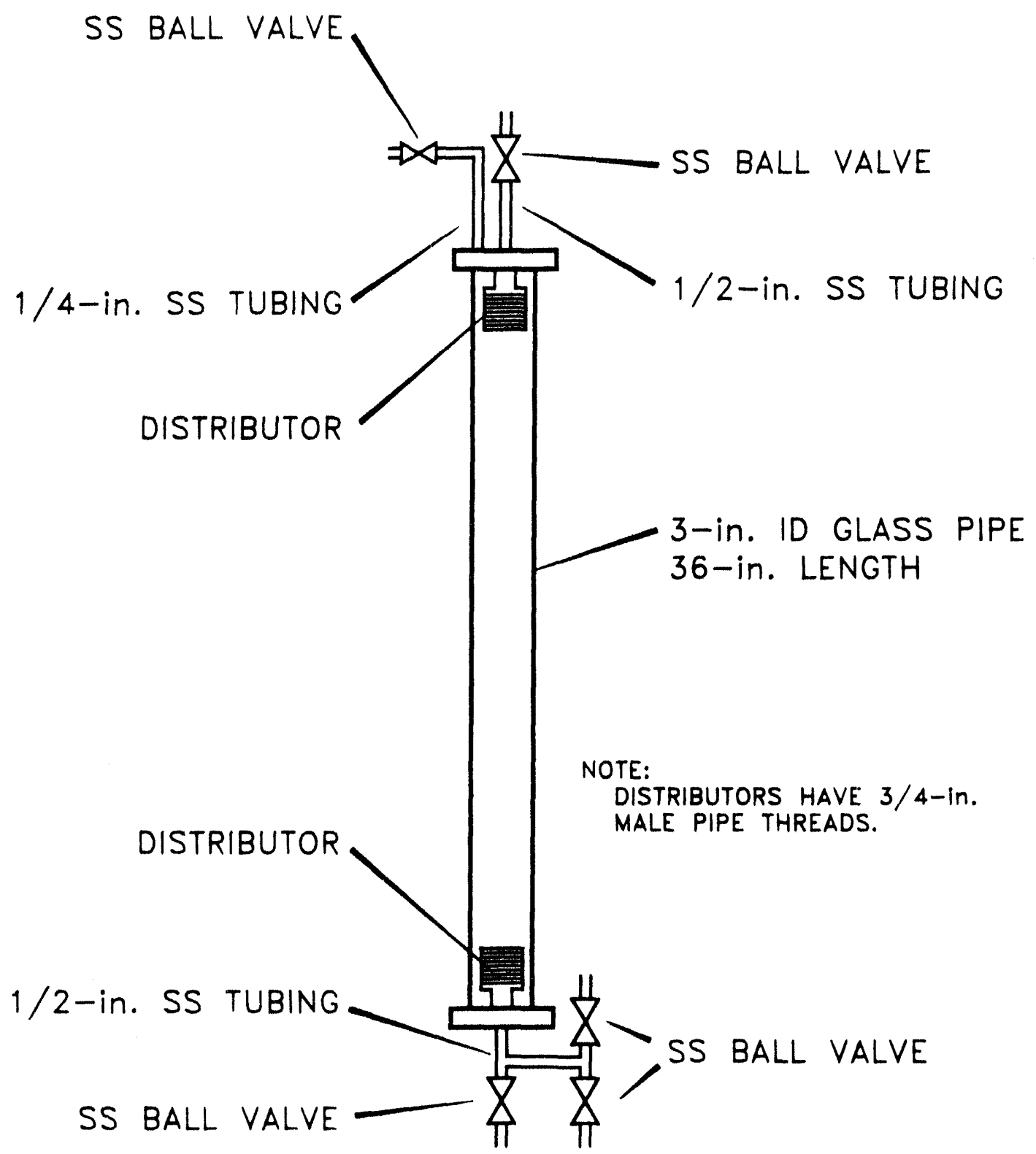

Fig. 1. Experimental-scale zeolite column. 
ORNL DWG 88-593
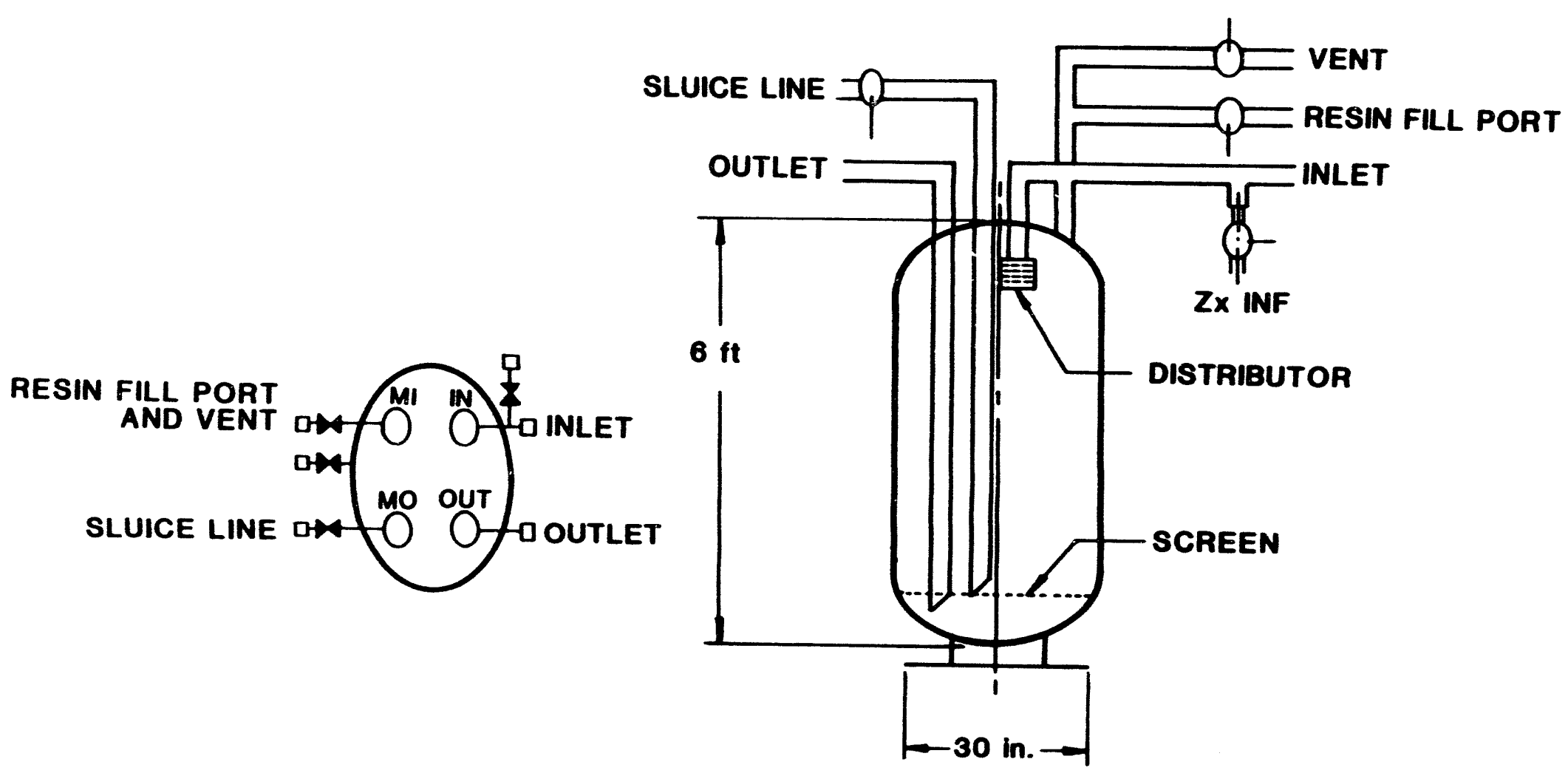

Fig. 2 Pilot-scale zeolite column. 
ORNL DWG 88-594R

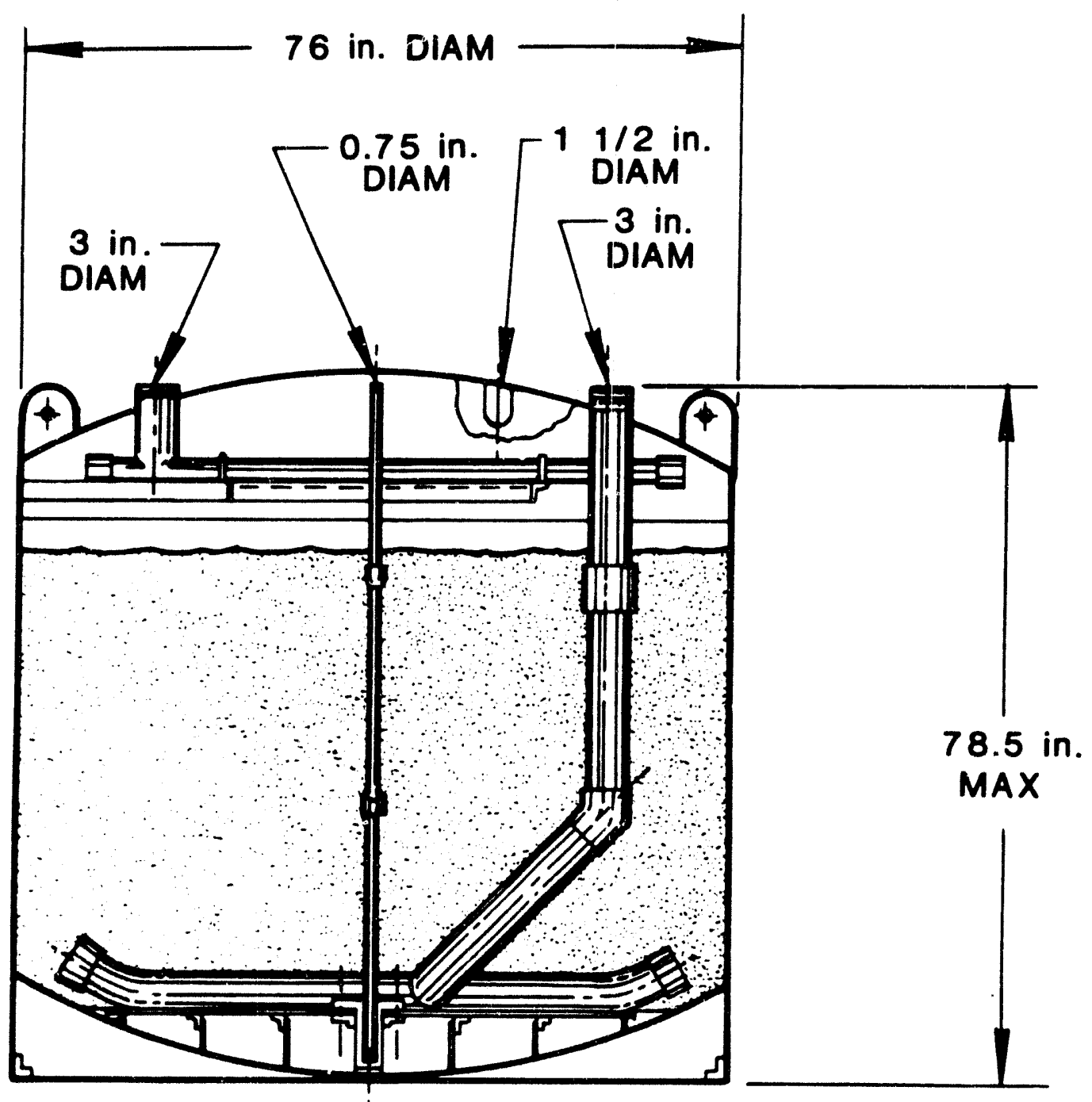

Fig. 3. Near-full-scale zeolite column. 


\section{Pilot-scale tests}

In the pilot-scale tests, several columns were operated in series in a "merry-go-round" fashion in which the first column is periodically removed from operation, filled with fresh material, and placed last in the train of columns. The number of columns operated in series and the desired effluent concentration from the system determine the change out frequency. The original tests ${ }^{3}$ were performed using four columns in series, while two columns were used in these tests. The columns had to be replaced after processing 2,200 bed volumes when using two columns in series (compared to 3,000 bed volumes for four columns) in order to keep the ${ }^{90} \mathrm{Sr}$ effluent concentration below $10 \mathrm{~Bq} / \mathrm{L}$.

The pressure drops across each system were also measured to determine if plugging problems were a function of the column configuration. Previous tests indicated that the pilotscale columns plugged much more rapidly than laboratory-scale or near-full-scale columns. It had also been noted that the Johnson screen distributors on the inlets of the pilot-scale columns tended to plug. Bypassing the feed distributors reduced the pressure buildup in the pilot-scale units and eliminated the need to backwash the columns under normal operating conditions. The pressure drop data indicated that the main cause of plugging for all columns was improper backwashing of the upstream sand filter that resulted in deposition of solids in the zeolite beds. Any effects of type of material or column configuration were masked by the effects of the sand filter operation.

\section{Experimental-scale tests}

A series of tests was performed using experimental-scale zeolite columns (Fig. 1) to determine the mechanisms causing column plugging. Two columns were installed in parallel at the PWTP using feed taken downstream of the roughing sand filter installed at the plant entrance to remove debris entering from the EB. One column was loaded with TSM-300 chabazite while the other was filled with sand that was the same size as the TSM-300 (20-50 mesh). The flow rates through each column were measured separately.

Identical columns containing zeolite and sand, respectively, were operated at the PWTP for approximately 4,400 bed volumes each before they were shut down due to excessive pressure drops across the columns. The pressures across each column began to build after about 1,500 bed volumes, and the pressure drop across the zeolite column was approximately double that of the sand column. When the columns were shut down, the top 3 to $6 \mathrm{~cm}$ of 
both beds contained a layer of fine silt-like material. This material was easily removed from the sand column by backwashing, but it had "cemented" together with the zeolite particles in the zeolite column, forming a solid plug. Backwashing and air sparging the column broke up only small portions of the plug. Continued backwashing only resulted in channeling around the plug.

A $10-\mu \mathrm{m}$ cartridge filter was installed upstream of the columns at the PWTP to determine if better prefiltration would eliminate the plugging. Similar results were obtained, but the pressure built up at a much slower rate. The columns operated for 7,400 bed volumes before they were shut down and contained less silty material than in the previous test. The material in the zeolite column was "cemented" together but the sand column was not. The cartridge filters were coated with a dark green gelatinous material similar to that seen previously in the pilot-scale columns. The material was probably a mixture of algae and silt from the EB. These tests indicate that very fine material from the feed is being deposited on top portion of beds and is resulting in column plugging. This material is either less than $10 \mu \mathrm{m}$ in size or it is precipitating from the feed after it enters the column. A difference between the sand and zeolite deposits indicates that the zeolite surfaces are more susceptible to material deposition than the sand.

\subsection{Tests Prior to Equalization}

An experimental-scale column (see Fig. 1) containing TSM-300 zeolite was installed upstream of the EB to determine if plugging problems would be reduced without algae and silt from the EB. The column was located at the monitoring station upstream of the EB, where it drew its feed from the diversion box (DB) at the entrance of the PWTP system. A sand filter containing sand that was the same mesh size as the zeolite was installed upstream of the column at the DB. The housing for this sand filter was initially a 24-in. by 2-in.-diam glass pipe. A flow rate of $0.15 \mathrm{gal} / \mathrm{min}$, regulated by a needle valve and rotameter, was maintained until excess pressure drop due to plugging caused the flow to decrease. The filter plugged quickly due to insufficient surface area, so it was replaced with a 12-in. by 6-in.-diam glass column. Reducing the flux from $0.3 \mathrm{~m} / \mathrm{min}\left(6.8 \mathrm{gal} / \mathrm{min} / \mathrm{ft}^{2}\right)$ to $0.03 \mathrm{~m} / \mathrm{min}$ $\left(0.76 \mathrm{gal} / \mathrm{min} / \mathrm{ft}^{2}\right)$ eliminated plugging problems in the filter. 
A simple flat deflection plate was used as a distributor for the 6-in.-diam sand filter to avoid the plugging problems of Johnson screen distributors used in earlier tests at the PWTP. A Johnson screen was used on the outlet to keep the sand in the column. Johnson screens were used for both the inlet distributor and the outlet screen in the zeolite column.

The 6-in.-diam sand filter and 3-in.-diam zeolite column were operated in series at the DB for over 20,000 bed volumes without significant plugging and without backwashing either unit. Visible differences were apparent in the media in both the sand filter and the zeolite column after 20,000 bed volumes. The sand was very dark, presumably with entrapped silt, in the top $90 \%$ of its volume. The entire top surface of the sand bed was covered with a 0.5-in.-deep layer of fine dark silt. The zeolite bed also had a thin ( $\sim 0.125$-in. thick) layer of very fine silt that had passed through the sand filter and distributor. The zeolite particles also became considerably larger and darker in color as time passed. After $\sim 19,000$ bed volumes, several large, deep cracks appeared in the top of the zeolite bed. When the zeolite column was finally backwashed (not due to plugging, but to remove some air that had become trapped in the bed when the column was periodically shut down to clean the feed pump), a large amount of silt was removed from the bed. Incomplete removal of slit from the zeolite column resulted in rapid buildup of pressure drop and repeated plugging problems.

The test system that was modified to test a zeolite prefilter since tests at the PWTP and Savannah River ${ }^{9}$ indicated that zeolite may be a better filter material than sand. An additional experimental-scale column filled with $1 \mathrm{~L}$ of TSM-300 was added as a prefilter upstream of the original zeolite column as shown in Fig. 4. A second feed pump was also installed to increase the flow rate and pressure across the columns to enhance backwashing capabilities of the system. Qualitative backwashing tests indicated that flow rates between 0.4 and $0.6 \mathrm{~m} / \mathrm{min}\left(10.5\right.$ and $\left.14 \mathrm{gal} / \mathrm{min} / \mathrm{ft}^{2}\right)$ were adequate for fluidization of the zeolite and removal of zeolite fines from the bed. This agrees with backwash flow rate of $0.5 \mathrm{~m} / \mathrm{min}$ (12 $\mathrm{gal} / \mathrm{min} / \mathrm{ft}^{2}$ ) recommended in the literature.

In the summer of 1989, the EB was replaced with holding tanks. Flow from the DB was redirected through a pipeline around the EB and into the Bethel Valley Storage Tanks (BVSTs). The DB was also isolated from the EB by installation of a flow baffle. All studies using the modified test system (with the zeolite prefilter) at the DB were conducted after the EB was removed from service. 
ORNL DWO MIA-320

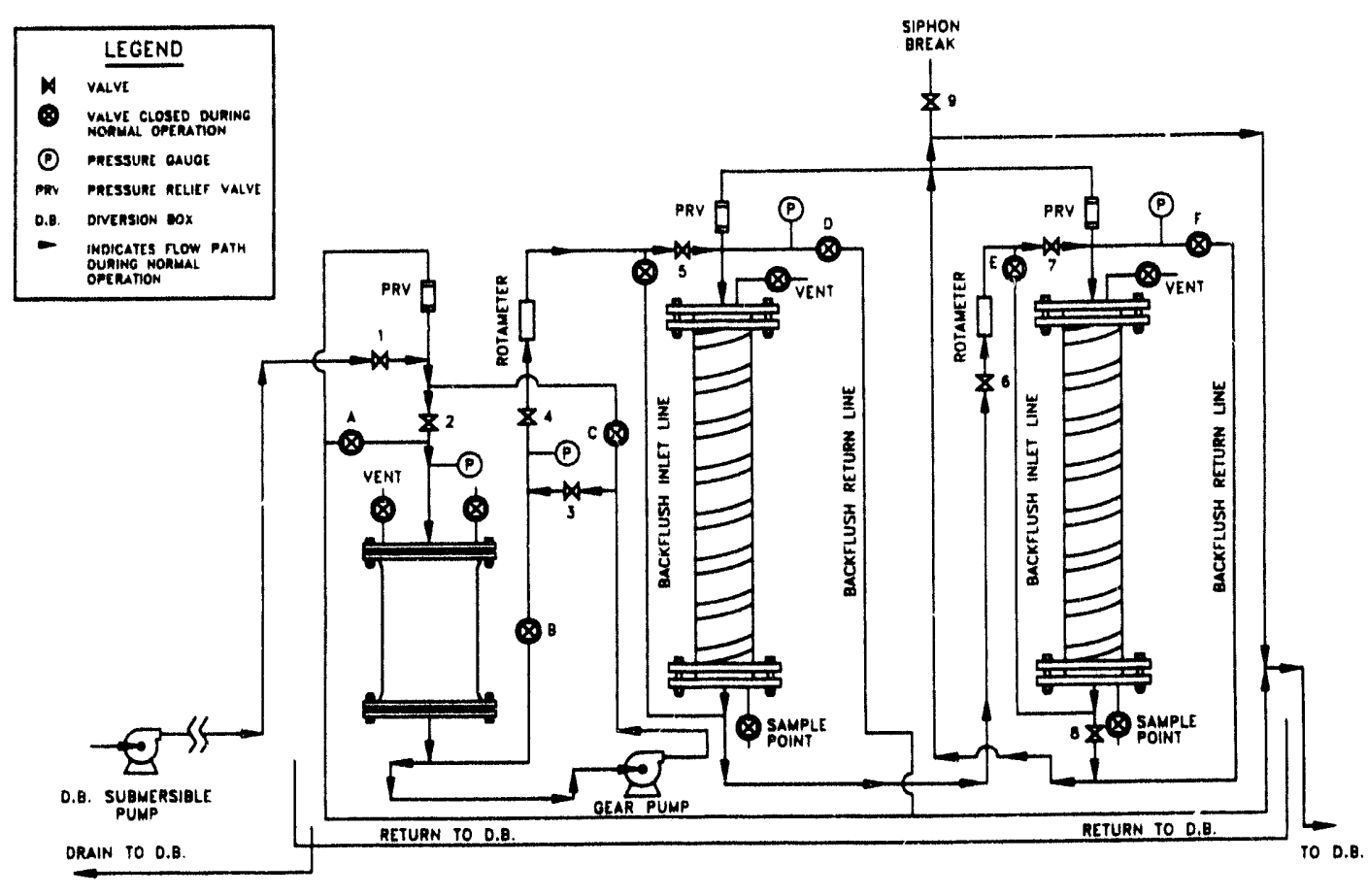

Fig. 4. Engineering-scale sand/zeolite filter and zeolite column. 
The morified experimental-scale system is presently being tested. After a throughput of over 8000 bed volumes, the pressure drop across the zeolite prefilter is less than 1 psig. The zeolite in the prefilter is slightly discolored while the zeolite in the second column appears unchanged. Though this test has not yet proceeded to the same duration as previous tests, the amount of material buildup on filters and on pump inlet screens is far less than that previously experienced. This is probably because the EB water is no longer allowed to back up into the $\mathrm{DB}$, thus reducing the algae and sediment in the feed to the columns.

The above results indicate that much of the plugging problem seen in the pilot-scale tests at the PWTP was due to deposition of materials from the EB on the zeolites. The zeolite surface characteristics must promote nucleation of fine materials from the PWTP feed (only after it has passed through the EB), and the resulting deposition is restricted to the upper portion of the zeolite bed. Avoiding the EB appears to be the key to increased zeolite column life by decreasing plugging of the column distributors and media beds. Tests to date at the $\mathrm{DB}$ indicate that prefiltration may not be necessary if the EB has been bypassed.

Materials other than silt from the EB could potentially cause plugging of zeolite cclumns. The practice of recycling high $\mathrm{pH}$ sump wastewaters to the BVSTs may cause precipitation of hardness compounds which could deposit on the zeolite bed. Mud and sand from groundwater inleakage into process wastewater pipelines will also be filtered out by the zeolite bed. Laboratory wastewater containing suspended solids will routinely be discharged into the process waste system for treatment through the zeolite columns. With these additional potential sources of suspended solids and the limited operating data available since the BVSTs were placed in service, further testing with actual process wastewater is needed to determine clairfication and prefiltration needs.

\subsection{COLUMN HARDWARE DESIGN}

The literature review on the subject of equipment design given in Sect. 3.1 indicates that the flow-through columns used to handle zeolites are somewhat unique due to the physical characteristics of the zeolites. The columns must be designed for adequate backwashing of the zeolites due to the tendency for the columns to plug. They must also provide a means of sluicing the zeolite out of the vessel such that all the spent zeolite is removed. In addition, since the zeolite at the surface of the bed tends to cement together under certain conditions, 
a means of breaking up the zeolite at the surface is necessary. Proper design of the internal column hardware will be an important factor in producing an effective, easily operated process plant. Tests described in Sect. 3.2 indicated that off-the-shelf columns would not be adequate for use as zeolite ion-exchange columns. Therefore, a conceptual design for a zeolite column was developed to be used as a guide for future pilot-scale equipment tes s.

The column consists of a pressure vessel with inlet and outlet distributors, sluicing transfer lines, fluidizing nozzles, and pressure safety devices. The distributor outlets/inlets were sized such that the feed will be distributed evenly across the zeolite bed and channeling minimized. The sluicing lines were sized such that the zeolite granules remain suspended during loading or unloading of the columns. Fluidizing nozzles were designed to mitigate channeling of the zeolite bed and aid in flushing zeolite out of the columns during sluicing. Protection of the column will be provided by installation of pressure relief and vacuum breaking devices.

The column design was based on a maximum flow rate of $100 \mathrm{gal} / \mathrm{min}$, the same as the near-full-scale columns previously tested (see Fig. 3). The residence time was set at $10 \mathrm{~min}$, the time necessary for removal of ${ }^{137} \mathrm{Cs}$ in the near-full scale column tests. The column was, therefore, designed to hold approximately $1000 \mathrm{gal}\left(130 \mathrm{ft}^{3}\right)$ of zeolite. The maximum working pressure for the column must be 50 psi based on a typical maximum pressure drop of 10 psi for one column and the possibility that as many as five could be run in series. Applying a factor of two for safety gave a 100 psi rating for the column.

A drawing of proposed column is shown in Fig. 5. The design basis is described below in detail.

\subsubsection{Flow Distributors}

The Darcy formula may be used to determine flow rate, channel size, or pressure drop for steady flow of liquids in uniform circular pipes running full of liquid under isothermal conditions. It is used for rule-of-thumb design of perforated pipe distributed. Perry and Chilton $^{10}$ state that to reduce maldistribution of flow to less than $5 \%$, the kinetic energy of the inlet stream to the distributor pipe must be equal to or less than one tenth of the pressure drop across the outlet hole. The following equation was given: 


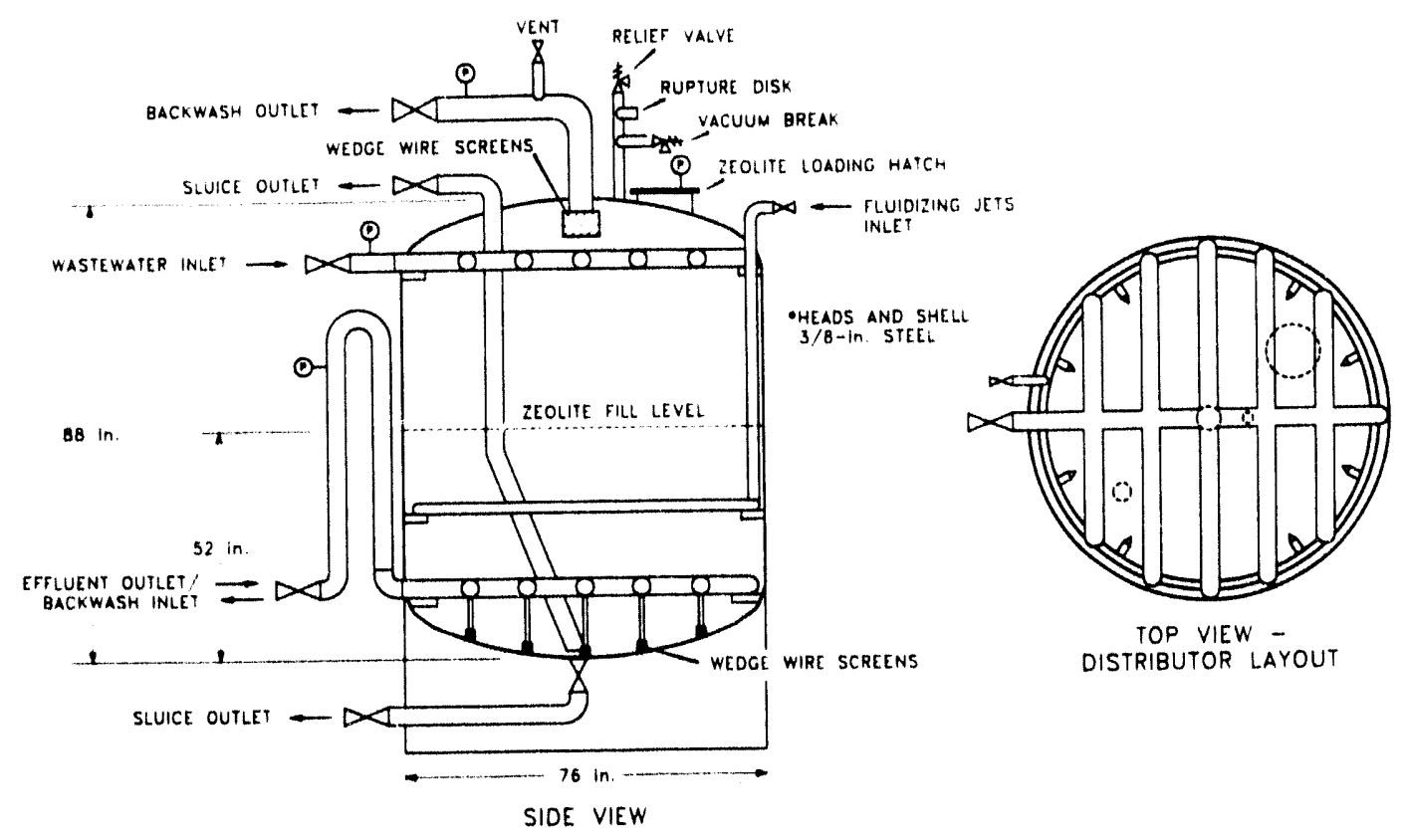

Fig. 5. Conceptual design of column hardware. 


$$
E_{k}=f v^{2} / 2 g_{c},
$$

where $E_{k}$ is the kinetic energy in feet of flowing fluid, $f$ is the correction factor for average velocity (which is 1.0 for plug flow), $v$ is the velocity in $\mathrm{ft} / \mathrm{sec}$, and $\mathrm{g}_{\mathrm{c}}$ is $32.17 \frac{l b_{m} \cdot f t}{l b_{f} \cdot \sec ^{2}}$. The kinetic energy divided by the pressure drop across the outlet hole must be $\leq 0.10$. The size of the outlet hole was considered to be the sum of the areas of all the holes in the distributor. A modified version of Darcy's formula for flow of fluid in pipe ${ }^{11}$ was used to calculate the hole size which gave the needed pressure drop for even flow distribution:

$$
Q=236 d_{0}^{2} k \sqrt{\Delta \mathrm{P}} / 0
$$

where $d_{o}$ is the orifice diameter, $k$ is the flow coefficicut that corrects for the velocity of approach, $\Delta \mathrm{P}$ is the pressure drop in psig, $\rho$ is the fluid density in $\mathrm{lb} / \mathrm{ft}^{3}$, and $\mathrm{Q}$ is the flow rate in $\mathrm{gal} / \mathrm{min}$. Using these formulas, it was determined that an inlet distributor with a 2-in. ID inlet would have an effective orifice diameter of $1.35 \mathrm{in}$. for even distribution of flow. The pressure drop across this distributor at $100 \mathrm{gal} / \mathrm{min}$ was calculated to be $7 \mathrm{psig}$. The orifice size for the outlet distributor was sized based on its use as the backwash inlet line. For even distribution of flow for a backwash flow rate of $345 \mathrm{gal} / \mathrm{min}\left(11.5 \mathrm{gal} / \mathrm{min} / \mathrm{ft}^{2}\right)$ using a 3 -in. ID inlet line, the orifice diameter was calculated to be $2.04 \mathrm{in}$. for even flow distribution. The pressure drop across this distributor was calculated to be $16.5 \mathrm{psig}$ at $345 \mathrm{gal} / \mathrm{min}$.

The use of the correct orifice size will ensure the even distribution of flow throughout the sength of the pipe distributor. The even distribution of flow through the column will then become a function of the layout of the perforated pipe. A widespread network of pipe with small and closely spaced perforations will result in more even distribution than one short length of pipe with only a few large perforations. The more complex layouts will be more expensive, however, the economics of waste disposal costs vs equipment costs will favor the more expensive distributors. The perforations should be sized such that as many as possible can be used on the distributor without making the holes so small that plugging becomes a problem. The economic considerations were not taken into account in design of the column shown in Fig. 5. The distributor is a simple design that is widely used in industry. 


\subsubsection{Sluicing Pipelines}

The minimum velocity for transporting solids in a liquid/solid mixture can be calculated using an equation from Perry and Chilton ${ }^{12}$ based on correlations of data for flow of water suspensions of sands, ash, and lime with particle sizes under 0.04 in. (1 mm) in horizontal pipe of 1- to 12-in. diam:

$$
\frac{v^{2} \rho_{L}}{g_{c} d_{s}\left(\rho_{s}-\rho_{L}\right)}=0.0251\left(\frac{v d_{t} \rho_{m}}{\mu_{L}}\right)^{0.77 s} \text {, }
$$

where $v$ is the velocity in $\mathrm{ft} / \mathrm{sec}, \rho_{\mathrm{L}}$ is the density of the liquid in $\mathrm{lb} / \mathrm{tt}^{3}, \mathrm{~g}_{\mathrm{c}}$ is $32.2 \mathrm{ft} / \mathrm{sec}^{2}, \mathrm{~d}_{\mathrm{s}}$ is the average diameter of the solid particles that are larger than $85 \%$ by weight of the total solids in feet, $\rho_{\mathrm{s}}$ is the density of solid particles in $\mathrm{lb} / \mathrm{ft}^{3}, \mathrm{~d}_{\mathrm{t}}$ is the diameter of pipe in $\mathrm{ft}, \rho_{\mathrm{m}}$ is the density of mixture in $\mathrm{lb} / \mathrm{ft}^{3}$, and $\mu_{\mathrm{L}}$ is the viscosity in $\mathrm{lb} / \mathrm{ft} \mathrm{sec}$.

For the heaviest zeolite slurry $\left(80 \mathrm{lb} / \mathrm{ft}^{3}\right)$ and a 2 -in.-diam pipe, the equation becomes

$$
22.42 v^{2}=0.0251(1,523 D v)^{0.775}
$$

A velocity of about $2 \mathrm{ft} / \mathrm{sec}$ satisfies this equation. For a 2 -in. pipe, this is equivalent to a flow rate of about $20 \mathrm{gal} / \mathrm{min}$. The term "per minute" takes the variation in solids concentrations in the slurries into account. The higher density mixtures (due to higher solids concentrations) result in higher velocities necessary to keep the solids suspended. Since the zeolite slurries are likely to be less concentrated than those used to calculate this velocity, flow rates between 10 and $20 \mathrm{gal} / \mathrm{min}$ should easily keep the zeolite suspended while unloading the columns. A 2-in. line size, therefore, should be adequate for this purpose.

\subsubsection{Fluidizing Jets}

The purpose of the fluidizing jets is to break up the zeolites which become clumped together during wastewater treatment. Clumps of spent zeolite would be difficult to sluice 
from the column unless the clumps could be broken up by some means. The jet type, size, pressure, and arrangement will be important for optimizing effectiveness, however, these parameters have not been studied. For the purpose of illustrating the concept, it was assumed that 12 jets with diameters of 0.2-in. would be adequate for breaking up the zeolite and enhancing zeolite removal from the vessel.

\subsubsection{Wedge-Wire Screens}

This type of screen has been used successfully in ORNL experimental-scale and near-fullscale tests and has proven to retain zeolite in the columns. These screens do not tend to plug, can be backwashed easily, and can be sized such that pressure drop across the screen is not significant. These screens are used in the design on the effluent distributor and on the backwash outlet line.

\subsubsection{Column Dimensions}

The optimum aspect ratio (height/diameter) for zeolite columns cannot be determined using general equations or correlations. The model being developed in Sect. 4 of this report is required for selection of the aspect ratio. The only general guidelines presently available for sizing columns pertain to the free board space required for backwashing. The column must allow for a zeolite bed expansion of about 1.6 times the bed height. ${ }^{6}$ Therefore, this column was designed with dimensions similar to those of the previously tested column shown in Fig. 3. The proposed column is 88 -in. high and 74-in. diam. The aspect ratio is 0.65 for the zeolite bed.

\subsubsection{Wall Thickness}

The wall thickness was estimated using standard guidelines ${ }^{10}$ for the above dimensioned colurnn size and the 100 psig pressure rating. Assuming steel construction with ellipsoidal heads and single butt-welded seams, the wall thickness for the vessel should be about 0.4 in. 


\subsubsection{Loading Hatch}

A 16-in. loading hatch was added for flexibility in loading the zeolites as either dry or slurried material.

\section{MODEL DEVELOPMENT FOR ION-EXCHANGE COLUMN DESIGN}

Most industrial multicomponent ion-exchange columns are presently designed using rather crude scale-up techniques based on laboratory- and pilot-scale data. ${ }^{13} \mathrm{~A}$ semiempirical model developed by Thomas is frequently used in the industry to scale-up experimental data. ${ }^{14}$ Previous zeolite tests at ORNL as described in Sect. 3.2.1 indicate that the Thomas equation is not adequate for the design of zeolite ion-exchange columns. The options available for design of full-scale columns are presently limited to design based on pilot-scale tests and/or mathematical models. The advantages and disadvantages of ea:h option are discussed below.

The pilot-plant design approach acknowledges the system specificity for particular applications, but it tends to be very time consuming and expensive. In addition, it does not easily lend itself to predicting system responses to variables other than those specifically tested. Columns can be designed for adequate performance using these methods, but the systems cannot be optimized without the use of more accurate models. The optimization of ion-excisange columns becomes increasingly important in applications where high efficiency is required to meet low discharge requirements and for treating hazardous or radioactive wastewaters where the disposal costs for the secondary waste is extremely high.

Predictive mathematical models avoid excess testing and aid in reducing the uncertainty involved in design of full-scale columns. These process models can be used to examine design parameters other than those directly measured. They can also project column response and sensitivity to a variety of circumstances that may not be easily reproduced or experimentally simulated in the pilot program. The logistics, time, and expense associated with pilot-scale test equipment and programs make the use of such models very attractive.

Predictive models have been used successfully to predict column operations in some cases. Unfortunately, genera! models have not been developed to the point that they can be used in industrial applications for multicomponent liquid systems. Mathematical models are presently being developed for specific applications using bench-scale data. 
A predictive mathematical model is being developed for optimum design of ion-exchange columns containing chabazite zeolites. This model will incorporate the effects of masstransfer mechanisms and equilibrium on the column dynamics for multicomponent liquid ion exchange with zeolites. Once verified, this model can be used to examine design parameters other than those directly measured and project column response and sensitivity to many different variables. It should also avoid the need for extensive pilot-scale tests in the future and reduce the uncertainty involved in design of full-scale zeolite columns.

The studies performed to date are summarized below. They include a literature review of the status of column design methods specifically for zeolite applications, the requirements for mathematical modeling, and the experimental results obtained to date.

\subsection{LITERATURE REVIEW}

\subsubsection{Zeolite Column Design}

Most of the applications of zeolites as ion exchangers to date have been restricted to gases, light hydrocarbons, and other simple molecules. Research has concentrated on the systems that have been used the most: the sodium/calcium/magnesium-A system and ammonium exchange in synthetic and natural zeolites. ${ }^{15}$

Applications of zeolites for treatment of contaminated groundwater began to emerge over the last decade. The decontamination of radioactive waste solutions using zeolites and other inorganic ion exchangers have been studied since the 1950s. Unfortunately, very few fundamental studies were performed, and it has been difficult to make use of much of the literature because of the lack of standard, rocedures and theoretical bases. ${ }^{4}$ Since mathematical models have not been available for column design of such systems, users have been restricted to designing columns based on pilot-plant tests and/or crude models. Neither of these approaches have been very successful for efficient column design.

Three sites are presently using zeolites to decontaminate groundwater. West Valley Nuclear Services Company is removing radioisotopes (e.g., cesium and strontium) from various waste streams with Phillipsite and Linde A-51 zeolites. The full-scale column designs were based on extensive laboratory-and pilot-scale data. ${ }^{5,6}$ No tests were made to determine 
equilibrium or mass-transfer mechanisms, even though bench-, pilot-, and full-scale data did not agree. ${ }^{7}$

The British Nuclear Fuels is using clinoptilolite zeolite to remove cesium and strontium from wastewaters. Their $\$ 180 \mathrm{M}$ treatment plant was also designed using the pilot-plant method. $^{8}$ "Because of the size and geometry of columns used," bench-scale column tests "were unable to predict the actual performance at plant size." Therefore, the plant was designed in four stages, using larger pilot columns in each test.

A mixture of Ionsiv IE-96 (a chabazite) and Linde A-51 zeolites is being used to remove cesium and strontium from water contaminated during the accident at the Three Mile Island Unit 2 Nuclear Power Station. The mix ratio and the residence time for this application were based on bench-scale tests using columns with the same length to diameter ratio as the fullscale columns. ${ }^{16,17}$ The column design was selected based on physical constraints of the building and the size of equipment that was commercially available. However, the system was modeled using the Thomas equation. The mass-transfer and distribution coefficients for the full-scale equipment were higher than predicted by the bench-scale data except for the strontium distribution coefficient which was lower. The observed differences were not considered to be greatly significant considering that the scale-up factor was $10^{5}$.

ORNL has been unsuccessful at using the Thomas model to predict scale-up from benchscale data for zeolites. ${ }^{3}$ The literature and ORNL studies also indicate that better methods of column design must be developed in order to optimize plant operation and minimize secondary waste generation. The data from the experimental-, pilot-, and near-full-scale tests described in the last section were plotted to determine the breakthrough curves for each system. These curves were modeled using the Thomas model ${ }^{3}$ that uses three dimensionless parameters to define an ion-exchange system: (1) the separation factor, $R$; (2) the throughput parameter, $\mathrm{T}$; and (3) the number of mass-transfer units, N. The shape of the breakthrough curve is determined by plotting $\mathrm{T}$ vs fractional breakthrough for a given $\mathrm{N}$ and $R$ where $T$ is the bed volumes of liquid processed divided by the distribution coefficient, $K_{d}$. The shape of experimental breakthrough curves were modeled by assuming $R=1$ and calculating values for $K_{d}$ and $N$. The values obtained for each column were: 


\begin{tabular}{llr}
\multicolumn{1}{c}{ Scale } & $\mathrm{K}_{\mathrm{d}}$ & $\mathrm{N}$ \\
\hline & & \\
Experimental & 2200 & 40 \\
Pilot & 3100 & 7 \\
Near-full & 4000 & 30
\end{tabular}

According to the Thomas model, the above values of $\mathrm{K}_{d}$ should have remained constant, and $\mathrm{N}$ should have been proportional to the residence time. Correlations between column performance and the length-to-diameter ratio or superficial velocity (which are not taken into account in the Thomas model) were not evident. Although some column plugging occurred during these tests, the extreme variation in the values for $\mathrm{K}_{d}$ and $\mathrm{N}$ reinforce the results from the previous tests, which indicated that the Thomas model is not adequate for modeling these systems.

\subsubsection{Model Development}

Ion-exchange columns are designed based on the effluent concentration profile as a funcion of throughput (i.e., the volume processed or the time of operation). This profile, commonly termed the breakthrough curve, represents the specific combination of equilibrium and rate factors that control process performance in a particular application. The rate of appearance and the shape of a breakthrough profile depend on several factors, including the nhysical and chemical properties of both the sorbate and sorbent, the particular rate-limiting mechanisms involved, the depth of the bed, and the velocity of flow. The relative effects of these factors are specific to each particular application.

Fixed-bed column design is usually predicted by direct measurement or modeling to determine the breakthrough characteristics for a particular set of feed-stream and operating conditions. Predictive modeling for multicomponent systems is complicated by competitive interactions among species. In the case of microporous materials such as zeolites, these interactions may involve mutual interference in intraparticle mass transport as well as competition for available adsorption capacity. ${ }^{18}$ 
The first step in developing a mathematical model that describes or predicts system dynamics is to provide a representation of the equilibrium behavior. ${ }^{19}$ The second step is to mathematically characterize the associated rate phenomena. The third step in structuring a model is implementation of the thermodynamic principle of mass continuity. The partial differential equations resulting from the differential mass balance are often highly nonlinear, and numerical methods are generally required for their solution. Only the equilibrium behavior is discussed in this report.

Binary ion exchange in zeolites may be represented by the following chemical reaction equation: $:^{20}$

$$
g_{A} B_{(z)}^{s_{i}^{*}}+g_{B} A_{(s)}^{s_{A}^{*}}=g_{A} B_{(s)}^{8_{i}^{*}}+g_{B} A_{(z)}^{8_{A}^{*}}
$$

where $g_{A}$ and $g_{B}$ are the charges of the exchanging cations $A$ and $B$, and the subscripts $z$ and $s$ refer to the zeolite and solution phases, respectively. The equivalent fractions of the exchanging cations in the solution and zeolite are defined by

$$
A_{s}=g_{A} c_{A} /\left(g_{A} c_{A}+g_{B} c_{B}\right)
$$

and

$$
A_{z}=\frac{\text { equivalents of exchanging cation } A}{\text { total equivalents of cations in the zeolite }} \text {, }
$$

where $c_{A}$ and $c_{B}$ are the molalities of the ions $A$ and $B$, respectively, in the equilibrium solution. The ion-exchange isotherm is a plot of $A_{2}$ as a function of $A_{8}$ at a given temperature. The preference of the zeolite for one of two ions is expressed by the separation factor defined as:

$$
\alpha{ }_{B}^{A}=A_{z} B_{s} / B_{z} A_{s} \text {. }
$$


If more than one cation is exchanging from either phase, the system is defined as multicomponent ion exchange, and Eqs. 5-8 can be expanded accordingly. If $g_{A}$ and $g_{B}$ are each equal to one, uni-univalent ion exchange is said to occur. If they each are equal to two, di-divalent exchange is occurring. If they are unequal, multivalent ion exchange is occurring.

Breakthrough profiles generated from predictive dynamics models are particularly sensitive to equilibrium parameters. This can be especially critical in the very low (so-called Henry's region) concentration as well as in very high concentration ranges. ${ }^{19}$ To be of the most use, the selected equilibrium model should be able to accurately describe isotherm data over a wide concentration range and translate single- or binary-solute data into a predictive multicomponent isotherm equation.

The majority of the equilibrium modeling has been done for adsorption of organics on activated carbon. Numerous single- and multicomponent equilibrium formulations, both theoretical and empirical in nature, have been developed in the past decade that vary considerably in applicability and utility. While attempts to develop competitive equilibrium models have met with limited success, there is currently no way in which the fundamental properties of compounds can be used to predict their respective mass-transport controlled rates of adsorption in multicomponent systems. ${ }^{17}$ Frequently used models are described below.

The simple Langmuir model ${ }^{21}$ has been extended to describe multicomponent equilibrium,

$$
\frac{q_{1}}{q_{s_{1}}}=\frac{b_{1} c_{i}}{1+b_{1} c_{1}+b_{2} c_{2}+\cdots} .
$$

This model is limited to monolayer adsorption and a homogenous adsorbent surface, but it has successfully described binary organic adsorption onto a synthetic resin. ${ }^{22}$ Semi-empirical models, such as the Freundlich equation,

$$
\frac{q_{i}}{q_{s_{1}}}=\frac{b_{i} c_{i}^{n_{1}}}{b_{1} c_{1}^{n_{1}}+b_{2} c_{2}^{n_{2}}+\cdots},
$$


have frequently been used in adsorber design efforts. ${ }^{19}$ The general form of the multicomponent Langmuir-Freundlich equation ${ }^{20}$ has also been used

$$
\frac{q_{1}}{q_{s_{1}}}=\frac{b_{1} c_{i}^{n_{1}}}{1+b_{1} c_{1}^{n_{1}}+b_{2} c_{2}^{n_{2}}+\cdots} .
$$

A more general empirical equation has been required to mathematically describe many multicomponent systems, ${ }^{12}$

$$
q=\frac{a_{i 0} C_{i}^{b_{10}}}{a_{i}+\sum_{j=1}^{m} a_{i j} C_{i j}^{b_{11}}}=f_{1}\left(C_{1}, C_{2}, \cdots C_{m}\right) .
$$

Equation 12 includes some well-known relationships as special cases. For $b_{i 0}=b_{i j}=a_{i}=1$, it becomes the Langmuir equation. The Freundlich equation is obtained when $a_{i}=0$, and the Langmuir-Freundlich equation when $a_{i}=1$. The ternary form of this equation contains the relationship developed by Jager and Erdos, and the binary form of the equation becomes the correlation suggested by Radke and Prausnitz. ${ }^{23}$ This empirical correlation has been successfully used to fit experimental adsorption data for two and three organic solutes. ${ }^{24}$ Unfortunately, it requires multicomponent isotherm data to calculate the model coefficients due to the equation's empirical nature.

The Ideal Adsorbed Solution Theory Model (IAST) is based on the Gibbs adsorption equation and only requires single-solute data to predict multicomponent equilibrium. ${ }^{19}$ When the Freundlich equation is substituted into the IAST model, the following equation is obtained for modeling purposes:

$$
c_{i, k}=\frac{q_{i, k}}{\sum_{j=k}^{m} q_{j, k}}\left(\frac{\sum_{j=k}^{m} \frac{q_{j, k}}{n_{j}}}{\frac{k_{i}}{n_{i}}}\right)^{\frac{1}{n_{i}}} \text { for } i=1 \text { to } \mathrm{m} \text {. }
$$

The model becomes increasingly difficult to use for increasing numbers of solutes. 
The IAST model has been simplified to use average, or lumped, isotherm constants so that it can be applied to complex mixtures of many solutes. However, this simplified competitive adsorption model does not incorporate the mass-balance relationship, has limited applications over broad concentration ranges, and is not always coincident with more rigorous calculations. Users of this model have often resorted to a semi-empirical graphical procedure for ternary mixtures. $^{25,26,27}$

The Dubinin-Polyani potential theory, an early empirical theory for adsorption, has been modified by Bering et al. ${ }^{28}$ to apply to microporous adsorption and void filling for binary mixtures. The multicomponent form of the equation ${ }^{21}$ for gases is

$$
\frac{V_{m}\left(q_{1}+q_{2}+\cdots\right)}{W_{0}}=\exp \left(-k \epsilon^{2}\right)
$$

where

$$
\begin{aligned}
& V_{m}=X_{1} \bar{V}_{1}+X_{2} \bar{V}_{2}+\cdots, \\
& \frac{1}{\sqrt{k}}=\frac{X_{1}}{\sqrt{k_{1}}}+\frac{X_{2}}{\sqrt{k_{2}}}+\cdots, \text { and } \\
& \epsilon=-R T \ln \left(\frac{c_{1}+c_{2}+\cdots}{c_{m}}\right) .
\end{aligned}
$$

Zeolite molecular sieves have several characteristics that are unique compared to activated carbon and ion-exchange resins. They are porous crystalline aluminosilicates with a framework that consists of an assemblage of $\mathrm{SiO}_{4}$ and $\mathrm{AJO}_{4}$ tetrahedra. These tetrahedra are joined together in various regular arrangements through shared oxygen atoms to form an open crystal lattice containing pores of precisely uniform molecular dimensions with no distribution of pore size. The guest molecules must diffuse into the micropores before they can exchange with cations that are attached to the aluminum atoms in the framework of the zeolite. Therefore, zeolites exhibit both molecular-sieve and ion-exchange properties. Because of the ion-sieve effect created by the uniform crystalline structure of zeolites, entering ions cannot always reach all the sites occupied by cations that are initially attached 
to the framework of the zeolite crystals. Therefore, zeolite isotherms can terminate at a point where the degree of exchange is less than $100 \%$.

Published reports of isotherms for zeolites fall into three groups: extension of pure gas isotherm equation, the Dubinin-Polyani potential theory, and thermodynamic methods. ${ }^{29}$ The simple gaseous model isotherms (Langmuir, BET, etc.) have been found to be accurate for some zeolite systems, but they are often not applicable to adsorption of gases in zeolite sorbents. ${ }^{30}$ The Polyani potential theory has been applied to carbon adsorption of organic mixtures from aqueous mixtures and with $c_{\mathrm{m}}{ }^{31}$ and has been found to apply to zeolites in many instances. ${ }^{20}$

The thermodynamic approach has received much attention in recent years, but the rigorous thermodynamic models have not been adequately developed or verified. Because of the structural regularity of zeolite adsorbents and the existence of more or less welldefined, identical cages that may be considered as a set of quasi-independent subsystems, equilibrium behavior in zeolites has been modeled using statistical thermodynamic principles. Ruthven et al. ${ }^{29}$ developed a model isotherm that successfully correlates multicomponent equilibrium data from the Henry's law constants and molecular volumes of the pure components. The theory suggests that when either the molecular volumes of the components are approximately equal or when the total sorbate concentration is less than about one molecule per cavity, the sorbed phase will behave as an approximately ideal mixture of the sorbed species. This model is restricted to nonpolar molecules and sorbent concentrations that are well below saturation. The cavities in the zeolite must also be sufficiently small so that they may be treated as statistically independent subsystems. Such an approach has been applied with some success for light hydrocarbons in $4 \mathrm{~A}, 5 \mathrm{~A}$, and Faujasite zeolites. ${ }^{32}$ This approach has been found to be unsatisfactory for high adsorbate loadings. ${ }^{20}$

Several thermodynamic formulations have been developed to evaluate activity coefficients within the exchanger phase of zeolites. ${ }^{15,33,34}$ However, none of these formulas yield a realistic model for calculating the activity coefficient for the adsorbed phase. ${ }^{35}$ The activity models developed for vapor-liquid equilibrium calculations in equilibrium studies (e.g., Wilson, UNI-QUAC) have been used traditionally, but these models are often not appropriate for adsorption equilibrium. Since a general model does not exist for estimating activity coefficients in adsorption systems, researchers are presently restricted to empirically fitting experimental adsorption data with vapor-liquid equilibrium models. 
Fletcher and Townsend ${ }^{33}$ found that solution-phase activity correction was not necessary for uni-univalent exchange in zeolites, provided the solution ionic strength was $<0.5 \mathrm{~N}$. But for most other cases, the solution-phase activity correction was necessary for accurate work. With ternary exchange (two cations in solution exchanging with a third cation on the zeolite), the correction for non-ideality in the solution phase was very substantial. Loizidou and Townsend $^{36}$ found that non-ideal solution behaviors occurred in the solution-phase at concentrations as low as $0.1 \mathrm{~N}$ for binary exchange of divalent electrolytes and failure to correct for non-ideality in the solution phase lead to errors of $200 \%$ at $0.1 \mathrm{~N}$ and $350 \%$ at $0.5 \mathrm{~N}$ for multivalent exchange in three zeolites.

Most zeolite studies to date have concentrated on gaseous and light hydrocarbon systems, but a few aqueous systems have been studied. Barri and Rees; ${ }^{37}$ Drummond, Jonge, and Rees; ${ }^{38}$ and Franklin and Townsend ${ }^{34}$ studied $\mathrm{Na}-\mathrm{Ca}-\mathrm{Mg}$ exchanges in zeolite $\mathrm{A}$ at various temperatures and solution-phase normalities. The studies were limited to obtaining experimental breakthrough and isotherm plots from which effective thermodynamic parameters were calculated. The first two authors empirically fit isotherm data to obtain equilibrium equations. Franklin and Townsend fit their data using the rigorous thermodynamic model, but their activity coefficients were correlated from experimental data. Although none of these researchers verified their models, their results indicate that multicomponent aqueous isotherms can probably not be modeled by simple equations. Unfortunately, for many mixtures, none of the existing adsorption models are adequate. ${ }^{19}$ In these cases, researchers are presently limited to developing new theoretical models, modifying existing models to account for observed abnormalities, or developing empirical equations based on experimental data.

\section{EXPERIMENTAL TESTS FOR MODEL DEVELOPMENT}

The experimental portion for the development of a mathematical model for zeolite ionexchange columns consists of three phases: (1) equilibrium studies, (2) mass-transfer studies, and (3) ion-exchange column studies. The first phase includes determination of the equilibrium isotherms for single and multicomponent cations in aqueous solutions. In the second phase, the controlling mass-transfer mechanisms are determined for these solutions under various conditions. Finally, experimental breakthrough curves are obtained for various 
sizes of experimental columns for comparison with results from the mathematical model. Only the equilibrium phase of the model development is covered in this report.

\subsection{MATERIALS}

The process waste system at ORNL is used to collect waste that has the potential to be radioactively contaminated and water that is contaminated with very low levels of radioactivity. A typical characterization of the ORNL process waste stream is shown in Tables 1 and 2. Wastewater pH is typically 8.8 , total dissolved solids is $250 \mathrm{mg} / \mathrm{L}$, total suspended solids is $3 \mathrm{mg} / \mathrm{L}$, total hardness is $133 \mathrm{mg} / \mathrm{L}$, alkalinity is $125 \mathrm{mg} / \mathrm{L}$, and total organic carbon (TOC) is $12 \mathrm{mg} / \mathrm{L}$. The major chemical constituents, bicarbonates of calcium, magnesium, and sodium, are introduced by local river water and shallow drainage wells. Discharge limits for radionuclides are established by the U. S. Department of Energy. These limits are presently at $11.1 \mathrm{~Bq} / \mathrm{L}$ for ${ }^{90} \mathrm{Sr}$ and $740 \mathrm{~Bq} / \mathrm{L}$ for ${ }^{137} \mathrm{Cs}$. A proposal has been made to change the limits to 37 and $111 \mathrm{~Bq} / \mathrm{L}$, respectively. The effluent concentrations of the other radionuclides are negligible and are well below discharge requirements.

Zeolites are aluminosilicate minerals that contain alkali and alkaline-earth metals, such as sodium, calcium, and potassium, as well as water, in their structural framework. ${ }^{20,21,39}$ The framework is porous, enclosing interconnected cavities in which the metal cations and water molecules are contained. The fundamental building block of the zeolites is a tetrahedron of four oxygen atoms surrounding a relatively small silicon or aluminum atom. The framework consists of $\mathrm{SiO}_{4}$ and $\mathrm{AJO}_{4}$ tetrahedra arranged so that each oxygen atom is shared between two tetrahedra. Because aluminum has one less positive charge than silicon, the framework has a net negative charge of one at the site of each aluminum atom and is balanced by an exchangeable cation. These zeolite crystals are often formed into pellets using clay binders for industrial use. 
Table 1. Radiochemical composition of ORNL process wastewater

\begin{tabular}{ccc}
\hline Radionuclide & Concentration $(\mathrm{Bq} / \mathrm{L})$ & Concentration, $(N)$ \\
\hline Gross alpha & 5 & - \\
Gross beta & 6000 & - \\
${ }^{60} \mathrm{Co}$ & 25 & $2.0 \times 10^{-14}$ \\
${ }^{90} \mathrm{Sr}$ & 4000 & $1.7 \times 10^{-11}$ \\
${ }^{137} \mathrm{Cs}$ & 400 & $9.1 \times 10^{.13}$ \\
${ }^{106} \mathrm{Ru}$ & 10 & $2.3 \times 10^{.15}$ \\
\hline
\end{tabular}

Table 2. Chemical composition of ORNL process wastewater

\begin{tabular}{|c|c|c|c|c|c|}
\hline \multirow[b]{2}{*}{ Cation } & \multicolumn{2}{|c|}{ Concentration } & \multirow[b]{2}{*}{ Anion } & \multicolumn{2}{|c|}{ Concentration } \\
\hline & $(m g / L)$ & $N$ & & $(\mathrm{mg} / \mathrm{L})$ & $\boldsymbol{N}$ \\
\hline $\mathrm{Ca}^{2+}$ & 40 & $2.0 \times 10^{-3}$ & $\mathrm{HCO}_{3}$ & 93 & $1.5 \times 10^{-3}$ \\
\hline $\mathrm{Mg}^{2+}$ & 8 & $6.6 \times 10^{-4}$ & $\mathrm{SO}_{4}{ }^{2 \cdot}$ & 23 & $4.8 \times 10^{-4}$ \\
\hline $\mathrm{Na}^{+}$ & 5 & $2.2 \times 10^{-4}$ & $\mathrm{Cl}^{\circ}$ & 10 & $2.8 \times 10^{-4}$ \\
\hline $\mathrm{K}^{+}$ & 2 & $5.1 \times 10^{.5}$ & $\mathrm{NO}_{3}{ }^{\circ}$ & 11 & $1.8 \times 10^{-4}$ \\
\hline $\mathrm{Si}^{3+}$ & 2 & $2.1 \times 10^{-4}$ & $\mathrm{CO}_{3}{ }^{2}$ & 7 & $2.3 \times 10^{-4}$ \\
\hline $\mathrm{Sr}^{2+}$ & 0.1 & $2.3 \times 10^{-6}$ & $\mathrm{~F}$ & 1 & $5.3 \times 10^{-5}$ \\
\hline $\mathrm{Al}^{3+}$ & 0.1 & $1.1 \times 10^{-5}$ & & & \\
\hline $\mathrm{Fe}^{2+}$ & 0.1 & $3.6 \times 10^{-6}$ & & & \\
\hline $\mathrm{Zn}^{2+}$ & 0.1 & $3.1 \times 10^{-6}$ & & & \\
\hline
\end{tabular}


The structure of chabazite, shown in Fig. 6, consists of stacked double six-membered ring prisms, interconnected through four rings, in a cubic close packed array. ${ }^{20,21,39}$ Repetition of the stacking of prisms produces cylindrical cavities, $11 \times 6.6 \AA$ joined to adjacent cavities through six eight-membered rings having free diameters of $4.1 \times 3.7 \AA$. The eight-membered rings have free apertures of $4.3 \AA$, and the six-membered ring prisms have diameters of $2.6 \AA$. The cation that neutralizes the negative charge of the zeolite framework is coordinated mainly to water molecules in the eight-membered rings. It is coordinated only to the oxygens of the double six-ring and is not usually active in ion exchange..$^{10}$

Previous treatability studies ${ }^{3}$ have indicated that zeolites can cost effectively decontaminate ORNL process waste to the present or proposed discharge limits. Chabazite zeolites have higher selectivities and loadings for removal of trace amounts of ${ }^{137} \mathrm{Cs}$ and ${ }^{90} \mathrm{Sr}$ from ORNL wastewater than other ion-exchange materials. A natural chabazite, TSM-300, distributed by Tenneco Speciaity Minerals, was determined to have a higher sorption capacity for strontium than any chabazite tested. Natural zeolite samples from different localities, however, have shown considerable differences in their composition and adsorption characteristics. ${ }^{8,20}$ Therefore, a synthetic, commercially available chabazite, manufactured by Union Carbide, which had a slightly lower sorption capacity than the natural chabazite, was used in the present studies to eliminate variability in the sorbent characteristics.

Samples of the zeolite Ionsiv IE-96 (lot 939685090015) were used in this study. Ionsiv IE-96 is shipped in the hydrated sodium form as 20-50 mesh irregularly shaped particles. The average composition of Ionsiv IE-96 is given in Table $3 .^{41}$ The physical properties are given in Table 4.

The physical properties of the zeolite were determined by ORNL Analytical Chemistry Division. The surface area was determined by BET surface area measurements, and pore-size distributions were obtained by mercury porosimetry.

The IE-96 sample was screened to size prior to use-83\% of the material was 30 to 35 mesh (660- to $550-\mu \mathrm{m}$ openings in wire screen). This sieve fraction was used in all tests unless otherwise indicated. Smaller particle sizes were obtained for intracrystalline masstransfer experiments by crushing and screening the pellets. 


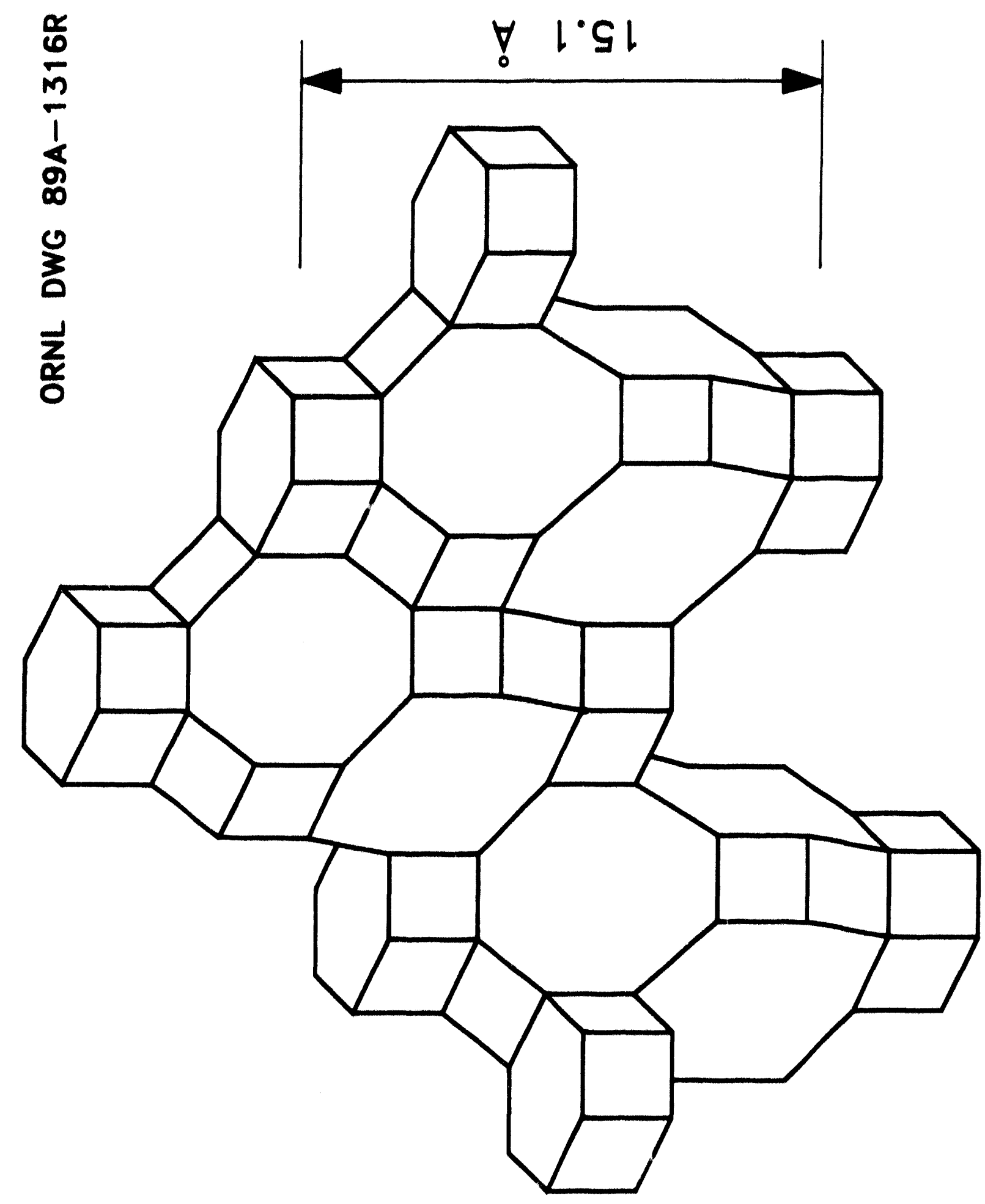

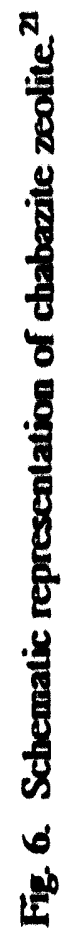


Table 3. Average composition of Ionsiv IE-96 zeolite

\begin{tabular}{cc}
\hline Metal Oxide & Composition (wt \%) \\
\hline $\mathrm{Na}_{2} \mathrm{O}$ & 7.9 \\
$\mathrm{~K}_{2} \mathrm{O}$ & 1.0 \\
$\mathrm{MgO}$ & 0.8 \\
$\mathrm{CaO}$ & 1.2 \\
$\mathrm{BaO}$ & 0.1 \\
$\mathrm{SiO}_{2}$ & 67.4 \\
$\mathrm{AJ}_{2} \mathrm{O}_{3}$ & 17.3 \\
$\mathrm{FeO}^{\mathrm{OOO}}$ & 4.0 \\
$\mathrm{TiO}$ & 0.2 \\
\hline
\end{tabular}

"Anhydrous basis

Table 4. Physical properties of Ionsiv IE-96 zeolite

\begin{tabular}{lc}
\hline \multicolumn{1}{c}{ Property } & Value \\
\hline Bulk density, $\mathrm{g} / \mathrm{cm}^{3}$ & 1.39 \\
Real density, $\mathrm{g} / \mathrm{cm}^{3}$ & 2.05 \\
Porosity, $\%$ & 32.00 \\
Avg. pore diameter, $\mu \mathrm{m}$ & 0.065 \\
Max. pore diameter, $\mu \mathrm{m}$ & 10.00 \\
Surface area, $\mathrm{m}^{2} / \mathrm{g}$ & 306 \\
Moisture content, wt \% & $6.9 \cdot 7.9$ \\
Cation form & $\mathrm{Na}$ \\
\hline
\end{tabular}


The experimental tests in this study were performed using simulated wastewater solutions to avoid variability in feed composition. These simulated wastewaters were made by dissolving various amounts of $\mathrm{SrCl} 2 \bullet 6 \mathrm{H}_{2} \mathrm{O}, \mathrm{CsCl}, \mathrm{CaCl}_{2}$, and $\mathrm{MgCl}_{2} \bullet 6 \mathrm{H}_{2} \mathrm{O}$ in distilled water. The solutions containing strontium and cesium were also spiked with ${ }^{85} \mathrm{Sr}$ and ${ }^{137} \mathrm{Cs}$ tracers, respectively. The aqueous solution chemistry was varied to determine the effects of multicomponent ion exchange in the zeolite. The composition of the simulated wastewaters was held as near to the concentrations listed in Tables 1 and 2 as possible, but was increased to concentrations that could be handled in the laboratory and accurately measured by the analytical equipment when necessary.

Both the number and position of cation sites in zeolites depend rather strongly on temperature and degree of hydration. ${ }^{42}$ The temperature of the solutions was held constant at 24 to $25^{\circ} \mathrm{C}$ in all tests. In order to eliminate the effects of hydration, the zeolite samples were preconditioned with deionized water. Zeolite samples used in all except the earliest tests were washed with about 4 bed volumes of deionized water in a column to remove fines and air dried prior to use. The water content of the preconditioned samples is listed in

\subsection{EXPERIMENTAL METHODS}

\subsubsection{Analytical Methods}

Calcium, sodium, and magnesium concentrations in the aqueous solutions were measured by atomic adsorption (AA). Cesium and strontium concentrations in the aqueous solutions were measured by gamma counting of ${ }^{137} \mathrm{Cs}$ and ${ }^{85} \mathrm{Sr}$ tracers. The strontium results were also periodically checked by $\mathrm{AA}$. The detection limit of the $\mathrm{AA}$ unit is approximately $0.05 \mathrm{mg} / \mathrm{L}$ $\left(2.5 \times 10^{-6} \mathrm{~N}\right)$ for $\mathrm{Ca}, 0.005 \mathrm{mg} / \mathrm{L}\left(4.1 \times 10^{-7} \mathrm{~N}\right)$ for $\mathrm{Mg}, 0.007 \mathrm{mg} / \mathrm{L}\left(3.0 \times 10^{-7} \mathrm{~N}\right)$ for $\mathrm{Na}$, and 0.05 $\mathrm{mg} / \mathrm{L}\left(1.1 \times 10^{-6} \mathrm{~N}\right) \mathrm{Sr}$. Cesium solutions used in these tests contained from $0.1 \mathrm{~N}$ nonradioactive cesium (traced with ${ }^{137} \mathrm{Cs}$ ) to trace levels of ${ }^{137} \mathrm{Cs}$. The detection limits for these solutions, based on counting the ${ }^{137} \mathrm{Cs}$, ranged from about $0.1 \mathrm{mg} / \mathrm{L}\left(7.5 \times 10^{-7} \mathrm{~N}\right)$ to about $1.2 \times 10^{-4} \mathrm{mg} / \mathrm{L}\left(9.2 \times 10^{-10} \mathrm{~N}\right)$. For strontium, the initial concentrations ranged from 0.2 $N$ natural strontium (traced with ${ }^{85} \mathrm{Sr}$ ) to trace levels of ${ }^{85} \mathrm{Sr}$, and the corresponding detection limits ranged from $0.05 \mathrm{mg} / \mathrm{L}\left(1.1 \times 10^{-6} N\right)$ to $3.3 \times 10^{-7} \mathrm{mg} / \mathrm{L}\left(7.6 \times 10^{-12} \mathrm{~N}\right)$. 
The concentration of cations in the zeolite were calculated from mass balances using the initial and final solution concentrations.

\subsubsection{Iun-Exchange Capacity Studies}

The ion-exchange capacity of lonsiv IE-96 was determined using the procedure developed by Tenneco Specialty Minerals, ${ }^{43}$ a vendor of natural zeolites. The zeolite was contacted three times with $20 \mathrm{~mL} / \mathrm{g}$ of $2 \mathrm{~N} \mathrm{NaCl}$ overnight to ensure that it was in the sodium form. The zeolite was then washed three times by mixing with $20 \mathrm{~mL} / \mathrm{g}$ of deionized water for $30 \mathrm{~min}$. The washed zeolite was dried overnight at $110^{\circ} \mathrm{C}$. The zeolite was then contacted with $20 \mathrm{~mL} / \mathrm{g}$ of $0.2 \mathrm{~N}$ exchange solution overnight. The mixture was weighed, centrifuged for $30 \mathrm{~min}$ at 5000 relative centrifugal force ( $\mathrm{rcf}$ ), and the supernate was decanted and analyzed by AA for sodium.

\subsubsection{Equilibrium Studies}

Equilibrium parameters may be obtained by batch reactor or column methods. 44,45 Both methods have advantages and disadvantages. Batch testing is a convenient method of obtaining equilibrium data over a wide range of equilibrium concentrations since either the mass of solids or the initial concentration of solution can be varied. The column method reduces the solids attrition problem often encountered in batch mixing of zeolites. ${ }^{46}$ In addition, Crittenden and Weber ${ }^{47}$ have indicated that the equilibrium dynamics of complicated transport-controlled multicomponent adsorption in fixed beds cannot be adequately predicted from batch tests. In column tests, only the solution concentration can be varied to obtain equilibrium isotherms. The isotherms should be independent of the experimental method if exchange is ideal.

Randtke and Snoeyin ${ }^{48}$ found that few single-solute carbon adsorption systems are ideal, even when they produced linear single-solute Freundlich isotherms. Several researchers have shown that zeolite exchange of cations with different valences is dependent on the solutionphase concentration, with increasing selectivities for the higher valent cations as the total normality of the solution phase decreases. ${ }^{49,50}$ Several references indicate that equilibrium 
will not be ideal if multicomponent feed solutions, multivalent cations, or high solution concentrations are used. ${ }^{36.51,52}$

In nonideal cases, the equilibrium isotherm will depend on the initial adsorbate concentration, and the isotherm must be determined by varying the solids dosage. Large variations in the total solution concentration during multivalent ion exchange can also affect the isotherm.

Because of the many problems described in the literature, three different experimental methods were compared for use in this study: (1) batch tests where the solution concentration was varied and solids dosage held constant, (2) batch tests where the solution concentration was held constant and the solids dosage was varied, and (3) column tests where the amount of solids was held constant and the solution concentration was varied.

Binary $\mathrm{Sr}-\mathrm{Na}$ and $\mathrm{Cs}-\mathrm{Na}$ and ternary $\mathrm{Sr}-\mathrm{Cs}-\mathrm{Na}$ isotherms were obtained by each method. All batch test samples were mixed for $24 \mathrm{~h}$ on a rocking shaker at $25 \mathrm{cycles} / \mathrm{min}$ and centrifuged at $5,000 \mathrm{rcf}$ for $30 \mathrm{~min}$ before being analyzed. The batch tests were performed in triplicate and averaged to obtain the equilibrium concentrations. Column tests were performed by recirculating solution through the system shown in Fig. 7. Typical examples of the solids loading as a function of time are shown in Fig. 8. The solution concentration and solids loading after $5,6,7,8$, and $24 \mathrm{~h}$ were averaged to obtain the equilibrium concentrations. The results are summarized in Table 5 and in Figs. 9-10.

A statistical analysis was performed on the individual experimental data to determine if the experimental method significantly affected the isotherm results. The analysis was performed using the Statistical Analysis System (SAS) computer program developed by SAS Institute, Inc. The SAS program used a regression procedure to evaluate a two way unbalanced analysis of variance using the Scheffe's test for variability. The results indicated that there was no statistical difference between the batch and column methods when the initial solution concentration was varied. There were statistical differences between the batch methods when the solids dosage varied and between the two methods (batch and column) when the solution concentration was varied.

There was not a statistically significant difference between the binary and ternary $\mathrm{Sr}$ and Cs isotherms obtained when the experimental method was not varied. These results indicate that the initial concentration of each cation in the solution phase affects the equilibrium results; however, there was no indication of $\mathrm{Sr}-\mathrm{Cs}$ interaction in threse tests. Since no $\mathrm{Sr}-\mathrm{Cs}$ 
interaction occurred, the differences in total solution concentrations between the binary and ternary systems did not affect the isotherms.

The results from the above statistical analyses indicate that column equilibrium can be accurately predicted from batch data. The results also indicate that the initial solution concentration of each cation significantly affects the equilibrium results. Therefore, the initial concentration of each cation should be held constant for all aqueous chabazite systems (single-solute uni-univalent systems as well as multicomponent multivalent systems).

The results from the column tests were used to determine the length of time required for subsequent equilibrium tests. The zeolite concentration in all column tests reached $>$ $90 \%$ of the equilibrium value in less than $1 \mathrm{~h}$ and at least $99.7 \%$ equilibrium after $5 \mathrm{~h}$. This indicates that the assumption that equilibrium in batch tests will be reached in less than 24 $h$ is a valid one. These results are consistent with equilibrium times for chabazite exchange with alkali metal and alkaline earth metal cations. ${ }^{53}$ Sodium analyses were performed for Runs SR-4 and SR-6 in order to complete the mass balance for the system. Mass balances (based on stoichiometric ion exchange with strontium and cesium removed from the solution phase) accurately predicted the actual sodium concentrations when the concentrations were above $0.001 \mathrm{~N}$. However, solutions that should have contained $1 \times 10^{-9}$ to $2 \times 10^{-4} \mathrm{~N}$ sodium actually contained approximately $5 \times 10^{-4} \mathrm{~N}$. Closer investigation indicated that the Ionsiv IE96 contained excess sodium that was presumably deposited on the surface and/or in the pores during conversion to the sodium form. Approximately $0.956 \mathrm{mg} \mathrm{Na} / \mathrm{g}$ zenlite was removed when a sample of new zeolite was washed with 200 bed volumes of deionized water. When tests were performed with the prewashed zeolite, the actual amount of sodium in the solution phase was accurately predicted from stoichiometric exchange with strontium even at very low concentrations. 
ORNL DWG 89A-1317R

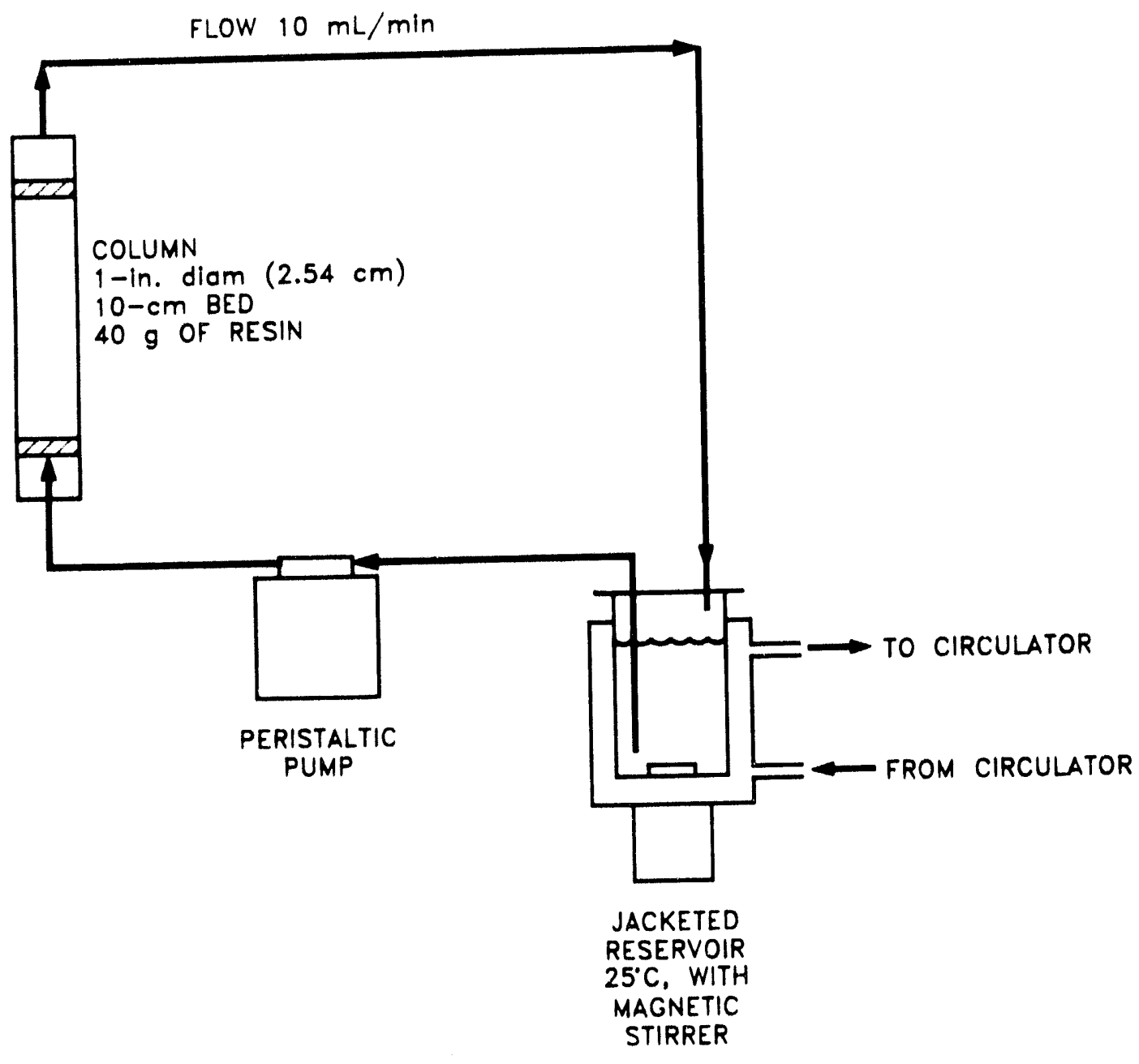

Fig. 7. Schematic of experimental system for column isotherm tests. 
ORNL DWG 91A-321R
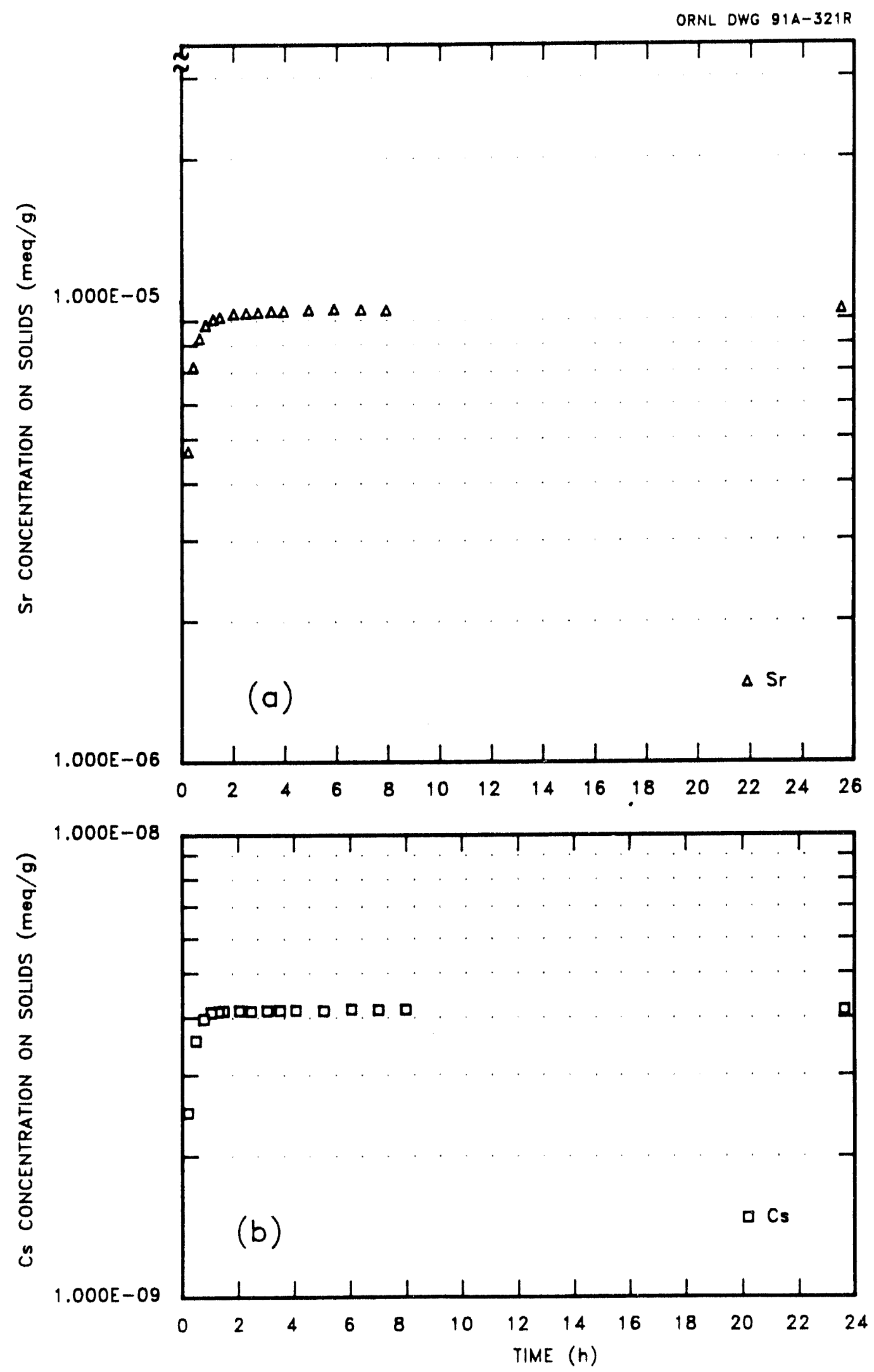

Fig. 8. Experimental data from column isotherm test: (a) $\mathrm{Sr}-\mathrm{Na}$, (b) $\mathrm{Cs}-\mathrm{Na}$. 
Table 5. Experimental conditions for equilibrium method tests

\begin{tabular}{|c|c|c|c|c|c|}
\hline $\begin{array}{c}\text { Run } \\
\text { number }\end{array}$ & $\begin{array}{c}\text { Experimental } \\
\text { method }\end{array}$ & $\begin{array}{l}\text { Exchanging } \\
\text { cations }\end{array}$ & $\begin{array}{l}\text { Amount of solids } \\
\text { (g) }\end{array}$ & $\begin{array}{c}\text { Volume of solution } \\
(\mathrm{mL})\end{array}$ & $\begin{array}{l}\text { Feed composition } \\
\text { (N) }\end{array}$ \\
\hline SR-1 & Batch & Sr-Na & 0.47 & 2.2 to 2.2 & $2.30 \times 10^{6}$ to $0.412 \mathrm{Sr}$ \\
\hline SR-4 & Batch & Cs-Na & 0.47 & 2.0 to 2.1 & $1.00 \times 10^{-9}$ to $0.200 \mathrm{Cs}$ \\
\hline SR-6 & Batch & Sr-Cs-Na & 0.47 & 2.0 to 2.2 & $\begin{array}{l}2.28 \times 10^{-6} \text { to } 0.434 \mathrm{Sr} \text {, } \\
100 \times 10^{9} \text { to } 0.500 \mathrm{Cs}\end{array}$ \\
\hline SR-25 & Batch & Sr-Na & 0.005 to 0.4 & 10.0 & $2.00 \times 10^{-3} \mathrm{Sr}$ \\
\hline SR-27 & Batch & $\mathrm{Cs}-\mathrm{Na}$ & 0.005 to 0.4 & 10.0 & $1.00 \times 10^{3} \mathrm{Cs}$ \\
\hline SR-26 & Batch & Sr-Cs-Na & 0.005 to 0.4 & 10.0 & $2.00 \times 10^{-3} \mathrm{Sr}, 1.00 \times 10^{3} \mathrm{Cs}$ \\
\hline SR-2 & Column & Sr-Na & 40.0 & 166.4 & $2.30 \times 10^{-6}$ to $0.434 \mathrm{Sr}$ \\
\hline SR-3 & Column & $\mathrm{Cs}-\mathrm{Na}$ & 40.0 & 165.6 & $1.00 \times 10^{-9}$ to $0.200 \mathrm{Cs}$ \\
\hline SR-5 & Column & Sr-Cs-Na & 40.0 & 166.5 & $\begin{array}{l}2.28 \times 10^{-6} \text { to } 0.434 \mathrm{Sr}, \\
1.00 \times 10^{-9} \text { to } 0.500 \mathrm{Cs}\end{array}$ \\
\hline
\end{tabular}



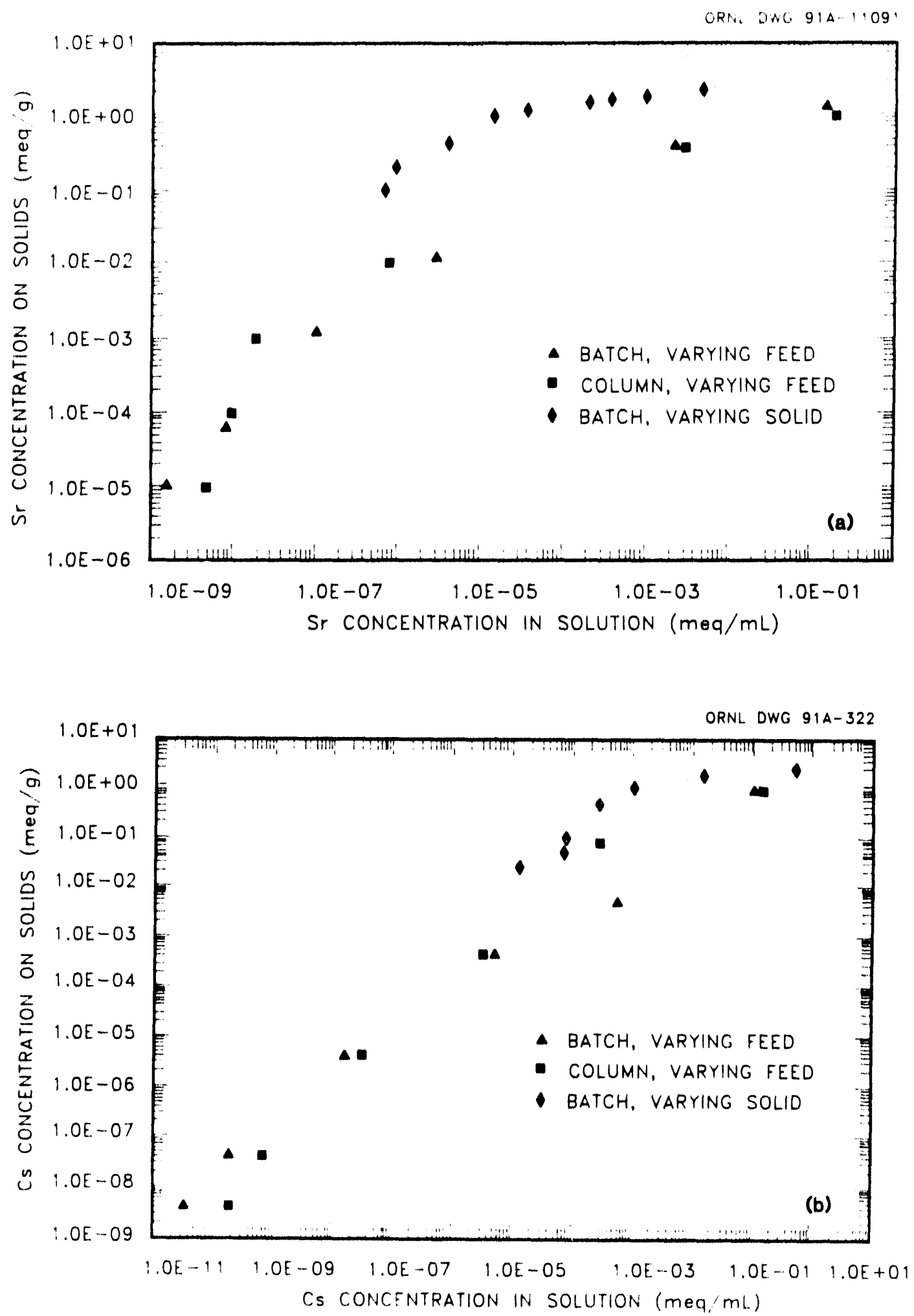

Fig. 9. The effect of experimental method on binary exchange: (a) $\mathrm{Sr}-\mathrm{Na}$ isotherm, (b) Cs-Na isotherm. 

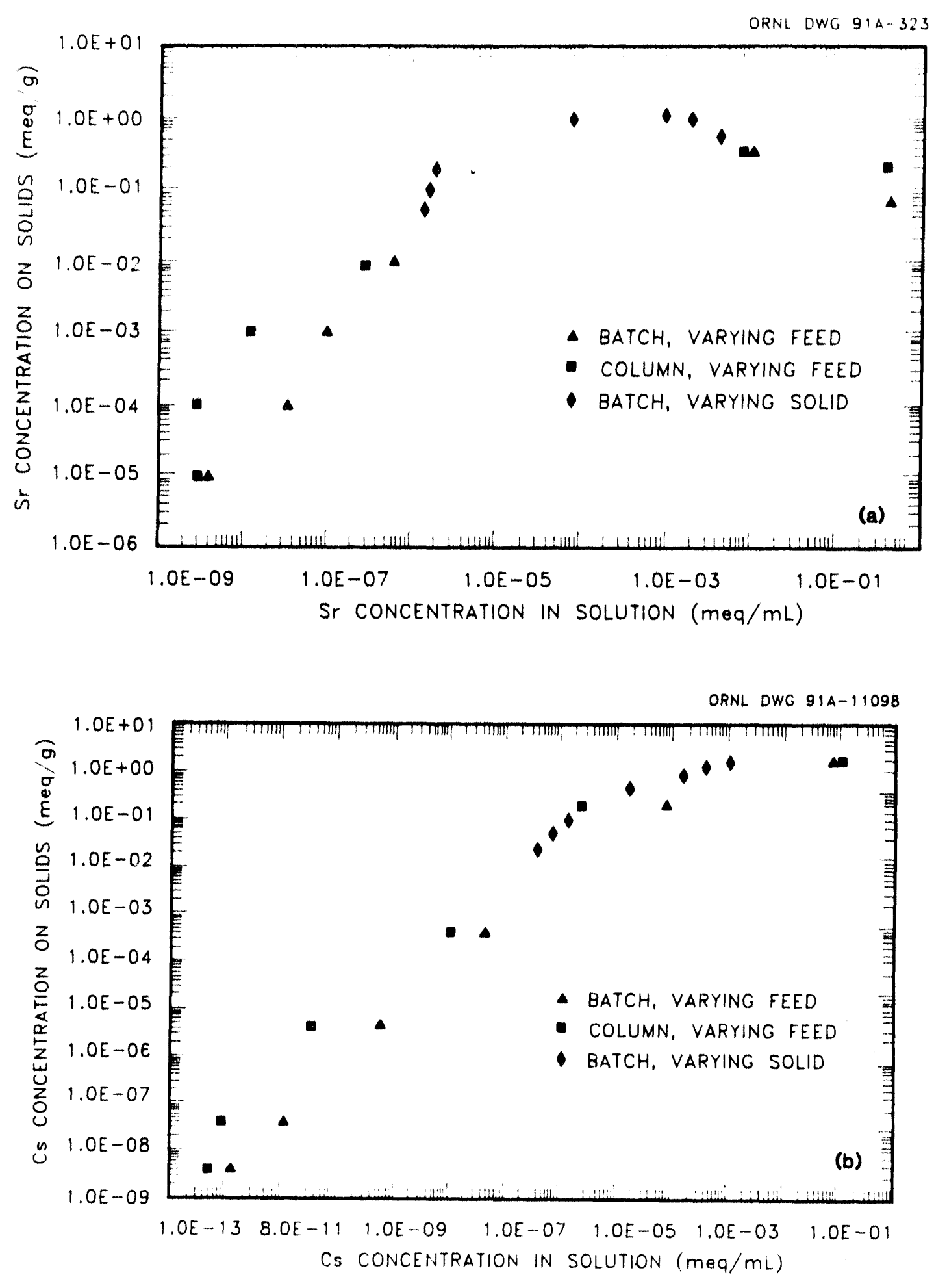

Fig. 10. The effect of experimental method on ternary Sr-Cs-Na ion exchange: (a) Sr isotherm, (b) Cs isotherm. 
phase) accurately predicted the actual sodium concentrations when the concentrations were above $0.001 \mathrm{~N}$. However, solutions that should have contained $1 \times 10^{-9}$ to $2 \times 10^{-4} \mathrm{~N}$ sodium actually contained approximately $5 \times 10^{-4} \mathrm{~N}$. Closer investigation indicated that the Ionsiv IE96 contained excess sodium that was presumably deposited on the surface and/or in the pores during conversion to the sodium form. Approximately $0.956 \mathrm{mg} \mathrm{Na} / \mathrm{g}$ zeolite was removed when a sample of new zeolite was washed with 200 bed volumes of deionized water. When tests were performed with the prewashed zeolite, the actual amount of sodium in the solution phase was accurately predicted from stoichiometric exchange with strontium even at very low concentrations.

A standard experimental method was adopted for all data reported in Sect. 5.3.2. The zeolite was washed with distilled water until the solution contained approximately $2 \mathrm{mg} / \mathrm{L} \mathrm{Na}$ and air dried prior to use. All isotherms were determined at 24 to $25^{\circ} \mathrm{C}$ by varying the weight of zeolite in batch tests between 0.002 and $0.4 \mathrm{~g}$. The volume in the solution phase was held constont at $10 \mathrm{~mL}$. The initial solution phase always was devoid of sodium ions and contained a constant ratio of $\mathrm{Sr}, \mathrm{Cs}, \mathrm{Ca}$, and $\mathrm{Mg}$. The initial concentrations of the exchanging ions in the solution phase were equal to the values listed in Table 6 unless otherwise noted. All samples were mixed for $24 \mathrm{~h}$ on a rocking shaker at 25 cycles/min and centrifuged at 5,000 rcf for $\mathbf{3 0} \mathrm{min}$ before being analyzed. All tests were performed in triplicate, and the total solution-phase concentration was checked for changes during the ion-exchange process.

\subsection{EXPERIMENTAL RESULTS}

\subsubsection{Ion-Exchange Capacity Studies}

The exchange capacity of IE-96 was determined for $\left(\mathrm{NH}_{4}\right)_{2} \mathrm{SO}_{4}, \mathrm{CsCl}, \mathrm{SrCl}_{2}$, and a CsCl$\mathrm{SrCl}_{2}$ mixture. The tests were performed in triplicate, and the averaged results are given in Table 7. They indicate that Ionsiv IE-96 has a cation-exchange capacity of $2.24 \mathrm{meq} / \mathrm{g}$ when the solution phase does not contain cesium and $2.60 \mathrm{meq} / \mathrm{g}$ when cesium is present. 
Table 6. Initial solution-phase concentration for isotherm tests

\begin{tabular}{cc}
\hline Cation & Concentration $(N)$ \\
\hline $\mathrm{Sr}$ & $2.0 \times 10^{-3}$ \\
$\mathrm{Cs}$ & $1.0 \times 10^{-3}$ \\
$\mathrm{Ca}$ & $2.0 \times 10^{-3}$ \\
$\mathrm{Mg}$ & $8.0 \times 10^{-4}$ \\
$\mathrm{Na}$ & 0 \\
\hline
\end{tabular}

Table 7. Cation-exchange capacity of Ionsiv IE-96 zeolite

\begin{tabular}{lcc}
\hline \multicolumn{1}{c}{ Exchange solution } & Capacity (meq/g) & Standard deviation \\
\hline $0.2 \mathrm{~N} \mathrm{CsCl}$ & 2.57 & 0.03 \\
$0.2 \mathrm{~N} \mathrm{SrCl}_{2}$ & 2.24 & 0.02 \\
$0.2 \mathrm{~N}\left(\mathrm{NH}_{4}\right)_{2} \mathrm{SO}_{4}$ & 2.24 & 0.02 \\
$0.1 \mathrm{~N} \mathrm{CsCl}+0.1 \mathrm{~N} \mathrm{SrCl}_{2}$ & 2.62 & 0.02 \\
\hline
\end{tabular}




\subsubsection{Equilibrium Studies}

Equilibrium studies were performed using the batch method described in Sect. 5.2.3 where the solution volume and the initial ratio of cations in the solution phase were held constant. The initial concentrations of the cations were equal to the values listed in Table 6 unless otherwise noted. The amount of solids was varied to obtain the isotherms. The data are summarized in Table 8 and in Figs. 11-15.

The data indicate that Ionsiv IE-96 has the following selectivity for the cations tested: $\mathrm{Cs}>\mathrm{Sr}>\mathrm{Ca}>\mathrm{Mg}$. The binary isotherms shown in Fig. 11 are typical of favorable equilibria systems. The shapes of the isotherms for the cation with the highest selectivity in each multicomponent system (Figs. 12-14) were similar to those of the corresponding binary isotherms. Cation interactions affected the isotherms for the cations with lower selectivities in the multicomponent systems. All cations loaded onto the zeolite when the cation concentration in the multicomponent solutions was low relative to the exchange sites available in the zeolite. However, the cations with lower selectivities were displaced when the solution concentration increased relative to the available exchange sites. This phenomenon was most pronounced for magnesium and resulted in magnesium isotherms with downward concave shapes. Slight displacement of strontium and calcium occurred at the highest loadings tested.

The information in Table 8 indicates that the analytical methods used in these studies were accurate. The sodium concentrations in the solution phase at equilibrium were accurately predicted from stoichiometric ion-exchange equations based on the loss of $\mathrm{Sr}, \mathrm{Cs}$, $\mathrm{Ca}$, and $\mathrm{Mg}$ cations in the solution phase. The measured sodium concentrations were typically within $10 \%$ of the calculated values. The total solution-phase concentrations did not vary significantly during the tests. The solid phase loadings were always less than the maximum ion-exchange capacities of the zeolite obtained in Sect. 5.3.1.

Ternary noninteracting Sr-Cs-Na equilibrium data obtained in Sect. 5.2.3 indicated that the concentration of each individual cation in the solution phase affected equilibrium more than the total cation concentration. Based on this information, the isotherms in Figs. 11-14 (Runs SR-17 through SR-27 in Table 8) were obtained using feed solutions containing the individual cation concentrations listed in Table 6. The total cation concentration in the solution phase for these systems varied between $8.2 \times 10^{-4}$ and $5.8 \times 10^{.3} \mathrm{~N}$, and the corresponding maximum solids loadings varied between 37 and $96 \%$. 
Table 8. Summary of equitibriun data

\begin{tabular}{|c|c|c|c|c|c|c|c|c|}
\hline \multirow[b]{2}{*}{ Run } & \multirow{2}{*}{$\begin{array}{c}\text { Exchanging } \\
\text { cations }\end{array}$} & \multirow{2}{*}{$\begin{array}{l}\text { Liquids to solids } \\
\text { ratio (mL/g) }\end{array}$} & \multicolumn{2}{|c|}{$\begin{array}{c}\text { Total solution } \\
\text { concentration }(N)\end{array}$} & \multicolumn{2}{|c|}{$\begin{array}{l}\text { Na concentration in } \\
\text { solution phase, }(N)\end{array}$} & \multicolumn{2}{|c|}{ Solids loading } \\
\hline & & & Initiar" & Finat & Actual & Calculated & (meq/g) & $(\%)^{c}$ \\
\hline \multirow[t]{8}{*}{ SR-25 } & Sr-Na & 1953 & $200 \times 10^{-3}$ & $200 \times 10^{-3}$ & $9.88 \times 10^{-4}$ & $8.99 \times 10^{4}$ & 1.76 & 79 \\
\hline & & 993 & $200 \times 10^{-3}$ & $.13 \times 10^{-3}$ & $1.76 \times 10^{3}$ & $.64 \times 10^{3}$ & 1.63 & 73 \\
\hline & & 846 & $200 \times 10^{-3}$ & - & $-d$ & - & 151 & 68 \\
\hline & & 612 & $200 \times 10^{-3}$ & - & - & - & .20 & 54 \\
\hline & & 504 & $200 \times 10^{-3}$ & $.24 \times 10^{3}$ & $2.23 \times 10^{-3}$ & $.98 \times 10^{3}$ & 1.00 & 45 \\
\hline & & 216 & $2.00 \times 10^{-3}$ & - & - & - & .43 & 20 \\
\hline & & 99 & $200 \times 10^{3}$ & $28 \times 10^{-3}$ & $2.28 \times 10^{3}$ & $.00 \times 10^{3}$ & 0.20 & 9 \\
\hline & & 50 & $200 \times 10^{3}$ & $.35 \times 10^{-3}$ & $2.35 \times 10^{6}$ & $200 \times 10^{-3}$ & .10 & 4 \\
\hline \multirow[t]{6}{*}{ SR-27 } & $\mathrm{C}_{5}-\mathrm{Na}$ & 1925 & $1.00 \times 10^{-3}$ & $.52 \times 10^{3}$ & $8.77 \times 10^{-4}$ & $8.58 \times 10^{4}$ & 1.66 & 64 \\
\hline & & 1014 & $1.00 \times 10^{-3}$ & $.03 \times 10^{-3}$ & $1.02 \times 10^{-3}$ & $.91 \times 10^{4}$ & 1.00 & 39 \\
\hline & & 500 & $1.00 \times 10^{-3}$ & $.03 \times 10^{3}$ & $1.03 \times 10^{-3}$ & $.00 \times 10^{-3}$ & e.5o & 19 \\
\hline & & 99 & $1.00 \times 10^{-3}$ & $.10 \times 10^{-3}$ & $1.10 \times 10^{3}$ & $.00 \times 10^{3}$ & 0.10 & 4 \\
\hline & & 50 & $1.00 \times 10^{-3}$ & $.12 \times 10^{-3}$ & $1.12 \times 10^{-3}$ & $.00 \times 10^{3}$ & 0.05 & 2 \\
\hline & & 25 & $1.00 \times 10^{-3}$ & $29 \times 10^{-3}$ & $1.29 \times 10^{-3}$ & $.00 \times 10^{-3}$ & 0.03 & 1 \\
\hline \multirow[t]{5}{*}{ SR-17 } & $\mathrm{Ca}-\mathrm{Na}$ & 3498 & $1.93 \times 10^{-3}$ & - & - & - & .69 & 75 \\
\hline & & 1318 & $1.93 \times 10^{-3}$ & - & - & - & .42 & 63 \\
\hline & & 901 & $210 \times 10^{3}$ & - & - & - & .46 & 65 \\
\hline & & 667 & $1.93 \times 10^{-3}$ & - & - & - & .24 & 56 \\
\hline & & 478 & $2.10 \times 10^{-3}$ & - & - & - & .00 & 45 \\
\hline \multirow[t]{5}{*}{ SR-18 } & $\mathrm{Mg}-\mathrm{Na}$ & 2484 & $8.18 \times 10^{-4}$ & - & - & - & 0.82 & 37 \\
\hline & & 2206 & $8.40 \times 10^{-4}$ & - & - & - & 1.06 & 47 \\
\hline & & 1274 & $8.18 \times 10^{-4}$ & - & - & - & 0.71 & 31 \\
\hline & & 1012 & $8.40 \times 10^{-4}$ & - & - & - & 0.78 & 34 \\
\hline & & 508 & $8.40 \times 10^{-4}$ & - & - & - & .43 & \\
\hline
\end{tabular}


Table 8 (contineod)

\begin{tabular}{|c|c|c|c|c|c|c|c|c|}
\hline \multirow[b]{2}{*}{ Run } & \multirow{2}{*}{$\begin{array}{c}\text { Exchanging } \\
\text { cations }\end{array}$} & \multirow{2}{*}{$\begin{array}{l}\text { Liquids to solids } \\
\text { ratio (mL/g) }\end{array}$} & \multicolumn{2}{|c|}{$\begin{array}{c}\text { Total solution } \\
\text { concentration }(M)\end{array}$} & \multicolumn{2}{|c|}{$\begin{array}{l}\text { Na concentration in } \\
\text { solution phase, }(N)\end{array}$} & \multicolumn{2}{|c|}{ Solids loading } \\
\hline & & & Initiat & Finat & Actual & Calculated & (meq/g) & $(\%)^{c}$ \\
\hline \multirow[t]{7}{*}{ SR-26 } & $\mathrm{Sr}-\mathrm{Cs}-\mathrm{Na}$ & 2015 & $3.00 \times 10^{-3}$ & $.07 \times 10^{3}$ & $1.14 \times 10^{3}$ & $.07 \times 10^{-3}$ & 217 & 83 \\
\hline & & 1007 & $3.00 \times 10^{3}$ & $.14 \times 10^{-3}$ & $202 \times 10^{3}$ & $.88 \times 10^{3}$ & 1.89 & 73 \\
\hline & & 497 & $3.00 \times 10^{-3}$ & $21 \times 10^{3}$ & $3.11 \times 10^{3}$ & $.91 \times 10^{-3}$ & 1.45 & 56 \\
\hline & & 99 & $3.00 \times 10^{-3}$ & $39 \times 10^{-3}$ & $3.38 \times 10^{3}$ & $.00 \times 10^{3}$ & 0.30 & 11 \\
\hline & & 50 & $3.00 \times 10^{-3}$ & $.42 \times 10^{-3}$ & $3.24 \times 10^{-3}$ & $.00 \times 10^{3}$ & 0.15 & 6 \\
\hline & & 25 & $3.00 \times 10^{-3}$ & $.44 \times 10^{3}$ & $3.44 \times 10^{3}$ & $.00 \times 10^{3}$ & 0.08 & 1 \\
\hline & & 50 & $200 \times 10^{-3}$ & $35 \times 10^{3}$ & $235 \times 10^{6}$ & $200 \times 10^{3}$ & 0.10 & 4 \\
\hline \multirow[t]{4}{*}{ SR-19 } & $\mathrm{Ca}-\mathrm{Mg}-\mathrm{Na}$ & 1940 & $2.80 \times 10^{3}$ & - & - & - & .75 & 79 \\
\hline & & 950 & $280 \times 10^{-3}$ & - & - & - & 58 & 71 \\
\hline & & 503 & $280 \times 10^{-3}$ & - & - & - & 27 & 57 \\
\hline & & 50 & $280 \times 10^{-3}$ & - & - & - & .14 & 6 \\
\hline \multirow[t]{6}{*}{ SR-21 } & $\mathrm{Sr}-\mathrm{Ca}-\mathrm{Mg}-\mathrm{Na}$ & 1790 & $4.67 \times 10^{-3}$ & $.63 \times 10^{3}$ & $57 \times 10^{-4}$ & $9.94 \times 10^{4}$ & .79 & 80 \\
\hline & & 1058 & $4.67 \times 10^{-3}$ & $.71 \times 10^{-3}$ & $.75 \times 10^{-3}$ & $1.71 \times 10^{-3}$ & .85 & 82 \\
\hline & & 495 & $4.67 \times 10^{-3}$ & $55 \times 10^{-3}$ & $.06 \times 10^{3}$ & $3.18 \times 10^{3}$ & 58 & 70 \\
\hline & & 98 & $4.67 \times 10^{-3}$ & $.09 \times 10^{3}$ & $.07 \times 10^{3}$ & $4.65 \times 10^{-3}$ & .46 & 20 \\
\hline & & 50 & $4.67 \times 10^{-3}$ & $.99 \times 10^{-3}$ & $.99 \times 10^{-3}$ & $4.66 \times 10^{-3}$ & .23 & 7 \\
\hline & & 25 & $4.67 \times 10^{-3}$ & $.25 \times 10^{-3}$ & $24 \times 10^{3}$ & $4.66 \times 10^{-3}$ & .12 & 3 \\
\hline \multirow[t]{6}{*}{ SR-22 } & $\mathrm{Cs}-\mathrm{Ca}-\mathrm{Mg}-\mathrm{Na}$ & 1960 & $3.70 \times 10^{-3}$ & $.70 \times 10^{-3}$ & $.02 \times 10^{3}$ & $1.03 \times 10^{3}$ & .02 & 78 \\
\hline & & 992 & $3.70 \times 10^{-3}$ & $58 \times 10^{-3}$ & $.85 \times 10^{3}$ & $1.97 \times 10^{-3}$ & .96 & 75 \\
\hline & & 502 & $3.70 \times 10^{-3}$ & $.43 \times 10^{3}$ & $.91 \times 10^{3}$ & $3.18 \times 10^{-3}$ & .60 & 61 \\
\hline & & 100 & $3.70 \times 10^{-3}$ & $22 \times 10^{-3}$ & $21 \times 10^{3}$ & $3.69 \times 10^{3}$ & 37 & 14 \\
\hline & & 49 & $3.70 \times 10^{-3}$ & $.22 \times 10^{3}$ & $21 \times 10^{-3}$ & $3.69 \times 10^{3}$ & .18 & 4 \\
\hline & & 25 & $3.70 \times 10^{-3}$ & $.65 \times 10^{-3}$ & $.65 \times 10^{-3}$ & $3.69 \times 10^{3}$ & .09 & 2 \\
\hline
\end{tabular}


Table 8 (continued)

\begin{tabular}{|c|c|c|c|c|c|c|c|c|}
\hline \multirow[b]{2}{*}{ Run } & \multirow{2}{*}{$\begin{array}{l}\text { Exchanging } \\
\text { caticns }\end{array}$} & \multirow{2}{*}{$\begin{array}{l}\text { Liquids to Solids } \\
\text { ratio (mL/g) }\end{array}$} & \multicolumn{2}{|c|}{$\begin{array}{c}\text { Total Solution } \\
\text { Concentration ( })\end{array}$} & \multicolumn{2}{|c|}{$\begin{array}{l}\text { Na concentration in } \\
\text { solution phase ( } M \text { ) }\end{array}$} & \multicolumn{2}{|c|}{ Solids loading } \\
\hline & & & Initiar & Finat & Actual & $\overline{\text { Calculated }}$ & (meq'g) & $(\%)^{c}$ \\
\hline \multirow[t]{6}{*}{ SR-23 } & $\mathrm{Sr}-\mathrm{Cs}-\mathrm{Ca}-\mathrm{Mg}-\mathrm{Na}$ & 1955 & $5.76 \times 10^{-3}$ & $89 \times 10^{-3}$ & $1.36 \times 10^{-3}$ & $27 \times 10^{-3}$ & 249 & 96 \\
\hline & & 1012 & $5.76 \times 10^{3}$ & $.73 \times 10^{-3}$ & $1.96 \times 10^{3}$ & $.03 \times 10^{-3}$ & 205 & 79 \\
\hline & & 504 & $5.76 \times 10^{-3}$ & $.74 \times 10^{-3}$ & $3.71 \times 10^{-3}$ & $.76 \times 10^{3}$ & 1.89 & 73 \\
\hline & & 99 & $5.76 \times 10^{-3}$ & $.49 \times 10^{-3}$ & $5.46 \times 10^{3}$ & $.73 \times 10^{3}$ & 0.57 & 22 \\
\hline & & 50 & $5.76 \times 10^{-3}$ & $53 \times 10^{-3}$ & $5.52 \times 10^{-3}$ & $.75 \times 10^{3}$ & 0.29 & 8 \\
\hline & & 25 & $5.76 \times 10^{-3}$ & $.47 \times 10^{-3}$ & $5.46 \times 10^{-3}$ & $.75 \times 10^{3}$ & 0.14 & 4 \\
\hline \multirow[t]{6}{*}{ SR-33 } & $\mathrm{Sr}-\mathrm{Na}^{e}$ & 2059 & $5.78 \times 10^{-3}$ & - & - & - & 30 & 89 \\
\hline & Cs- $\mathrm{Na}^{e}$ & 2078 & $5.78 \times 10^{-3}$ & - & - & - & .16 & 96 \\
\hline & $\mathrm{Ca}-\mathrm{Na}^{\mathrm{e}}$ & 1941 & $5.78 \times 10^{-3}$ & - & - & - & .05 & 91 \\
\hline & $\mathbf{M g}-\mathrm{Na}^{\mathrm{e}}$ & 1968 & $5.78 \times 10^{-3}$ & - & - & - & .85 & 38 \\
\hline & $\mathrm{Sr}-\mathrm{Cs}-\mathrm{Na}^{\mathrm{e}}$ & 2004 & $5.78 \times 10^{3}$ & - & - & - & .08 & 80 \\
\hline & $\mathrm{Ca}-\mathrm{Mg}_{\mathrm{g}} \mathrm{Na}^{\mathrm{e}}$ & 2072 & $5.78 \times 10^{-3}$ & - & - & - & .03 & 91 \\
\hline \multirow[t]{7}{*}{ SR-34 } & $\mathrm{Sr}-\mathrm{Cs}-\mathrm{Ca}-\mathrm{Mg}_{\mathrm{g}}-\mathrm{Na}^{e}$ & 2367 & $1.45 \times 10^{-3}$ & - & - & - & .95 & 75 \\
\hline & & 1241 & $1.45 \times 10^{-3}$ & - & - & - & .64 & 63 \\
\hline & & 830 & $1.45 \times 10^{-3}$ & - & - & - & .19 & 46 \\
\hline & & 506 & $1.45 \times 10^{3}$ & - & - & - & .73 & 28 \\
\hline & & 201 & $1.45 \times 10^{3}$ & - & - & - & 29 & 11 \\
\hline & & 100 & $1.45 \times 10^{-3}$ & - & - & - & .14 & 6 \\
\hline & & 50 & $1.45 \times 10^{-5}$ & - & - & - & .07 & 3 \\
\hline
\end{tabular}

Total cation concentration in feed.

botal cation concentration in solution phase at equilibrium

cPercentage of maximum capacity listed in Table 7.

dSodium concentration not measured.

'Cation concentrations varied from values in Table 6. Ratio of cation concentrations held constant. 


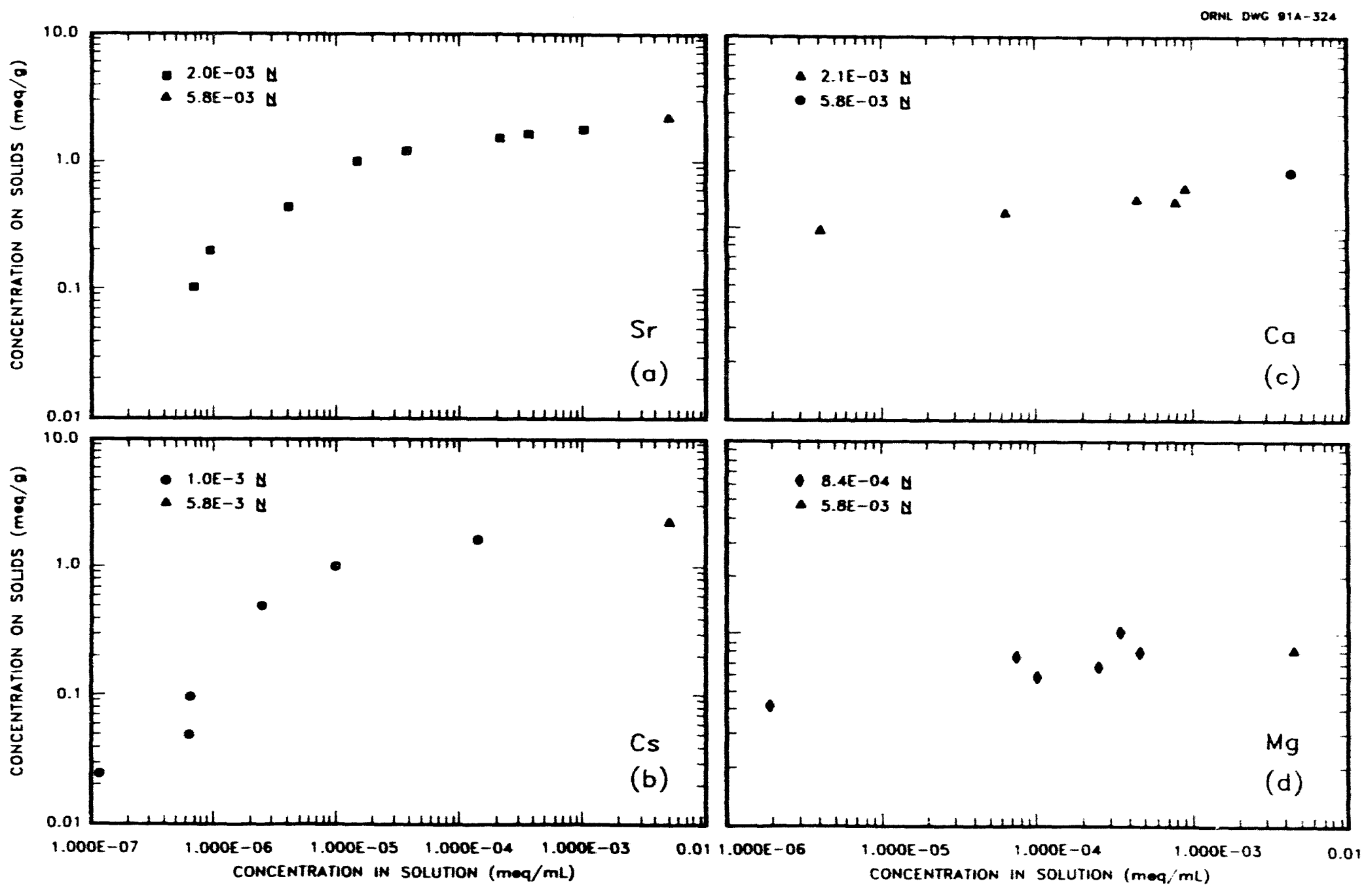

Fig. 11. Isotherms for binary eschange: (a) $\mathrm{Sr}-\mathrm{Na}$, (b) $\mathrm{Cs}-\mathrm{Na}$, (c) $\mathrm{Ca}-\mathrm{Na}$; (d) $\mathrm{Mg}-\mathrm{Na}$ 

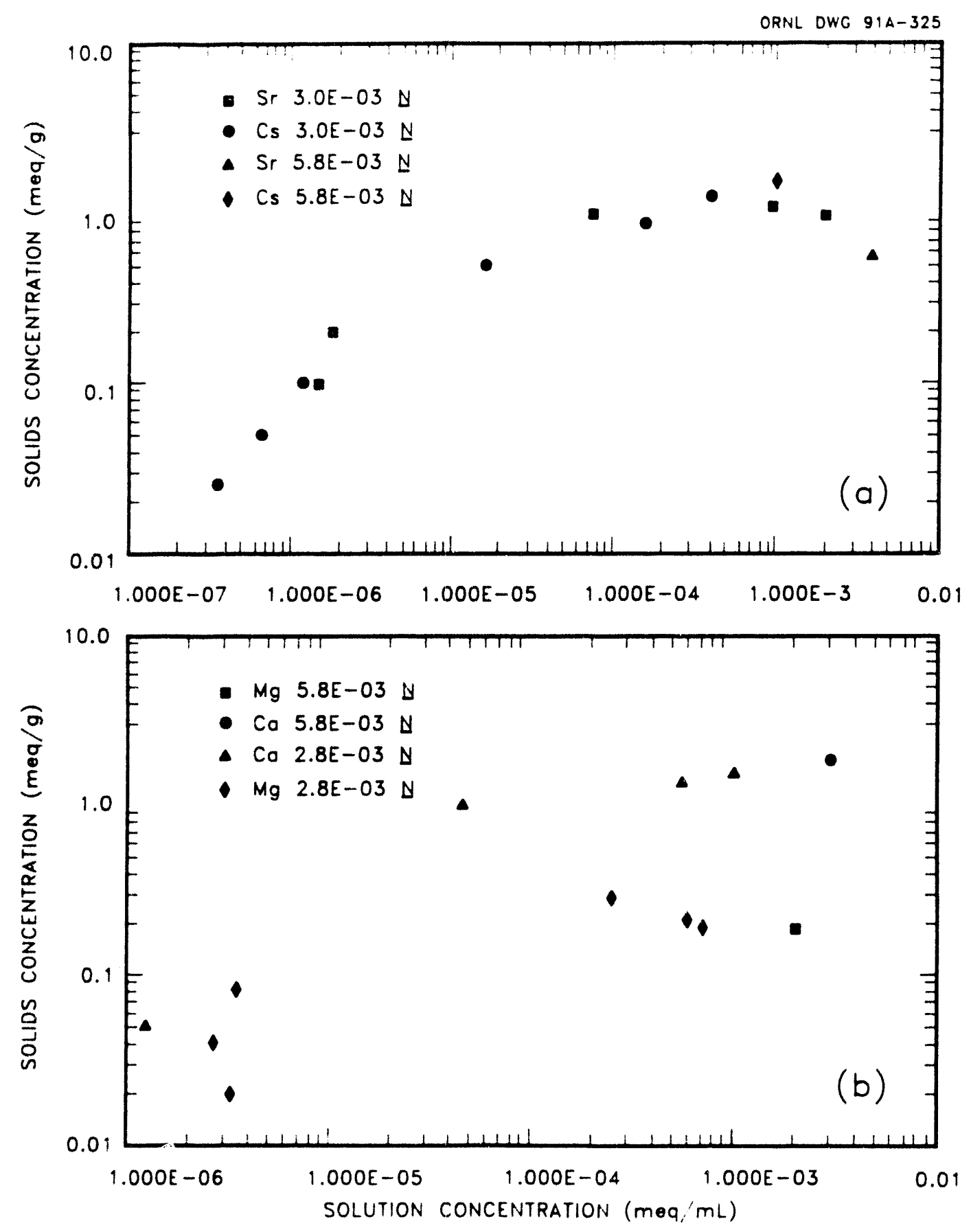

Fig. 12 Isotherms for three component ion exchange: (a) Sr-Cs-Na, (b) Ca-Mg-Na. 


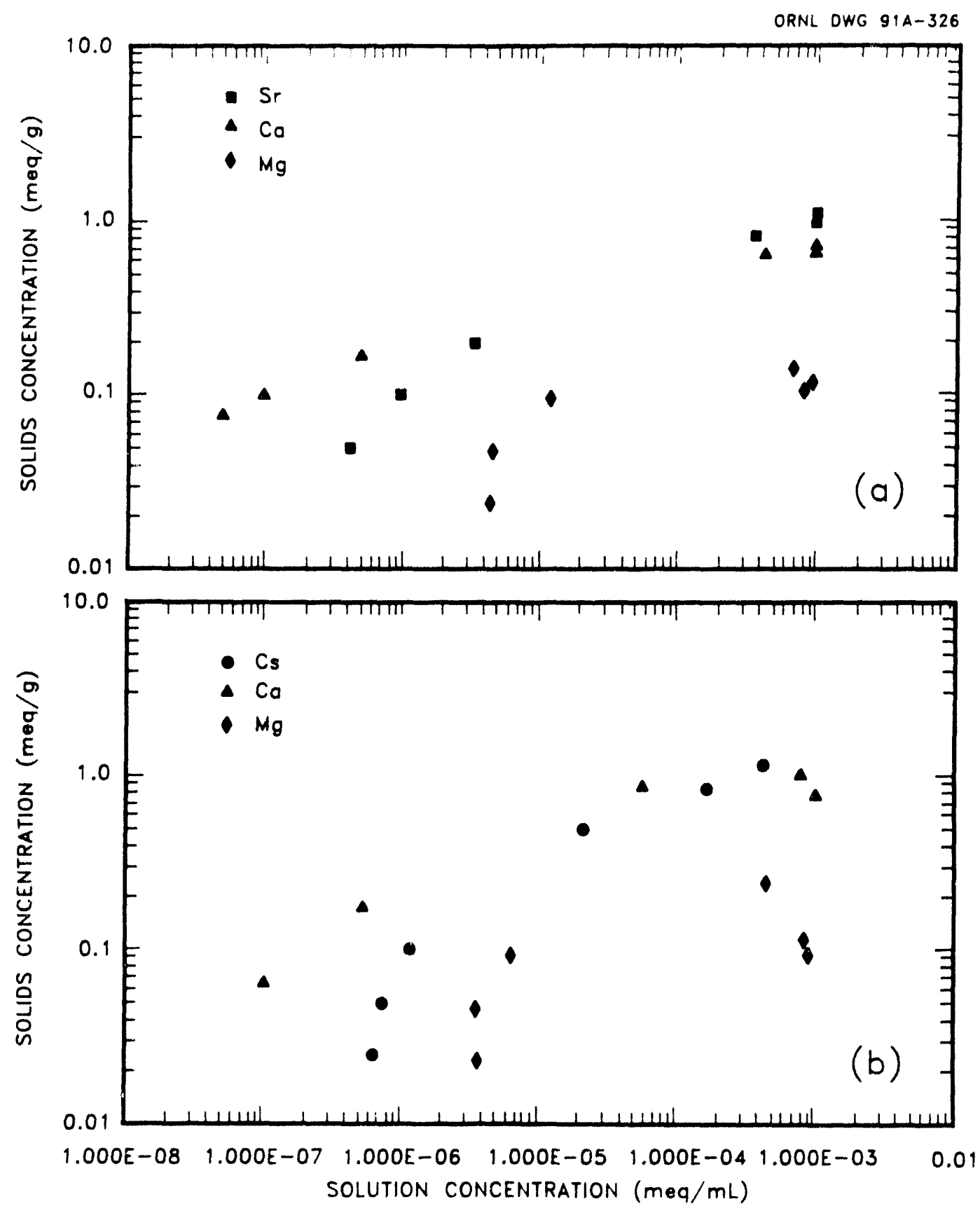

Fig. 13. Isotherms for four component ion exchange: (a) Sr-Ca-Mg-Na, (b) Cs-Ca-Mg-Na. 
ORNL DWG 91A-327

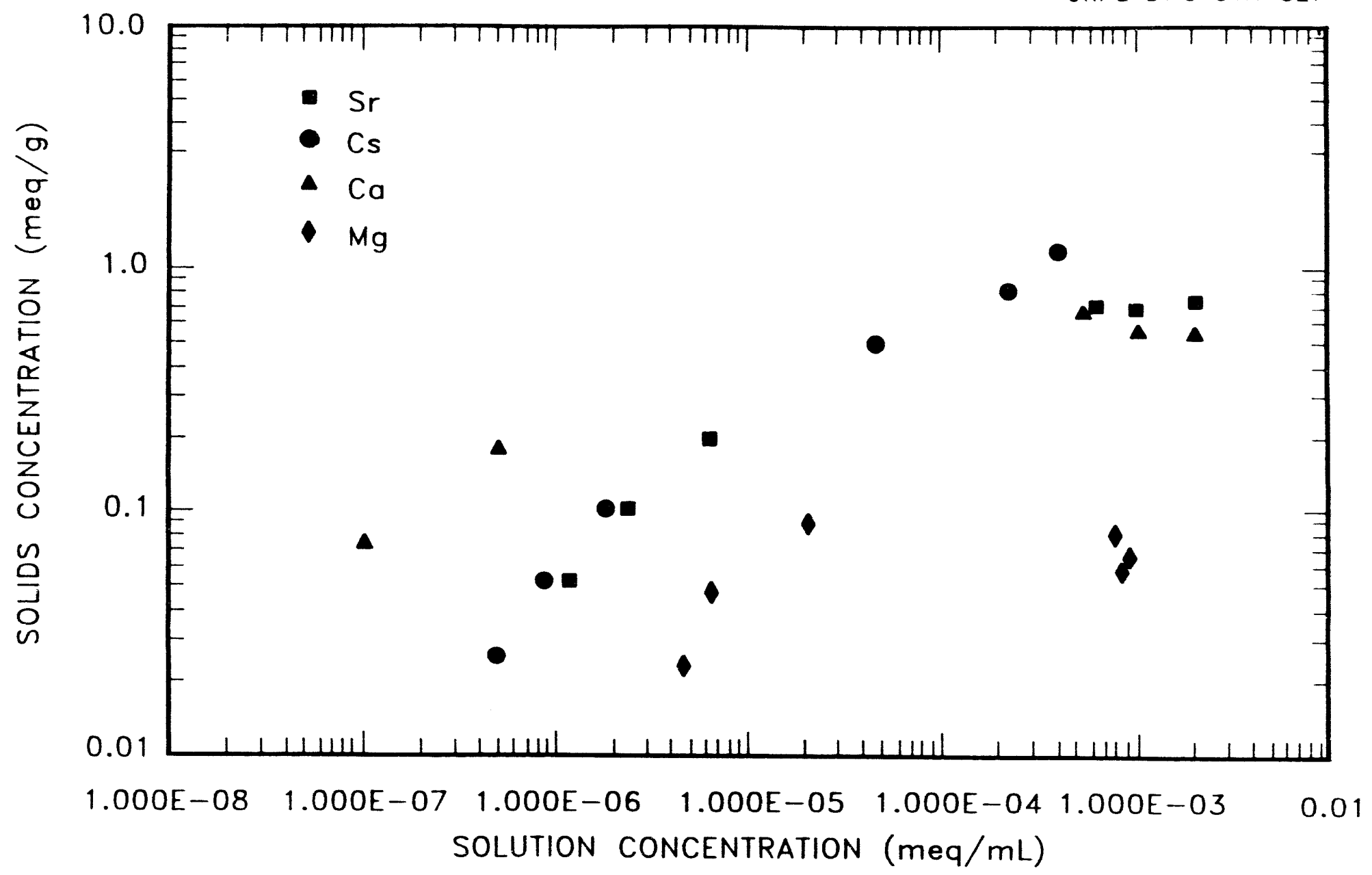

Fig. 14. Isotherm for $\mathrm{Sr}-\mathrm{Cs}-\mathrm{Ca}-\mathrm{Mg}-\mathrm{Na}$ ion exchange. 

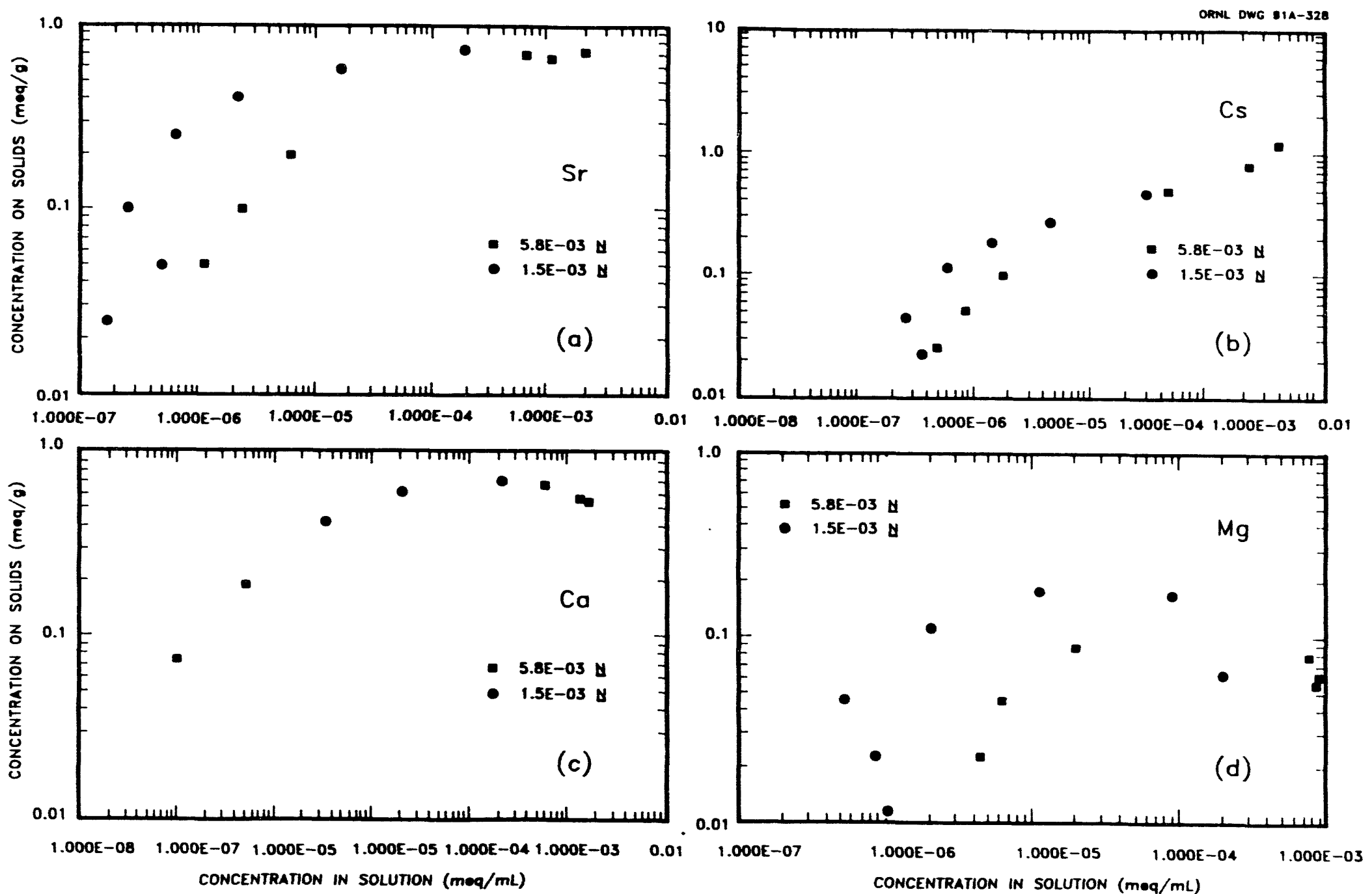

Fig. 15. Effect of total solution concentration $\mathrm{Sr}-\mathrm{Cs}-\mathrm{Ca}-\mathrm{Mg}-\mathrm{Na}$ ion exchange: (a) $\mathrm{Sr}$ isotherm, (b) Cs isotherm, (c) Ca isotherm, (d) Mg isotherm. 
Since significant cation interactions were noted in the systems containing calcium and magnesium ions, additional tests were performed to qualify the validity of the experimental method selected in Sect. 5.2.3. The standard procedure described in Sect. 5.2.3 was followed, but the cation concentrations listed in Table 6 were not used. The ratio of individual cations was held constant, but the total solution concentration was varied as described below. The total solution concentration was increased to $5.7 \times 10^{-3} \mathrm{~N}$ for several binary and multicomponent isotherm points in Run SR-33. Run SR-23 was repeated in Run SR-34, but the total solution concentration was reduced from $5.7 \times 10^{-3}$ to $1.5 \times 10^{-3} \mathrm{~N}$.

The data from Run SR-23 and SR-34 are compared in Fig. 15. The isotherms follow the concentration valence theory which states that the exchange material will have a higher selectivity for higher valence cations when the total normality of the solution phase decreases. This resulted in statistically different isotherms for strontium, cesium, and magnesium. The strontium, cesium, and calcium isotherms for the two total solution concentrations converged at the upper end of the graphs where the solution- and solids-phase concentrations are highest, while the magnesium isotherm shifted slightly to the left. This also occurred for Run SR-33 where the total solution concentration for several isotherm points was increased from $1.0 \times 10^{-3}$ and $3.0 \times 10^{-3}$ to $5.7 \times 10^{-3}$. The equilibrium points from Run SR-33 fell on the upper portion of the isotherm curves for data from Runs SR-17 to SR-27 (see Figs. 11-12).

These results indicate that isotherms for multicomponent ion-exchange systems will be affected by the total cation concentration in the solution phase as well as the ratios of the individual cations. These effects will be most pronounced on the low end of the isotherms, but the upper end of the isotherms for each cation will tend to converge. Since the PWTP ion-exchange columns will be used for applications that only involve the upper portion of the isotherms, the data shown in Figs. 11-14 should be appropriate for use in design models. Therefore, the data from Runs SR-17 through SR-33 were used in the remaining sections of this report. The data from SR-34 was not used in any additional analyses. 


\subsection{EVALUATION OF DATA}

\subsubsection{Ion-Exchange Capacity Studies}

Variations in exchange capacity, such as those given in Table 7, are not uncommon for zeolites. The literature is filled with possible explanations to account for variations in isotherms and maximum loading capacities. They include inaccurate analyses, not reaching true equilibrium, hydrolysis, precipitation in the zeolite pores, ${ }^{36,54}$ ion-sieve effects, and other ion-exchange properties unique to zeolites.

Hydronium exchange (or hydrolysis) and associated de-alumination of the zeolite framework has been used to explain unusual equilibrium and loading results in $\mathrm{X}$ and $\mathrm{Y}$ zeolites. ${ }^{33,55,56}$ The framework charge of the sodium forms of these zeolites were partly balanced by hydronium ions in these studies. Hydronium and sodium were both removed from the solid phase during ion exchange.

De-alumination, hydronium ion exchange, and precipitation in zeolite pores would result in apparent non-stoichiometry of exchange. Since all data in Table 8 indicate that ion exchange in the chabazite system is stoichiometric, these are not likely to have caused the increased loading capacity when cesium was present. Analyses by two different methods indicate the analytical procedures in this study were accurate. Results from Sect. 5.3.2 also indicate that equilibrium had been reached. Therefore, the loading capacity changes are probably due to unique properties associated with zeolite ion exchange.

Exchange in zeolites may be affected by steric problems, unfavorable local charge distributions, and energetically unfavorable endothermal displacement of water by the cation from the zeolite into the aqueous phase. ${ }^{57}$ The latter two reasons should reduce the exchange capacity for large ions and cannot account for the effects observed in this study.

There are three types of steric effects: (1) ions can be locked into certain small cavities during preparation cannot be exchanged at room temperature, (2) the ion-sieve effect may not allow large cations to invade certain cavities in the zeolite structure, and (3) the intracrystalline pore space may not be sufficient to contain the number of large ions that would be needed to fully neutralize the anionic framework charge. ${ }^{57}$ The first of these steric effects would not affect exchange capacity at a constant temperature, and the latter two effects would negatively impact exchange for large ions, such as cesium. 
Barrer and Klinowski ${ }^{57}$ indicated that electrostatic and hydration effects can also impact ion exchange. Hydration effects will be looked at in more detail below.

The $\mathrm{Ca}, \mathrm{Cs}, \mathrm{Mg}, \mathrm{Na}$, and $\mathrm{Sr}$ have diameters of $1.98,3.38,1.30,1.90$, and $2.26 \AA$, respectively. ${ }^{58}$ Since the eight-membered rings of chabazites have free operation of $4.3 \AA$, all of the ions should be able to enter the zeolite cavities and eight-membered rings in their dehydrated forms. Since the six-membered rings have diameters of $2.6 \AA$, only Cs should not be able to enter thesc smaller rings because of steric effects.

To pass through the eight-membered rings, the ions must shed some of their waters of hydration. Two forces determine whether an ion will become dehydrated and enter a site on the zeolite: (1) the negative pole of attraction in the zeolite framework pulls the cation towards the site; and (2) the hydration energy inhibits water stripping from the cation and, hence, its migration to the site. The hydration energy increases with ionic potential (charge/radius) of the cation and the attractive force increases with the charge density of the framework of the zeolite. ${ }^{40}$ Since cesium has the lowest charge and largest radius, it should release its water of hydration and enter the chabazite more easily than the other competing ions.

\subsubsection{Equilibrium Studies}

Barrer, Davies, and Rees; ${ }^{59}$ Barrer and Klinowski; ${ }^{57}$ and Passaglia ${ }^{40}$ reported incomplete solids loadings for cesium in natural chabazites. They did not obtain similar results for calcium or strontium although each solution phase contained 0.1 to $1 \mathrm{~N}$ of the exchanging cation. The results from Table 8 of this study do not indicate that incomplete loadings occurred for cesium, strontium, or calcium.

At equilibrium, the systems in Table 8 had solids loadings between 1 and $96 \%$ of the maximum loading capacity of the zeolite. The solids loading varied with the total solution concentration and liquid to solids ratios. When the total solution concentration was $5.7 \times 10^{-3} \mathrm{~N}$ and the liquid to solids ratio was 2000 , most systems (including the Cs-Na system) had total solids loadings between 90 and $96 \%$ of the theoretical capacity. The notable exception was the $\mathrm{Mg}-\mathrm{Na}$ system, which had a maximum loading of $40 \%$. Since chabazite has a low selectivity for magnesium, low total solids loadings over the tested concentration ranges are reasonable. These results indicate that loading capacities of slightly less than $100 \%$ were 
obtained because the total cation concentrations used in this study were not high enough to cause the zeolite to reach its total loading capacity at equilibrium.

The reasoning used to explain increased cesium exchange capacity in Sect. 5.4.1 can also explain the apparent conflicts between the results of this study and the literature for cesium exchange in chabazites. The chabazites used in the literature had $\mathrm{Si} / \mathrm{Al}$ ratios of 0.6 to 0.8 while the Ionsiv IE-96 used in this study had a much higher Si/Al ratio of 6.9. Since the charge density of the zeolite framework increases with the Si/Al ratio, the Ionsiv IE-96 should have a larger attractive force for cesium than the other chabazites.

Standard isotherm equations were fit to the binary data shown in Fig. 11. The equations tested included Langmuir model,

$$
q=q, b \times c /(1+b)=a \times c /(1+b \times c) ;
$$

the Freundlich model,

$$
q=k \times c^{n}
$$

and the Dubinin-Polyani model,

$$
q=q, \times \exp \left(-k R^{2} T^{2}\left[\ln \left(c_{m} / c\right)\right]^{2}\right\}
$$

The Dubinin-Polyani equation was solved for $k$ by substituting values for $R, T$, and $c_{\mathrm{w}}$ into Eq. 18. Values for $c_{m}$, the solubility of the salt in water, were obtained from the literature: ${ }^{60}$ $15.9 \mathrm{meq} / \mathrm{mL}$ for calcium, $11.4 \mathrm{meq} / \mathrm{mL}$ for cesium, 11.4 for magnesium, and 7.0 for strontium. A modified version of the Dubinin-Polyani equation was also tested:

$$
q=\exp \left\{b_{0}+b_{1} \times \ln (c)+b_{2} \times[\ln (c)]^{2}\right\}
$$

When the Dubinin-Polyani equation is solved for $b_{0}, b_{1}$, and $b_{2}$, the equation is referred to as the modified Dubinin-Polyani equation. If the systems are ideal, Eqs. 18 and 19 should be equal, making $b_{0}=\ln \left(q_{s}\right)-k R^{2} T^{2}\left[\ln \left(c_{m}\right)\right]^{2}, b_{1}=2 k R^{2} T^{2} \ln \left(c_{m}\right)$, and $b_{2}=-k R^{2} T^{2}$. 
The constants for the binary isotherm equations were determined from the isotherm data by regression analyses using the SAS computer program. The coefficient of determination, commonly called $\mathrm{R}^{2}$, was used to determine the adequacy of the model. The coefficients and $\mathrm{R}^{2}$ values for each model are given in Table 9. An example of how well the models fit the strontium binary isotherm is shown in Fig. 16. The results indicate that all of the models except the Dubinin-Polyani equation are reasonable fits for the data. The modified DubininPolyani model is the best equation for fitting the data for all four systems.

The fact that Eqs. 18 and 19 are not equal for any of the four binary isotherms indicates that the solubility of salts in the liquid phase adequately account for the nonidealities that occur during liquid ion exchange. This is not surprising since the Dubinin-Polyani equation was developed from the theory of pore filling for gases in microporous carbon adsorbents.

The data in Fig. 16 indicate that the binary isotherms are selective for the entering cations over the entire range of zeolite composition. This type isotherm has been classified as a Type I isotherm and is typical for zeolites. ${ }^{20}$ Type I isotherms are said to be "favorable" for the uptake of the solute. The coefficients for the isotherms listed in Table 9 substantiate this observation. For favorable isotherms, the coefficient $b$ in the Langmuir equation will be greater than zero and the coefficient $n$ in the Freundlich isotherm will be less than one. ${ }^{10}$ For systems in which the equilibrium isotherm is "favorable", the mass-transfer front will acquire a "constant pattern" shape at the entrance of the ion-exchange column. Once this shape is attained, it will not change as it progresses through the column. This will be very important in the modeling of the breakthrough curve.

The multicomponent systems, shown in Figs. 12-14, were evaluated to determine if the isotherms could be predicted from binary data using the multicomponent Langmuir (Eq. 9), Freundlich (Eq. 10), Langmuir-Freundlich (Eq. 11), and the IAST (Eq. 13) models. When the coefficients listed in Table 9 for the binary isotherms were substituted into Eqs. 9, 10,11, and 20 , the results did not accurately predict the experimental multicomponent data. A typical example is shown in Fig. 17. These results indicate that the multicomponent data in this study cannot be predicted from binary data, and rigorous thermodynamic or empirical equations fit to each isotherm will be required to model the multicomponent data. Since thermodynamic models are not well developed for these types of systems, the empirical approach was selected for further investigation. 
Table 9. Model parameters for binary isotherms

\begin{tabular}{|c|c|c|c|c|c|}
\hline \multirow[b]{2}{*}{ Model } & & \multicolumn{4}{|c|}{ Binary isotherm } \\
\hline & & $\mathrm{Sr}-\mathrm{Na}$ & $\mathrm{Cs}-\mathrm{Na}$ & $\mathrm{Ca}-\mathrm{Na}$ & $\mathrm{Mg}-\mathrm{Na}$ \\
\hline \multicolumn{6}{|c|}{ Langmuir" } \\
\hline & a & 173,702 & 211,193 & 689,655 & 481,696 \\
\hline & $\mathbf{b}$ & 98,176 & 544,677 & 446,827 & 610,790 \\
\hline & $\mathrm{R}^{2}$ & 0.95 & 0.91 & 0.67 & 0.78 \\
\hline \multicolumn{6}{|c|}{ Freundlich ${ }^{b}$} \\
\hline & k & 18.81 & 55.98 & 3.050 & 1.696 \\
\hline & $\mathbf{n}$ & 0.3183 & 0.4399 & 0.0626 & 0.0977 \\
\hline & $\mathrm{R}^{2}$ & 0.84 & 0.80 & 0.92 & 0.65 \\
\hline \multicolumn{6}{|c|}{$\begin{array}{l}\text { Dubinin- } \\
\text { Polyanic }^{c}\end{array}$} \\
\hline & $\mathbf{k}$ & $2.34 \times 10^{-8}$ & $3.15 \times 10^{-8}$ & $2.20 \times 10^{-8}$ & $1.09 \times 10^{-8}$ \\
\hline & $\mathbf{R}^{2}$ & 0.73 & 0.73 & 0.09 & 0.88 \\
\hline \multicolumn{6}{|c|}{$\begin{array}{l}\text { Modified } \\
\text { Dubinin- } \\
\text { Polyanid }^{\text {- }}\end{array}$} \\
\hline & $b_{0}$ & -1.637 & -2.165 & -1.833 & -0.4651 \\
\hline & $b_{1}$ & -0.6839 & -0.885 & 0.2655 & -0.12700 \\
\hline & $b_{2}$ & -0.05015 & -0.06261 & 0.009608 & -0.01202 \\
\hline & $\mathrm{R}^{2}$ & 0.97 & 0.95 & 0.96 & 0.74 \\
\hline
\end{tabular}

'See Eq. 16.

'See Eq. 17.

'See Eq. 18.

'See Eq. 19. 
ORNL DWG 91A-329

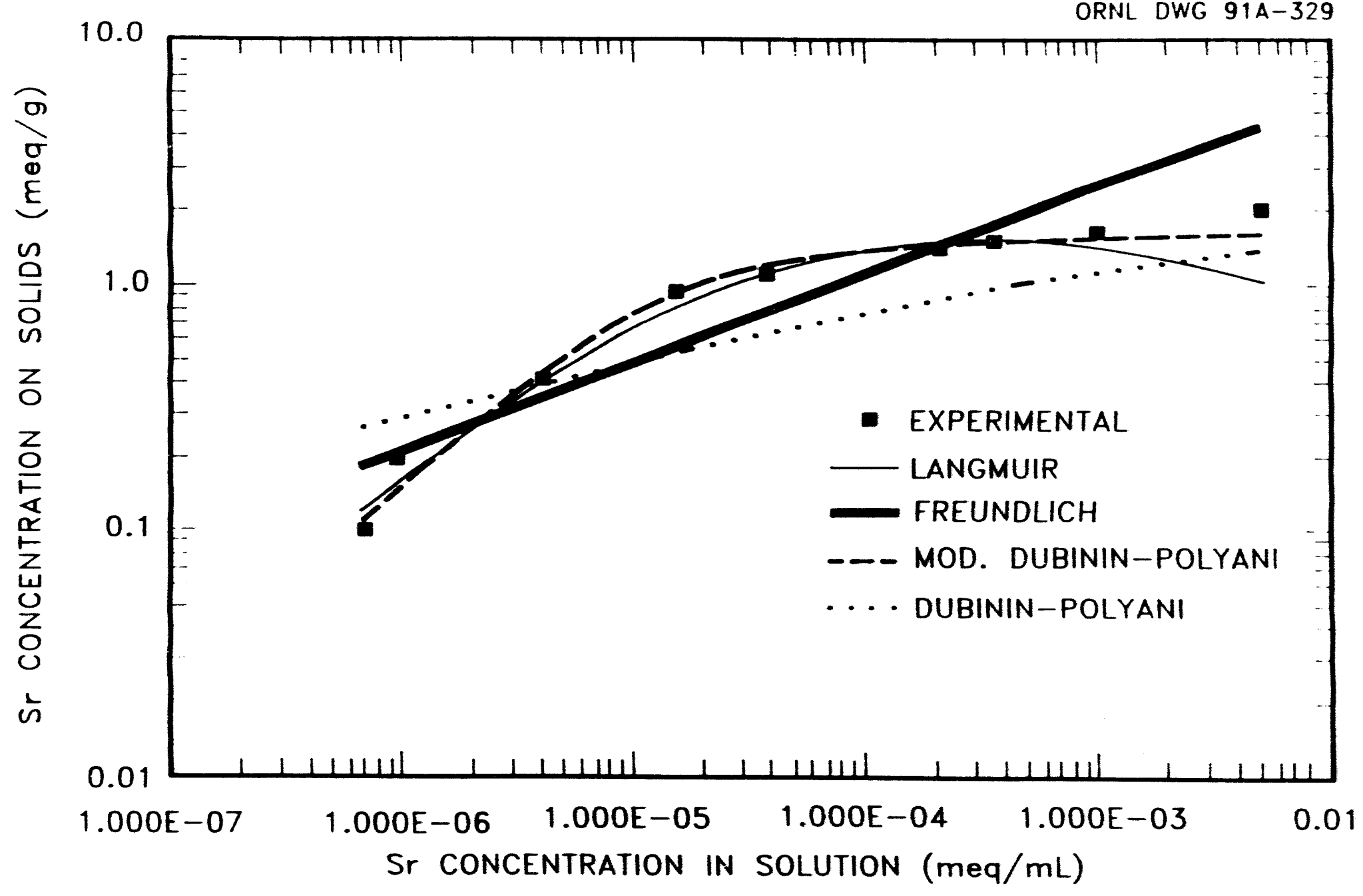

Fig. 16. Models for binary Sr-Na ion exchange. 


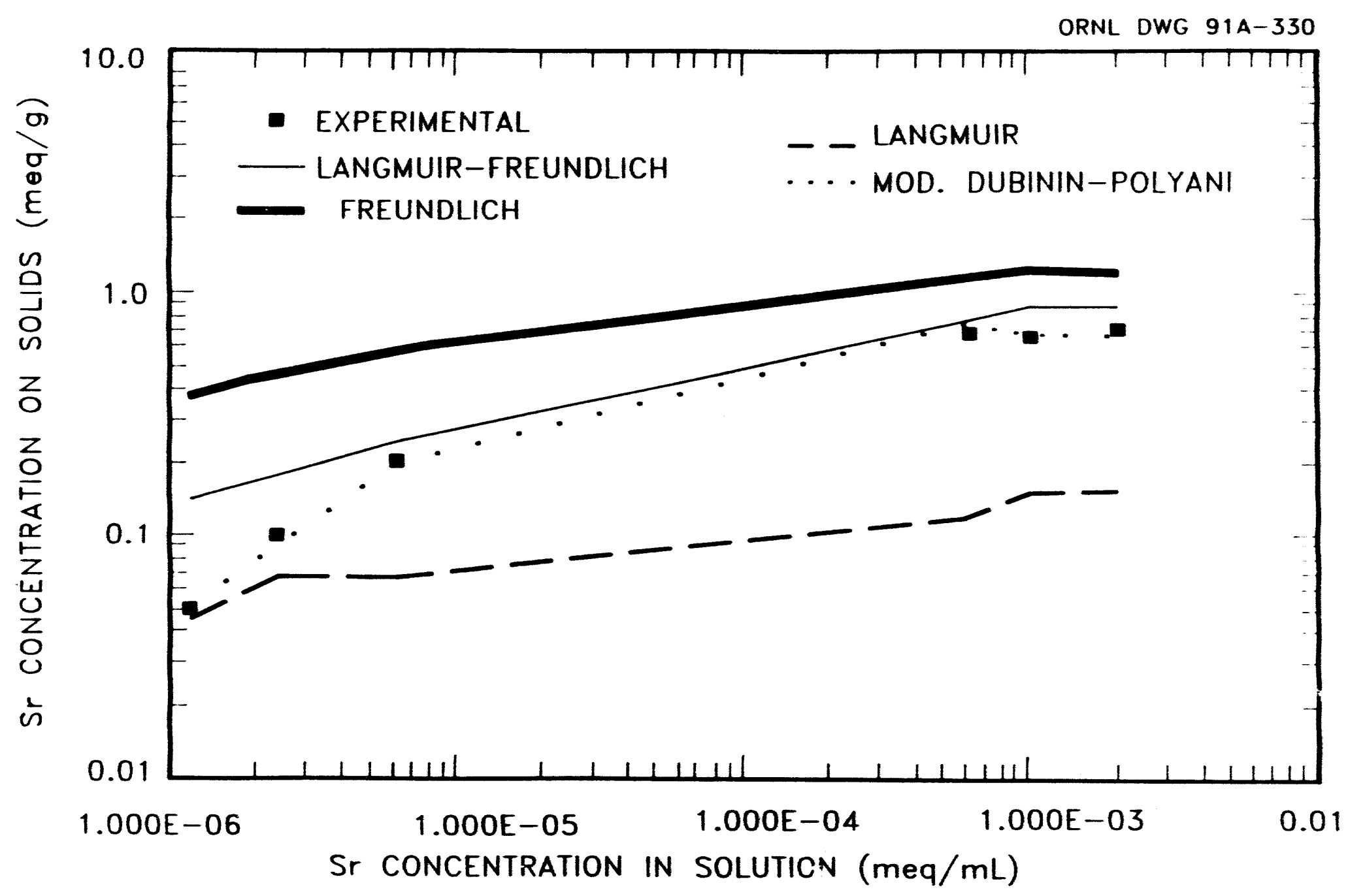

Fig 17. Models for Sr isotherm for Sr-Cs-Ce-Mg-Na ion exchange. 
Empirical equations having the basic forms of Eqs. 12,14,16, 17, and 19 were fit to the equilibrium data given in Figs. 12-14. The constants for these equations were determined by linear or nonlinear regression subroutines using the SAS computer program. Equation 19 fits the data most accurately. The resulting equations are listed in Table 10. The results are also shown in Fig. 17.

Statistical analyses were performed on the isotherm data given in Table 8 and in Figs. 11-14 using a SAS regression program to evaluate a two way unbalanced analysis of variance using the Scheffe's test for variability. The results indicated that there was not a statistically significant difference between any of the cesium isotherms shown in Figs. 11-14. There was a statistically significant difference between the binary $\mathrm{Sr}-\mathrm{Na}$ isotherm in Fig. 11 and the strontium isotherms for the multicomponent systems. The strontium isotherms for the multicomponent systems were not significantly different from one another. Similar results were obtained for the calcium and magnesium isotherms. These results indicate that there is significant interaction between exchanging cations for the multicomponent systems. Since the zeolite has such a high selectivity for cesium, its isotherms were least affected by other cations.

Since there is statistically no difference between any of the multicomponent isotherms for a given cation, all the multicomponent data for each cation was fit to Eq. 19. These resulting coefficients are listed in Table 11, and the isotherms are shown in Fig. 18. These isotherms will be used in mathematical models for column design.

\section{SUMMARY}

Studies are PWTP. Studies to date have addressed column plugging and columin design. Column plugging studies have shown that the equalization basin at the PWTP caused most of the problems in the previous pilot-scale tests. Clarification or filtration using zeolites instead of sand should be sufficient to eliminate plugging problems now that holding tanks have replaced the equalization basin. 
Table 10. Modified Dubinin-Polyani parameters" for individual multicomponent isotherms

\begin{tabular}{|c|c|c|c|c|}
\hline \multirow[b]{2}{*}{ Isotherm } & \multicolumn{4}{|c|}{ Coefficients } \\
\hline & $\mathrm{b}_{0}$ & $b_{1}$ & $b_{2}$ & $\mathrm{R}^{2}$ \\
\hline \multicolumn{5}{|l|}{ Sr-Cs-Na system } \\
\hline $\mathrm{Sr}$ isotherm & -6.104 & -1.498 & -0.0894 & 0.97 \\
\hline Cs isotherm & -2.214 & -0.7606 & -0.05744 & 0.99 \\
\hline \multicolumn{5}{|l|}{$\mathrm{Ca}-\mathrm{Mg}-\mathrm{Na}$ system } \\
\hline $\mathrm{Ca}$ isotherm & -3.253 & -1.096 & -0.07902 & 0.99 \\
\hline $\mathrm{Mg}$ isotherm & -9.320 & -1.955 & -0.1209 & 0.98 \\
\hline \multicolumn{5}{|l|}{ Sr-Ca-Mg-Na system } \\
\hline Sr isotherm & -1.592 & -0.5100 & -0.04096 & 0.99 \\
\hline $\mathrm{Ca}$ isotherm & -0.6791 & -0.1495 & -0.01558 & 0.99 \\
\hline $\mathrm{Mg}$ isotherm & -18.07 & -3.674 & -0.2017 & 0.91 \\
\hline \multicolumn{5}{|l|}{$\mathrm{Cs}-\mathrm{Ca}-\mathrm{Mg}-\mathrm{Na}$ system } \\
\hline Cs isotherm & -5.073 & -1.287 & -0.08128 & 0.97 \\
\hline $\mathrm{Ca}$ isotherm & -3.219 & -0.7620 & -0.04545 & 0.99 \\
\hline $\mathrm{Mg}$ isotherm & -29.40 & -6.105 & -0.3213 & 0.91 \\
\hline \multicolumn{5}{|l|}{ Sr-Cs-Ca-Mg-Na system } \\
\hline Sr isotherm & -4.742 & -1.157 & -0.07507 & 0.99 \\
\hline Cs isotherm & -1.532 & -0.5890 & -0.05002 & 0.99 \\
\hline $\mathrm{Ca}$ isotherm & -4.212 & -0.8560 & -0.04703 & 1.00 \\
\hline $\mathrm{Mg}$ isotherm & -17.28 & -3.345 & -0.1818 & 0.93 \\
\hline
\end{tabular}

'See Eq. 19. 
Table 11. Modified Dubinin-Polyani parameters for lumped multicomponent isotherms

\begin{tabular}{lcccc}
\hline & \multicolumn{4}{c}{ Coefficients } \\
\cline { 2 - 5 } Isotherms & $\mathrm{b}_{0}$ & $\mathrm{~b}_{1}$ & $\mathrm{~b}_{2}$ & $\mathrm{R}^{2}$ \\
\hline $\mathrm{Sr}$ isotherm & -3.631 & -0.925 & -0.0613 & 0.94 \\
Cs isotherm & -1.026 & -0.530 & -0.0463 & 0.91 \\
& & & & \\
Ca isotherm & -1.041 & -0.317 & -0.0266 & 0.69 \\
$\mathrm{Mg}$ isotherm & -13.23 & -2.612 & -0.1469 & 0.71 \\
\hline
\end{tabular}

'See Eq. 19. 


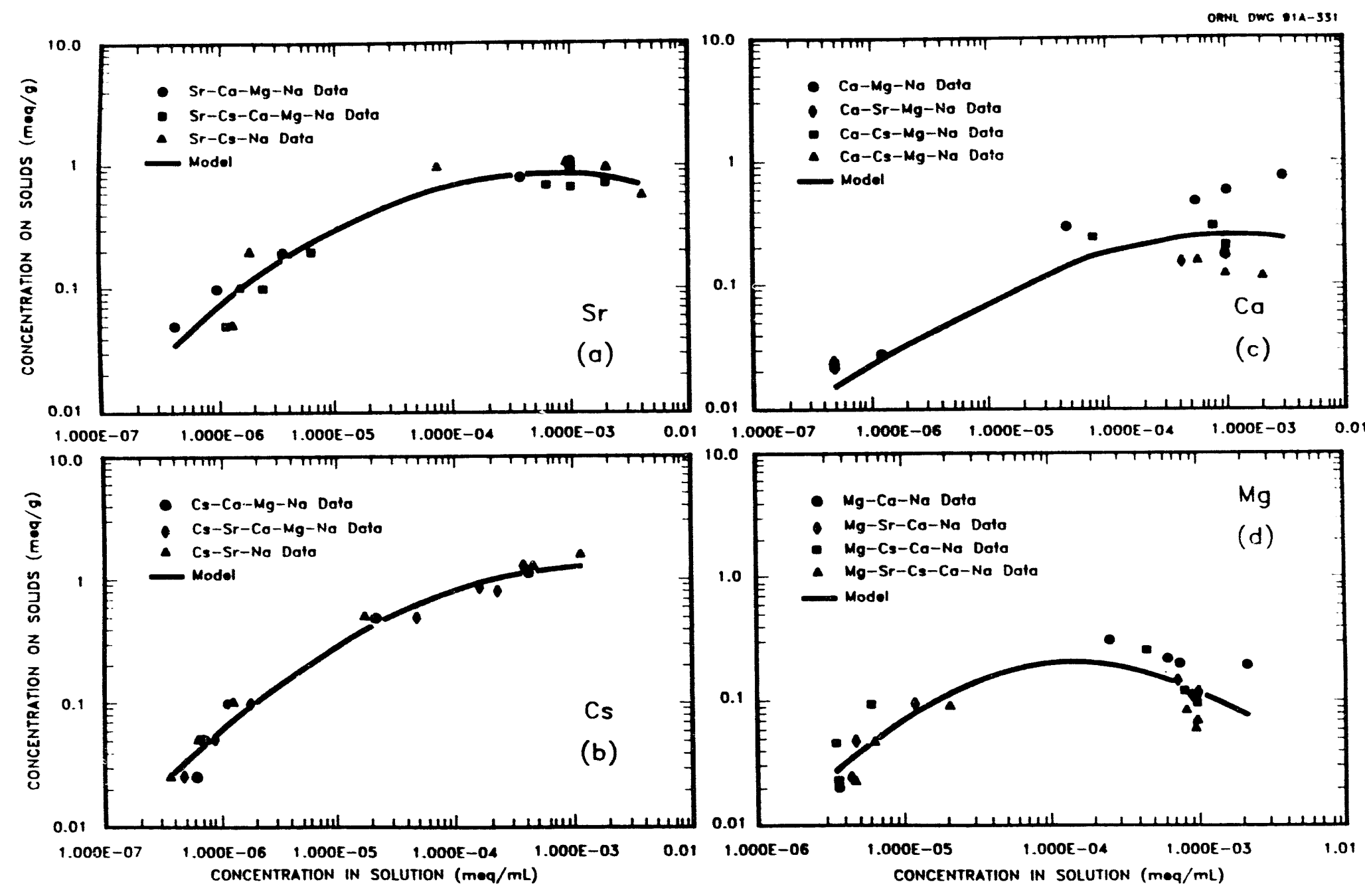

Fig. 18. Models for lumped multicomponent data: (a) strontium isotherm, (b) cesium isotherm, (c) calcium isotherm, (d) magnesium isotherm. 
A mathematical model is being developed to accurately model zeolite columns in order to design columns and set operating parameters for secondary waste minimization. This report summarizes the results of equilibrium studies to be used in this model. Kinetic studies and the model development will be described in later reports.

\section{NOMENCLATURE}

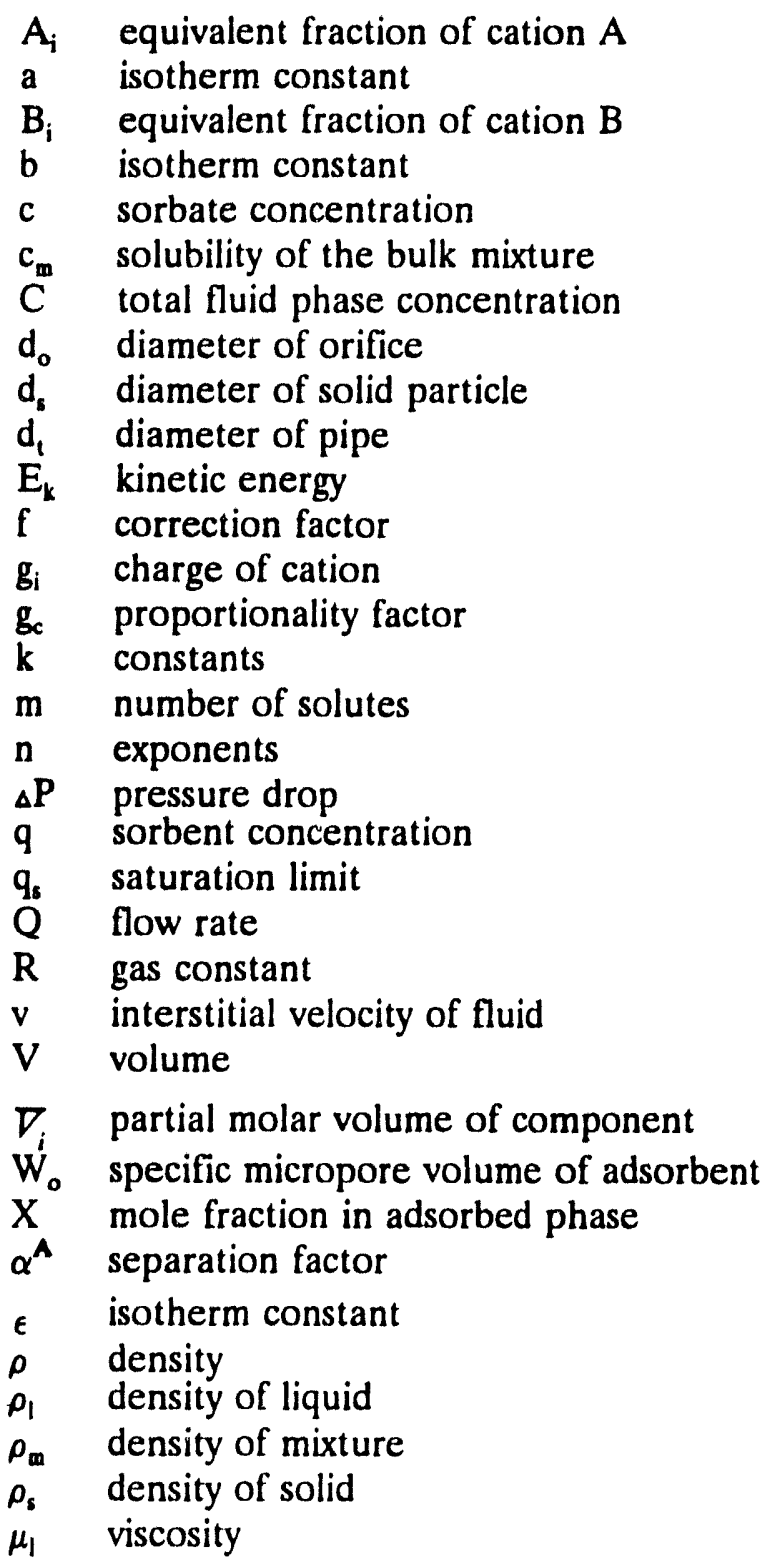


A mathematical model is being developed to accurately model zeolite columns in order to design columns and set operating parameters for secondary waste minimization. This report summarizes the results of equilibrium studies to be used in this model. Kinetic studies and the model development will be described in later reports.

\section{NOMENCLATURE}

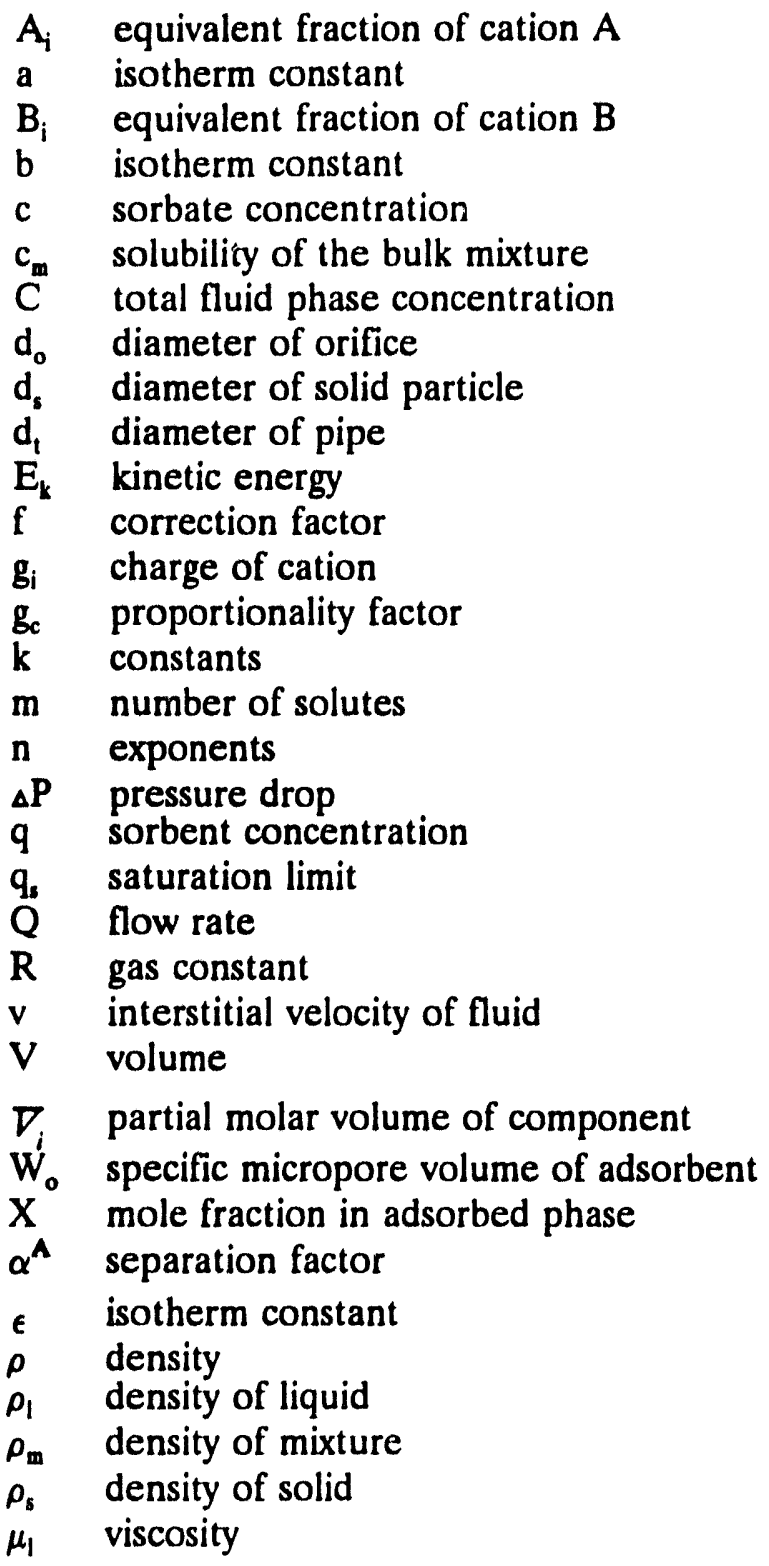




\section{REFERENCES}

1. S. M. Robinson and J. M. Begovich, Treatment Studies at the Process Waste Treatment Plant at Oak Ridge National Laboratory, ORNL/TM-10352, Oak Ridge National Laboratory, Oak Ridge, TN, March 1991.

2. S. M. Robinson, Evaluation of Alternative Flowsheets for Upgrade of the Process Waste Treatment Plant, ORNL/TM-10576, Oak Ridge National Laboratory, Oak Ridge, TN, April 1991.

3. S. M. Robinson and J. R. Parrott, Pilot-Scale Demonstration of Process Wastewater Decontamination Using Chabazite Zeolites, ORNL/TM-10836, Oak Ridge, National Laboratory, Oak Ridge, TN, December 1989.

4. A. Dyer and D. Keir, Zeolites, 4, pp. 215-7, 1984.

5. P. Burns et al., AIChE Symp. Series, 83(259), pp. 67-73 (1987).

6. D. C. Grant et al., "Effects of Process Variables on the Removal of Contaminants from Radioactive Waste Streams Using Zeolites," presented at the Waste Management '87 Symposium, Tucson, Arizona, March 1987a.

7. D. C. Grant et al, "Design and Optimization of a Zeolite Ion Exchange System," presented at the AlChE Annual Meeting, New York, November $1987 \mathrm{~b}$.

8. British Nuclear Technology, BNT Paper No. 9, Risley, Warrington, England, 1987.

9. R. H. Hawkins and J. H. Horton, DP-1245, Savannah River Laboratory, Aiken, South Carolina, January 1971.

10. R. H. Perry and C. L. Chilton, eds., Chemical Engineers' Handbook, Fifth Edition, Chapter 16, McGraw-Hill, New York, 1973.

11. Crane Co., Flow of Fluids through Valves, Fittings, and Pipe, Technical Paper No. 410, Chicago, IL, 1965.

12. R. H. Perry and C. H. Chilton, Chemical Engineers' Handbook, Fifth Edition, McGrawHill Book Co., 1973, p. 5-46.

13. P. C. Wankat, Large-Scale Adsorption and Chromatography, Vol 1., CRC Press, 1986.

14. H. K. S. Tan, Chem. Engr., 91(26), pp. 57-61 (1984).

15. R. P. Townsend, Pure \& Appl. Chem., 58(10), pp. 1259-66 (1986).

16. E. D. Collins, et al., "The Three Mile Island Accident," ACS Symp. Series, 293, pp. 21327, Washington, DC, 1986. 
17. E. D. Collins et al., IAEA-TECDOC-337, International Atomic Energy Agency, Vienna, 1985.

18. S. Liang and W. J. Weber Jr., Chem. Eng. Commun., 35, pp. $49-61$ (1985).

19. W. J. Weber Jr. and E. H. Smith, Environ. Sci. Technol., 21(11), pp. 1040-50 (1987).

20. D. W. Breck, Zeolite Molecular Sieves, John Wiley \& Sons, New York, 1974.

21. D. M. Ruthven, Principles of Adsorption and Adsorption Processes, John Wiley \& Sons, New York, 1984.

22. G. Marton et al., Hung. J. Ind. Chem., 19, pp. 251 (1981).

23. A. I. Liapis and D. W. T. Rippin, Chem. Eng. Sci., 32, pp. 619-27.

24. A. Mansour et al., AIChE J., 28(5), pp. 765-73 (1982).

25. M. Streat, Trans. Instn. Chem. Engrs., 48, pp. 151-5 (1970).

26. M. Sengupta and T. B. Paul, Reactive Polymers, 3, pp. 217-229 (1985).

27. Chakravarti, A. K., and Sengupta, M., J. Indian Chem. Soc., LX, pp. 1124-28 (1983).

28. B. P. Bering et al., Dokl. Akid. Nauk SSSR, 153(1), p. 129 (1963).

29. A. K. Singhal, AIChE Symposium Series, 74(179), pp. 36-41, 1978.

30. D. M. Ruthven et al., Chemi. Engr. Sc., 28, pp. 701-9 (1973).

31. T. F. Speth, Masters Thesis, Michigan Technology University, 1986.

32. D. M. Ruthven and M. Goddard, Zeolites, 6, pp. $275-82$ (1986).

33. P. Fletcher and R. P. Townsend, J. Chem. Soc. Faraday Trans. 2(77), pp. 955-80, 2077-89, (1985).

34. K. R. Franklin and R. P. Townsend, J. Chem. Soc. Faraday Trans. 1(81)34., pp. 1071-86, 3127-41 (1985).

35. B. K. Kaul and N. H. Sweed, Fundamentals of Adsorption, AIChE, 249-58, New York, 1984.

36. M. Loizidou and R. P. Townsend, Zeolites, 7(2), 1987.

37. S. A. I. Barri and L. V. Rees, J. Chromatogr., 201, p 21 (1980).

38. D. Drummond, A. D. Jonge, and L. V. C. Rees, Fundamentals and Applications of Ion Exchange, pp. 345-69, Martinus Nijhoff Publishers, Boston, 1985. 
39. Vaughn, 1978.

40. E. Passaglia, Natural Zeolites: Occurrences, Properties, and Use, Pergamon Press, 45-52, New York, 1978.

41. Fennelly, 1988.

42. Society of Chemical Industry, 1968.

43. Tennessee Specialty Minerals, 1987.

44. K. T. Liu and W. J. Weber, Journal WPCF, 53(10), pp. $1541-50$ (1981).

45. O. O. Omatate et al., Chem. Eng. J., 19, pp. 241-50 (1980).

46. W. K. Teo and D. M. Ruthven, Ind. Eng. Chem. Process Des. Dev., 25, pp. 17-21 (1986).

47. J. C. Crittenden and W. J. Weber, Jr., ASCE Env. Eng. Div., 104(EE6), pp. 1175-1195 (1978).

48. S. J. Randtke and V. L. Snoeyink, Journal AWWA Research and Technology, 406-13, August 1983.

49. S. A. I. Barri and L. V. C. Rees, J. Chromatogr., 201, p 21 (1980).

50. A. Cremers, "Molecular Sieves-II," J. R. Katzer, ed., ACS Symp. Series, 40, pp. 179-93, Washington, DC, 1977.

51. J. D. Sherman, AIChE Symposium Series, 74 (179), pp. 36-41, 1978.

52. J. P. Ausikaitis, Fundamentals of Adsorption, AIChE, New York, pp. 49-63, 1984.

53. L. L. Ames, Jr., The American Mineralogist, 46, pp. 1120-31, 1961.

54. J. F. O'Connor and R. P. Townsend, Zeolites, 5, 1985.

55. K. R. Franklin et al., "New Developments in Zeolite Science and Technology," Proceedings of the 7th International Zeolite Conference, 289-296, Y. Murakami, A. Iijima, and J. W. Ward, eds., Elsevier Science Publishing Company, Inc., 1986.

56. Fletcher, Franklin, and Townsend, 1984.

57. R. M. Barrer and J. Klinowski, J. Chem. Soc. Faraday Trans. 1(9), pp. 1956-63 (1972).

58. J. A. Dean, ed., Lange's Handbook of Chemistry, McGraw-Hill, 3-121-3-126, New York, 1985.

59. Barrer et al., J. Inorg. Nucl. Chem., 31, pp. 219-32 (1969).

60. Nemeth, 1975. 


\section{DISTRIBUTION}

1. H. L. Adair

2. W. J. Armento

3-8. W. D. Arnold

9. J. S. Baldwin

10. P. T. Barton

11. L. D. Bates

12. J. M. Begovich

13. J. B. Berry

14. S. E. Boit

15. S. E. Breeding

16. C. H. Brown, Jr.

17. C. H. Byers

18. D. O. Campbell

19. R. M. Cannon

20. E. D. Collins

21. J. L. Collins

22. K. W. Cook

23. R. M. Counce

24. A. G. Croff

25. F. P. Delozier

26. S. M. DePaoli

27. B. Z. Egan

28. B. M. Eisenhower
29. S. B. Garland

30. S. E. Gentry

31. R. K. Genung

32. R. W. Glass

33. R. E. Helms

34. L. Holder

35. L. S. Jones

36. C. M. Kendrick

37-42. T. M. Kent

43. J. R. Lawson

44. J. J. Maddox

45. C. P. Manrod

46. R. C. Mason

47. L. E. McNeese

48. D. R. Mc'Taggart

49. C. E. Nix

50. J. C. Nix

51. J. R. Parrott

52. J. J. Perona

53. D. Peterson

54. B. R. Reed

55. S. A. Richardson
56-61. S. M. Robinson

62. S. T. Rudell

63. M. K. Savage

64. T. F. Scanlan

65. C. B. Scott

66. C. D. Scott

67. L. R. Simmons

68. M. A. Smith

69. R. C. Stewart

70. P. A. Taylor

71. J. R. Trabalka

72. M. W. Tull

73. D. W. Turner

74. J. H. Wilson

75. Central Research Library

76. ORNL-Y-12 Tech. Library, Document Reference Section

77. Laboratory Records-RC

78. ORNL Patent Section

\section{EXTERNAL DISTRIBUTION}

79. Office of Assistant Manager, Energy Research and Development, DOE-OR, P.O. Box 2001, Oak Ridge, Tennessee 37831-8600.

80. Office of Scientific and Technical Information, DOE-OR, P.O. Box 62, Oak Ridge, Tennessee 37831 

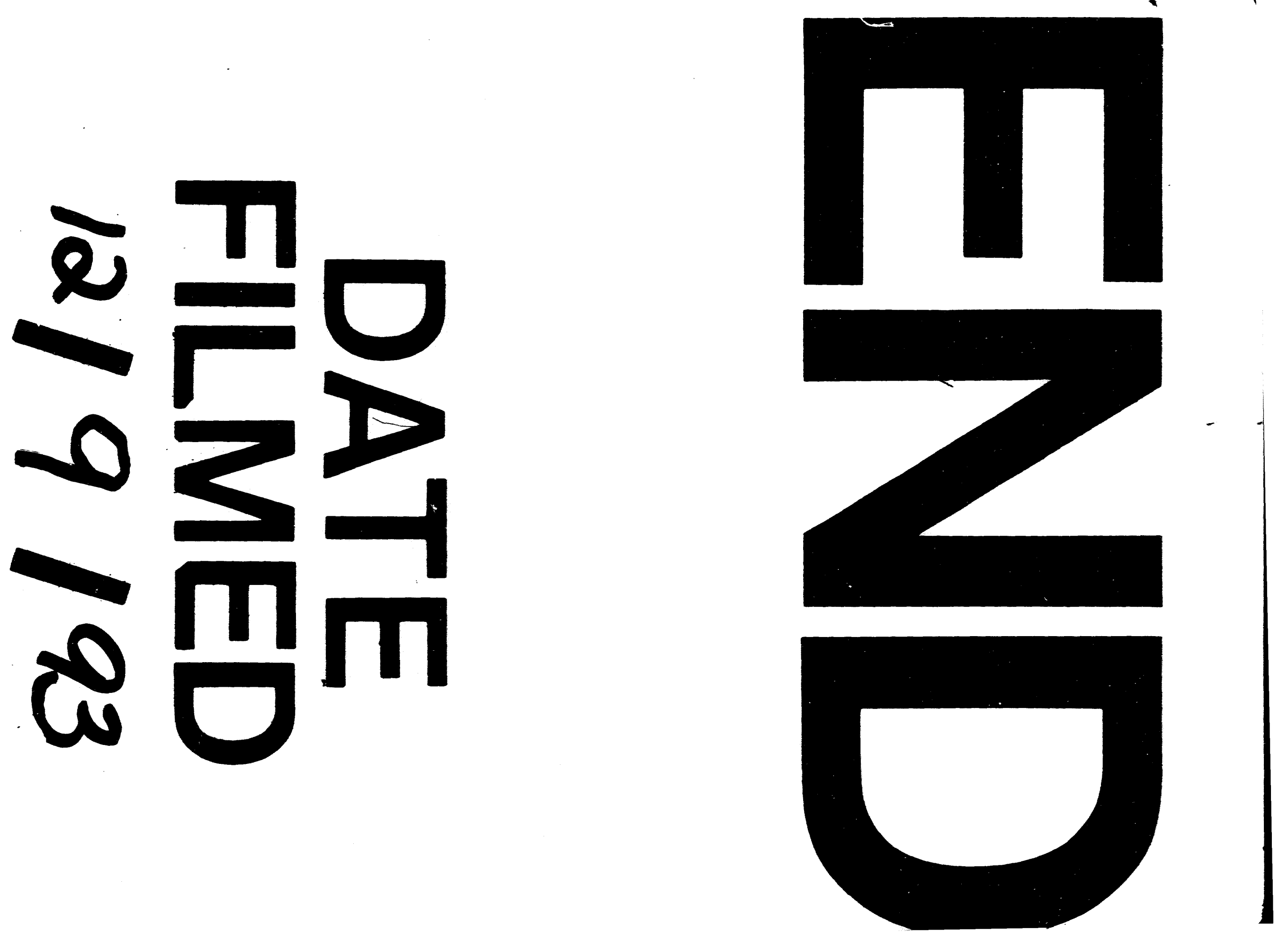
